\title{
Assessing the Cell Permeability of Bivalent Chemical Degraders Using the Chloroalkane Penetration Assay
}

Caroline A. Foley, Frances Potjewyd, Kelsey N. Lamb, Lindsey I. James, and Stephen V. Frye

Center for Integrative Chemical Biology and Drug Discovery, Division of Chemical Biology and Medicinal Chemistry, UNC Eshelman School of Pharmacy, University of North Carolina at Chapel Hill, Chapel Hill, North Carolina 27599, United States

\section{Table of Contents}

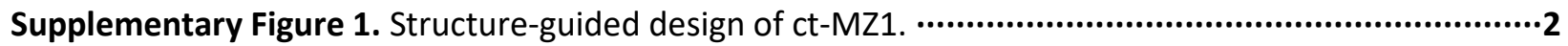

Supplementary Table 1. $\mathrm{CP}_{50}$ values and the standard error from five independent experiments. $\cdots \cdots \cdots \cdot \cdots \cdot \mathbf{2}$

Supplementary Table 2. Comparing ct-compound properties to experimental $\mathrm{CP}_{50}$ values. …................2

Supplementary Table 3. $\mathrm{CP}_{50}$ values and the standard error from three independent experiments. $\cdots \cdots \cdot \cdots \cdot \mathbf{2}$

Supplementary Table 4. Comparing ct-compound properties to experimental $\mathrm{CP}_{50}$ values. $\cdots . . . \cdots \cdot \cdots \cdot \cdots \cdot \cdots \cdot \cdot \cdot 2$

Supplementary Table 5. Summary of $\mathrm{P}_{\text {app }}$ and efflux ratios from two independent experiments. $\cdots . . . \cdots \cdot \cdots \cdot 3$

Supplementary Figure 2. Full uncropped western blots showing BRD4 degradation. ...............................4

Tissue culture

Chloroalkane penetration assay (CAPA)

CAPA data analysis

Caco-2 assay

Western blot analysis

General chemistry procedures $\cdots \cdots$

Analysis of products

Chemistry abbreviations

Synthetic schemes

Synthetic procedures

NMR spectra

References 
a)

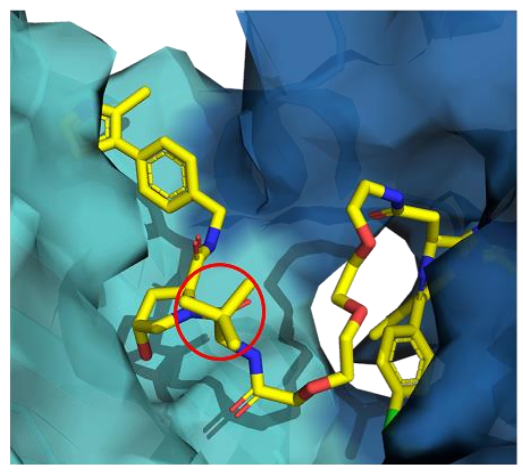

b)

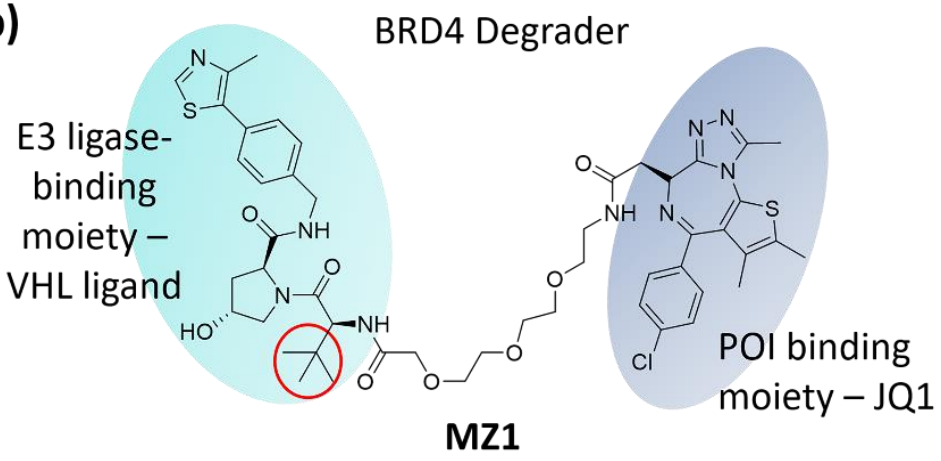

Supplementary Figure 1. Structure-guided design of ct-MZ1. (a) Crystal structure of MZ1 bound to VHL (aqua) and BRD4 (blue) (PDB 5T35). A solvent exposed tert-butyl group identified by Gadd et al. is circled in red. ${ }^{1}$ (b) Chemical structure of MZ1 with the tert-butyl group circled in red.

Supplementary Table 1. $\mathrm{CP}_{50}$ values $(\mathrm{nM})$ and the standard error from five independent experiments.

\begin{tabular}{|c|c|c|c|c|c|}
\hline Replicate & ct-MZ1 (3) & ct-S-VHL (4) & ct-PEG ${ }_{3}=\mathrm{JQ1}$ (6) & ct-VHL (5) & ct-JQ1 (7) \\
\hline 1 & 1553 & 1011 & 112 & 37.3 & 0.00856 \\
\hline 2 & 1383 & 212 & 321 & 33.1 & 0.00699 \\
\hline 3 & 1365 & 2720 & 78.0 & 16.3 & 0.00877 \\
\hline 4 & 1250 & 209 & 115 & 21.9 & 0.00921 \\
\hline 5 & 1554 & $\mathrm{n} / \mathrm{a}$ & 74.8 & 15.9 & 0.00878 \\
\hline Ave. $\mathrm{CP}_{50} \pm \mathrm{SEM}$ & $1420 \pm 60$ & $1040 \pm 590$ & $140 \pm 46$ & $24.9 \pm 4.4$ & $0.00846 \pm 0.00038$ \\
\hline
\end{tabular}

Supplementary Table 2. Comparing ct-compound properties to experimental $\mathrm{CP}_{50}$ values $(\mathrm{nM})$.

\begin{tabular}{|l|c|c|c|c|c|}
\hline & ct-MZ1 (3) & ct-S-VHL (4) & ct-PEG - -JQ1 (6) & ct-VHL (5) & ct-JQ1 (7) \\
\hline MW (g/mol) & 1227 & 697 & 796 & 694 & 607 \\
cLogP & 6.8 & 4.0 & 4.2 & 4.1 & 5.1 \\
tPSA $\left(\mathbf{A}^{2}\right)$ & 227 & 130 & 145 & 142 & 88 \\
Ave. $\mathbf{C P}_{\mathbf{5 0}} \pm$ SEM & $\mathbf{1 4 2 0 \pm 6 0}$ & $1040 \pm 590$ & $140 \pm 46$ & $24.9 \pm 4.4$ & $0.00846 \pm 0.00038$ \\
\hline
\end{tabular}

Supplementary Table 3. $\mathrm{CP}_{50}$ values $(\mathrm{nM})$ and the standard error from three independent experiments.

\begin{tabular}{|c|c|c|c|c|c|c|}
\hline Replicate & ct-PEG 6 -VHL (11) & ct-PEG -VHL (12) & ct-alkyl ${ }_{2}$-VHL (13) & ct-VHL (5) & ct-O-Pom (9) & ct-N-Pom (10) \\
\hline 1 & 28.1 & 27.5 & 1.66 & 6.68 & 3.74 & 0.821 \\
2 & 117 & 57.2 & 22.0 & 17.2 & 9.88 & 0.942 \\
3 & 157 & 84.1 & 27.8 & 22.6 & 1.14 & 1.84 \\
\hline Ave. CP $_{\mathbf{5 0}} \pm$ SEM & $\mathbf{1 0 1 \pm 3 8}$ & $\mathbf{5 6 . 2 \pm 1 6 . 3}$ & $17.1 \pm 7.9$ & $15.5 \pm 4.7$ & $4.92 \pm 2.59$ & $1.20 \pm 0.32$ \\
\hline
\end{tabular}

Supplementary Table 4. Comparing ct-compound properties to experimental $\mathrm{CP}_{50}$ values $(\mathrm{nM})$.

\begin{tabular}{|c|c|c|c|c|c|c|}
\hline Property & ct-PEG - -VHL (11) & ct-PEG ${ }_{2}-\mathrm{VHL}$ (12) & ct-alkyl ${ }_{2}$-VHL (13) & ct-VHL (5) & ct-O-Pom (9) & ct-N-Pom (10) \\
\hline $\mathrm{MW}$ (g/mol) & 1030 & 854 & 850 & 694 & 538 & 537 \\
\hline cLogP & 3.0 & 3.7 & 5.5 & 4.1 & 2.0 & 2.0 \\
\hline $\operatorname{tPSA}\left(\AA^{2}\right)$ & 226 & 189 & 171 & 142 & 140 & 143 \\
\hline Ave. $\mathrm{CP}_{50} \pm \mathrm{SEM}$ & $101 \pm 38$ & $56.2 \pm 16.3$ & $17.1 \pm 7.9$ & $15.5 \pm 4.7$ & $4.92 \pm 2.59$ & $1.20 \pm 0.32$ \\
\hline
\end{tabular}


Supplementary Table 5. Summary of $\mathrm{P}_{\mathrm{app}}$ and efflux ratios from two independent experiments.

\begin{tabular}{|c|c|c|c|}
\hline Compounds & Direction & $\begin{array}{c}\mathbf{P}_{\mathrm{app}} \\
\left(10^{-6} \mathrm{~cm} / \mathrm{sec}\right)^{a}\end{array}$ & $\begin{array}{c}\text { Efflux Ratio } \\
\left(P_{\text {app, B-A }} / P_{a p p, A-B}\right)\end{array}$ \\
\hline $\begin{array}{l}\text { Loperamide } \\
\text { Loperamide }\end{array}$ & $\begin{array}{l}A-B \\
B-A\end{array}$ & $\begin{array}{l}1.3 \pm 0.0 \\
5.7 \pm 0.1\end{array}$ & 4.4 \\
\hline $\begin{array}{l}\text { Loperamide + Verapamil } \\
\text { Loperamide + Verapamil }\end{array}$ & $\begin{array}{l}A-B \\
B-A\end{array}$ & $\begin{array}{l}5.2 \pm 0.0 \\
4.8 \pm 0.1\end{array}$ & 0.9 \\
\hline $\begin{array}{l}(+)-\mathrm{JQ1}{ }^{b} \\
(+)-J Q 1^{b}\end{array}$ & $\begin{array}{l}\mathrm{A}-\mathrm{B} \\
\mathrm{B}-\mathrm{A}\end{array}$ & $\begin{array}{l}12.6 \pm 0.0 \\
13.3 \pm 0.3\end{array}$ & 1.1 \\
\hline $\begin{array}{l}(+)-J Q 1^{b}+\text { Verapamil } \\
(+)-J Q 1^{b}+\text { Verapamil }\end{array}$ & $\begin{array}{l}\mathrm{A}-\mathrm{B} \\
\mathrm{B}-\mathrm{A}\end{array}$ & $\begin{array}{l}7.7 \pm 0.1 \\
8.4 \pm 0.5 \\
\end{array}$ & 1.1 \\
\hline $\begin{array}{l}\text { ct-JQ1 (7) } \\
\text { ct-JQ1 (7) }\end{array}$ & $\begin{array}{l}A-B \\
B-A\end{array}$ & $\begin{array}{l}5.4 \pm 0.0 \\
11.2 \pm 0.1\end{array}$ & 2.1 \\
\hline $\begin{array}{l}\text { ct-JQ1 (7) + Verapamil } \\
\text { ct-JQ1 (7) + Verapamil }\end{array}$ & $\begin{array}{l}\mathrm{A}-\mathrm{B} \\
\mathrm{B}-\mathrm{A}\end{array}$ & $\begin{array}{l}5.0 \pm 0.5 \\
6.4 \pm 0.4 \\
\end{array}$ & 1.3 \\
\hline $\begin{array}{l}\text { S-VHL (8) } \\
\text { S-VHL (8) }\end{array}$ & $\begin{array}{l}A-B \\
B-A\end{array}$ & $\begin{array}{c}\text { BLQ } \\
6.8 \pm 0.4\end{array}$ & $\mathrm{n} / \mathrm{a}$ \\
\hline $\begin{array}{l}\text { S-VHL (8) + Verapamil } \\
\text { S-VHL (8) + Verapamil }\end{array}$ & $\begin{array}{l}A-B \\
B-A\end{array}$ & $\begin{array}{l}0.4 \pm 0.0 \\
4.6 \pm 0.1\end{array}$ & 11.4 \\
\hline $\begin{array}{l}\text { ct-S-VHL (4) } \\
\text { ct-S-VHL (4) }\end{array}$ & $\begin{array}{l}A-B \\
B-A\end{array}$ & $\begin{array}{c}\text { BLQ } \\
14.1 \pm 1.0\end{array}$ & $\mathrm{n} / \mathrm{a}$ \\
\hline $\begin{array}{l}\text { ct-S-VHL (4) + Verapamil } \\
\text { ct-S-VHL (4) + Verapamil }\end{array}$ & $\begin{array}{l}A-B \\
B-A\end{array}$ & $\begin{array}{l}0.7 \pm 0.1 \\
9.9 \pm 0.8\end{array}$ & 14.1 \\
\hline $\begin{array}{l}\mathrm{MZ1}^{b} \\
\mathrm{MZ1}^{b}\end{array}$ & $\begin{array}{l}A-B \\
B-A\end{array}$ & $\begin{array}{c}\text { BLQ } \\
5.6 \pm 0.3\end{array}$ & $\mathrm{n} / \mathrm{a}$ \\
\hline $\begin{array}{l}\mathbf{M Z 1}^{b}+\text { Verapamil } \\
\mathbf{M Z 1}^{b}+\text { Verapamil }\end{array}$ & $\begin{array}{l}\mathrm{A}-\mathrm{B} \\
\mathrm{B}-\mathrm{A}\end{array}$ & $\begin{array}{c}\text { BLQ } \\
3.7 \pm 0.1\end{array}$ & $\mathrm{n} / \mathrm{a}$ \\
\hline $\begin{array}{l}\text { ct-MZ1 (3) } \\
\text { ct-MZ1 (3) }\end{array}$ & $\begin{array}{l}A-B \\
B-A\end{array}$ & $\begin{array}{c}\text { BLQ } \\
0.9 \pm 0.0\end{array}$ & $\mathrm{n} / \mathrm{a}$ \\
\hline $\begin{array}{l}\text { ct-MZ1 (3) + Verapamil } \\
\text { ct-MZ1 (3) + Verapamil }\end{array}$ & $\begin{array}{l}A-B \\
B-A\end{array}$ & $\begin{array}{l}\text { BLQ } \\
\text { BLQ }\end{array}$ & $\mathrm{n} / \mathrm{a}$ \\
\hline
\end{tabular}

${ }^{a} \mathrm{P}_{\text {app }}$ values are averages of two independent experiments testing compounds at $10 \mu \mathrm{M}$. In general, compound permeability is classified as low $\left(\leq 3 \times 10^{-6} \mathrm{~cm} / \mathrm{sec}\right)$, moderate $\left(3-15 \times 10^{-6} \mathrm{~cm} / \mathrm{sec}\right)$, or high (> $15 \times 10^{-6} \mathrm{~cm} / \mathrm{sec}$ ) depending on the $P_{\text {app }}$ value of the compound. BLQ indicates compound quantification was below the limit of quantification $\left(<0.4 \times 10^{-6} \mathrm{~cm} / \mathrm{sec}\right) .{ }^{b}(+)-\mathrm{JQ} 1$ and MZ1 were purchased and tested without further purification. 
a)

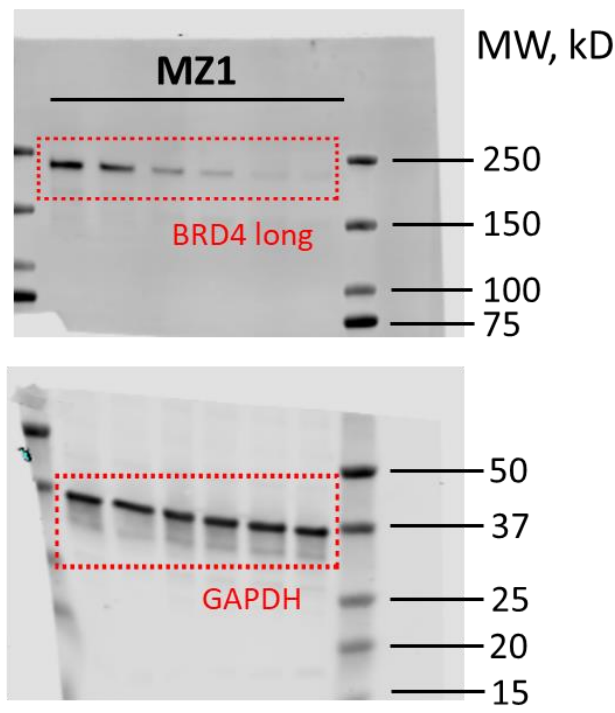

b)

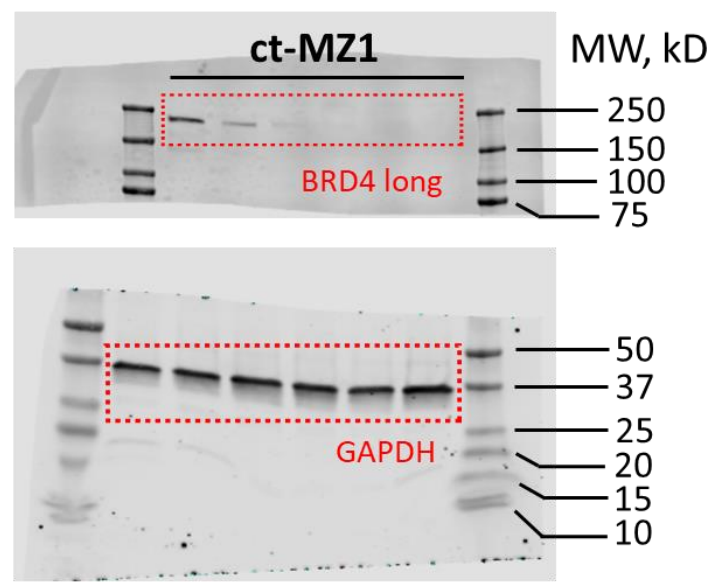

Supplementary Figure 2. Full uncropped western blots showing BRD4 degradation. (a) Full blot showing MZ1-induced degradation of BRD4 shown in Figure 2 with the cropped areas highlighted in red. These results are representative of two independent experiments. (b) Full blot showing ct-MZ1-induced degradation of BRD4 shown in Figure 2 with the cropped areas highlighted in red. These results are representative of two independent experiments.

\section{Biology Methods}

\section{Tissue culture}

Human HeLa cells stably expressing the HaloTag-GFP-Mitochondria construct were provided by the Kritzer lab. ${ }^{2}$ Cells were cultured using DMEM high glucose media (Sigma) supplemented with $10 \%$ FBS (VWR Life Sciences Seradigm), $1 \%$ penicillin-Streptomycin (Sigma), as well as $1 \mu \mathrm{g} / \mathrm{mL}$ puromycin (InvivoGen) to select for Halo-Tag expressing populations. Human HeLa cells for Western blot analysis were obtained from ATCC (No. CCL 2) and were cultured using MEM- $\alpha$ (Gibco) supplemented with 10\% FBS (VWR Life Sciences Seradigm), and 1\% MEM non-essential amino acids (Gibco). Cells were kept in an incubator at $37^{\circ} \mathrm{C}$ with $5 \% \mathrm{CO}_{2}$.

\section{Chloroalkane penetration assay (CAPA)}

CAPA was performed as described in literature with some modifications. ${ }^{2}$ Cells were seeded at 5000 cells per well on a 384-well plate and allowed to adhere overnight. For the first ct-compound series (ct-MZ1, ct-S-VHL, ct-VHL, ct-PEG $-J Q 1$, and ct-VHL), a $100 \mathrm{X}$ mother plate of compound dilutions was prepared in a separate 384-well plate. Twenty concentration points were generated by performing a three-fold serial dilution of $1 \mathrm{mM}$ DMSO compound stocks using DMSO. Compound-free DMSO control wells were also included in the mother plate to be used as no-pulse (100\%) and no-pulse/no-chase $(0 \%)$ controls. On the day of the experiment, a 10X daughter plate of compound dilutions and control samples was prepared, and the wells were diluted with media to ensure a final DMSO concentration of $1 \%$. The media of the $384-$ well assay plate containing cells was aspirated and $50 \mu \mathrm{L}$ of the compound and control solutions from the daughter plate were added to each well. The plate was incubated for $4 \mathrm{~h}$ at $37^{\circ} \mathrm{C}$ with $5 \% \mathrm{CO}_{2}$. The media was aspirated, and the wells were washed using phenol red-free Opti-MEM (Gibco) and incubated for 30 min. The media was aspirated, and compound and no-pulse $100 \%$ control wells were chased using $5 \mu \mathrm{M}$ ct-TAMRA that was synthesized according to literature procedures ${ }^{2}$ and incubated for $30 \mathrm{~min}$. The nopulse/no-chase $0 \%$ control wells were washed with phenol red-free Opti-MEM instead. The media was 
aspirated, and the wells washed with phenol red-free Opti-MEM media supplemented with $10 \%$ FBS and $1 \%$ penicillin-streptomycin and incubated for $15 \mathrm{~min}$. The media was aspirated, and the wells were washed with phosphate-buffered saline (PBS) (Corning). The media was aspirated, and the cells were trypsinized using phenol red-free $0.5 \%$ trypsin-EDTA solution (Gibco) diluted 1:1 with PBS. After a 20 min incubation, the cells were resuspended in 50\% FBS in PBS and analyzed using a flow cytometer (iQue Screener PLUS, Intellicyt $\left.{ }^{\circledR}\right)$.

For the second ct-compound series (ct-PEG ${ }_{6}-\mathrm{VHL}$, ct-PEG 2 -VHL, ct-alkyl ${ }_{2}-\mathrm{VHL}$, ct-VHL, ct-O-Pom, and ct-NPom), a mother plate of compound dilutions was not prepared. Instead, on the day of the experiment, compound dilutions and control samples were prepared in a separate 384-well plate. Twenty concentration points were generated by performing a three-fold serial dilution of $10 \mathrm{mM}$ DMSO compound stocks using media, ensuring a final DMSO concentration of $1 \%$. Compound-free control wells containing $1 \%$ DMSO in media were also prepared. The media of the 384-well assay plate containing cells was aspirated and $50 \mu \mathrm{L}$ of the compound and control solutions from the dilution plate were added to each well and treated as described above.

Mean red fluorescence was normalized to the no-pulse/no-chase $0 \%$ and no-pulse $100 \%$ signals from control wells to generate cell penetration dose response curves.

\section{CAPA data analysis}

For every independent experiment, three technical replicates were performed simultaneously for each ct-compound. The normalized fluorescence signals (see description of normalization process above) for each ct-compound technical replicate was plotted against the log of the dosing concentration in nM units. GraphPad Prism 8 was used to fit the dose response curves using the "log(inhibitor) vs. response -Variable slope (four parameters)" model. $\mathrm{CP}_{50}$ values generated from the antilog of the fitted $\log \mid \mathrm{C}_{50}$ values were recorded for each ct-compound for every independent experiment. The $\mathrm{CP}_{50}$ values were averaged across the independent experiments and the standard error of the mean (SEM or $\sigma_{\bar{x}}$ ) was determined by computing the following equation:

$$
\sigma_{\bar{x}}=\frac{\sigma}{\sqrt{N}}
$$

where $\sigma$ is the standard deviation and $N$ is the number of replicates or independent experiments.

\section{Caco-2 assay}

Compounds were evaluated by Sai Life Sciences Ltd. at the DMPK testing facility in India. Caco-2 cells were grown in DMEM (20\% FBS) until $85-90 \%$ confluence. After attaining required confluence, cells were trypsinized and seeded into 24 -well millcell plates at a density of $0.6 \times 10^{5}$ cells/insert. The plates were maintained for 21 days at $37^{\circ} \mathrm{C}$ in a $\mathrm{CO}_{2}$ incubator with change of medium every alternative day. Monolayer integrity was monitored by measuring trans-epithelial electrical resistance (TEER) before each

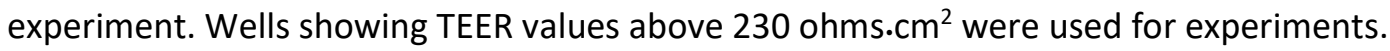

For the A-B transport assay, test compounds and the positive control compound loperamide at $10 \mu \mathrm{M}$ were prepared in HBSS and added to the apical side of the monolayer, followed by addition of HBSS to the basolateral side. For the B-A transport assay, test compounds and loperamide were prepared in HBSS and added to the basolateral side of the monolayer, followed by addition of HBSS to apical side. At selected time points $(0,15,30,60,90$ and $120 \mathrm{~min})$, an aliquot of $50 \mu \mathrm{L}$ was collected from the receiver compartment and the volume withdrawn was replaced immediately with HBSS buffer. The test samples were then diluted with acetonitrile containing an internal standard, vortexed for $5 \mathrm{~min}$, and analyzed via LC-MS/MS for determination of compound concentrations. TEER was measured at the end to the 
experiment to confirm there was no damage to the monolayer during the experiment. Any wells with TEER not meeting the criteria described above were excluded from the study. These procedures were then repeated in the presence of P-gp inhibitor verapamil at $100 \mu \mathrm{M}$.

The apparent permeability $\left(P_{a p p, ~ A-B}\right.$ and $\left.P_{a p p, ~ B-A}\right)$ of each compound was calculated using the following formula:

$$
P_{a p p}=\frac{d Q / d t}{A \cdot C_{0}}
$$

where $d Q / d t$ is the linear slope of the compound concentration in the receptor chamber at each time point after correcting for dilution, $A$ is the area of the filter, and $C_{0}$ is the initial concentration of the compound in the donor compartment.

The efflux ratio (RE) was calculated using the following equation:

$$
R E=\frac{P_{a p p, B-A}}{P_{a p p, A-B}}
$$

In general, compounds are classified based on $\mathrm{P}_{\text {app }}$ values as:

\begin{tabular}{|l|l|}
\hline Low & $\leq 3 \times 10^{-6} \mathrm{~cm} / \mathrm{sec}$ \\
\hline Moderate & $3-15 \times 10^{-6} \mathrm{~cm} / \mathrm{sec}$ \\
\hline High & $>15 \times 10^{-6} \mathrm{~cm} / \mathrm{sec}$ \\
\hline
\end{tabular}

Compounds with efflux ratio of $>2$ are considered potential P-gp substrates, and in presence of P-gp inhibitor (e.g. verapamil), if the efflux ratio reduces by $>50 \%$ or is equal to 1 , the compound is also likely to be a P-gp substrate.

\section{Western blot analysis}

HeLa (ATCC No. CCL 2) cells were seeded at $2.5 \times 10^{5}$ cells per well on a 6 -well plate. The next day, cells were treated with compound and incubated for $24 \mathrm{~h}$. The 6 -well plate was placed on ice and the cells were washed with PBS twice. The cells were removed from the plate using cell scrapers and lysed using CytoBuster ${ }^{\mathrm{TM}}$ Protein Extraction Reagent (EMD Millipore), 1X protease inhibitor (Active Motif), and 0.05 $\mathrm{U} / \mu \mathrm{L}$ benzonase (EMD Millipore) for $30 \mathrm{~min}$ on ice. Lysate was centrifuged at $14,000 \mathrm{xg}$ at $4^{\circ} \mathrm{C}$ for $15 \mathrm{~min}$. Supernatant was isolated and protein concentration was quantified using the Bradford assay. Lysates were used immediately or aliquoted, flash frozen in liquid nitrogen, and stored at $-80^{\circ} \mathrm{C}$ for later use. SDSPAGE was performed using $20 \mu \mathrm{g}$ protein and 4-15\% Mini-PROTEAN ${ }^{\circledR}$ TGX $^{\mathrm{TM}}$ Precast Protein Gels (BioRad) containing 10 or 15 wells, with 50 or $15 \mu \mathrm{L}$ loading capacity, respectively. The gels were transferred to PVDF membranes and blocked with Odyssey Blocking Buffer (LiCor). The membranes were cut in order to treat simultaneously with the following primary antibodies: GAPDH (G-9) anti-mouse (Santa Cruz Biotechnology, No. sc-365062, 1:5,000 dilution) and BRD4 anti-rabbit (Bethyl Laboratories, A700-005, 1:1,000 dilution). The membranes were incubated with primary antibodies at $4^{\circ} \mathrm{C}$ overnight in TBST. The next day, the membranes were washed with TBST and incubated at room temperature for $1 \mathrm{~h}$ with the corresponding secondary antibodies: IRDye ${ }^{\circledast} 800 \mathrm{CW}$ Goat (polyclonal) Anti-Rabbit IgG (H+L) (Li-Cor, No. 926-32211, 1:10,000 dilution) and IRDye ${ }^{\circledR}$ 680RD Goat (polyclonal) Anti-Mouse IgG (H+L) (Li-Cor, No. 926$68070,1: 10,000$ dilution) in TBST. The membranes were visualized using a Li-Cor Odyssey imaging system. 


\section{General chemistry procedures}

\section{Chemistry Methods}

All reagents and solvents were obtained from commercial suppliers and were used without further purification unless otherwise stated. MZ1 and (+)-JQ1 were purchased from MedChemExpress. Reactions were performed using conventional glassware, and room temperature (rt) was generally $22^{\circ} \mathrm{C}$. Reactions were performed at elevated temperatures using a temperature regulated hot plate-stirrer. Thin layer chromatography (TLC) was performed using Merck silica plates coated with fluorescent indicator UV254. TLC plates were visualized under $254 \mathrm{~nm}$ UV light or using a basic potassium permanganate solution.

Normal phase flash column chromatography was performed with a Teledyne Isco CombiFlash ${ }^{\circledR} \mathrm{Rf} 200$ using RediSep ${ }^{\circledR} \mathrm{Rf}$ silica columns with the UV detector set to $254 \mathrm{~nm}$ and $280 \mathrm{~nm}$. Reverse phase column chromatography was performed with a Teledyne Isco CombiFlash ${ }^{\circledR} \mathrm{Rf} 200$ using C18 RediSep ${ }^{\circledR} \mathrm{Rf}$ Gold columns with the UV detector set to $220 \mathrm{~nm}$ and $254 \mathrm{~nm}$. Mobile phases $\mathrm{A}\left(\mathrm{H}_{2} \mathrm{O}+0.1 \% \mathrm{TFA}\right)$ and $\mathrm{B}(\mathrm{MeOH}$ or ACN) were used. Preparative HPLC was performed using an Agilent Prep 1200 series with the UV detector set to $220 \mathrm{~nm}$ and $254 \mathrm{~nm}$. Samples were injected onto either a Phenomenex Luna $250 \times 30 \mathrm{~mm}$ $(5 \mu \mathrm{m}) \mathrm{C} 18$ column or a Phenomenex Luna $75 \times 30 \mathrm{~mm}(5 \mu \mathrm{m}) \mathrm{C} 18$ column at rt. Mobile phases $\mathrm{A}\left(\mathrm{H}_{2} \mathrm{O}+\right.$ $0.1 \%$ TFA) and $B(\mathrm{MeOH}$ or $\mathrm{ACN}$ ) were used with a flow rate of $40 \mathrm{~mL} / \mathrm{min}$ for the larger column and 30 $\mathrm{mL} / \mathrm{min}$ for the smaller column.

\section{Analysis of products}

Analytical LCMS was used to establish the purity of targeted compounds. All final compounds that were evaluated in biochemical assays had $>95 \%$ purity as determined by LCMS. Analytical LCMS data for compounds were acquired on an Agilent 6110 Series system with UV detector set to 220 and $254 \mathrm{~nm}$. Samples were injected onto an Agilent Eclipse Plus $4.6 \times 50 \mathrm{~mm}, 1.8 \mu \mathrm{m}, \mathrm{C} 18$ column at rt. Mobile phases $A\left(\mathrm{H}_{2} \mathrm{O}+0.1 \%\right.$ acetic acid) and $\mathrm{B}(\mathrm{MeOH}$ or $\mathrm{ACN}+0.1 \%$ acetic acid) were used in a linear gradient from $10 \%$ to $100 \%$ B in $5 \mathrm{~min}$, followed by a flush at $100 \%$ B for another 2 min with a flow rate of $1.0 \mathrm{~mL} / \mathrm{min}$. Mass spectra (MS) data were acquired in positive ion mode using an Agilent 6110 single quadrupole mass spectrometer with an electrospray ionization (ESI) source. ${ }^{1} \mathrm{H}$ and ${ }^{13} \mathrm{C}$ NMR spectra were obtained on a Bruker AV 400 at $400 \mathrm{MHz}$ and $101 \mathrm{MHz}$, respectively. Chemical shifts are reported in ppm and coupling constants are reported in $\mathrm{Hz}$ with $\mathrm{CDCl}_{3}$ referenced at $7.26\left({ }^{1} \mathrm{H}\right)$ and $77.16 \mathrm{ppm}\left({ }^{13} \mathrm{C}\right)$, DMSO- $d_{6}$ referenced at $2.50\left({ }^{1} \mathrm{H}\right)$ and $39.5 \mathrm{ppm}\left({ }^{13} \mathrm{C}\right)$, and MeOD- $d_{4}$ referenced at $3.31\left({ }^{1} \mathrm{H}\right)$ and $49.00\left({ }^{13} \mathrm{C}\right)$.

\section{Chemistry abbreviations}

Methanol (MeOH), acetonitrile (ACN), dichloromethane (DCM), ethyl acetate (EtOAc), dimethyl sulfoxide (DMSO), $\mathrm{N}, \mathrm{N}$-dimethylformamide (DMF), chlorotriisopropylsilane (TIPSCl), tetrabutylammonium fluoride (TBAF), 4-methylbenzenesulfonyl chloride ( $\mathrm{TsCl}$ ), 4-dimethylaminopyridine (DMAP), trifluoroacetic acid (TFA), 2-(1H-benzo[d][1,2,3]triazol-1-yl)-1,1,3,3-tetramethyluronium tetrafluoroborate (TBTU), $N$-ethyl$\mathrm{N}$-isopropylpropan-2-amine (DIPEA), 1-[bis(dimethylamino)methylene]-1H-1,2,3-triazolo[4,5b]pyridinium 3-oxidhexafluorophosphate (HATU), 1-hydroxy-7-azabenzaotriazole (HOAT), 1,8diazabicyclo[5.4.0] undec-7-ene (DBU), triethylamine $\left(\mathrm{Et}_{3} \mathrm{~N}\right)$. 


\section{Synthetic Schemes}

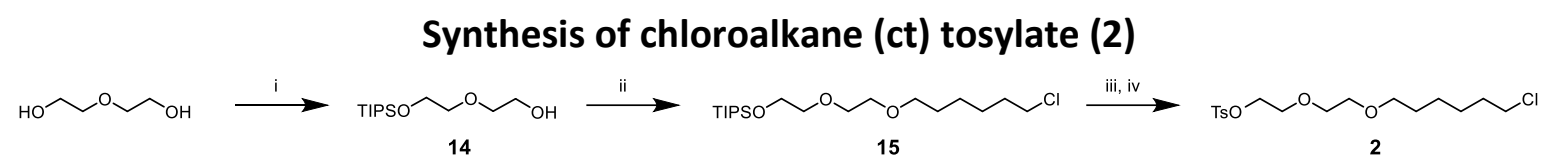

Supplemental scheme 1. Reagents and conditions: i) TIPSCl, imidazole in DCM, rt, 36\%; ii) 1-Chloro-6iodohexane, $\mathrm{NaH}$ in $\mathrm{THF}, 0^{\circ} \mathrm{C}$ to rt, $36 \%$; iii) TBAF in THF, rt, 79\%; iv) Compound 16, $\mathrm{TsCl}$, DMAP in DCM, rt, $67 \%$

\section{Synthesis of PEG $-J Q 1$ (19)}

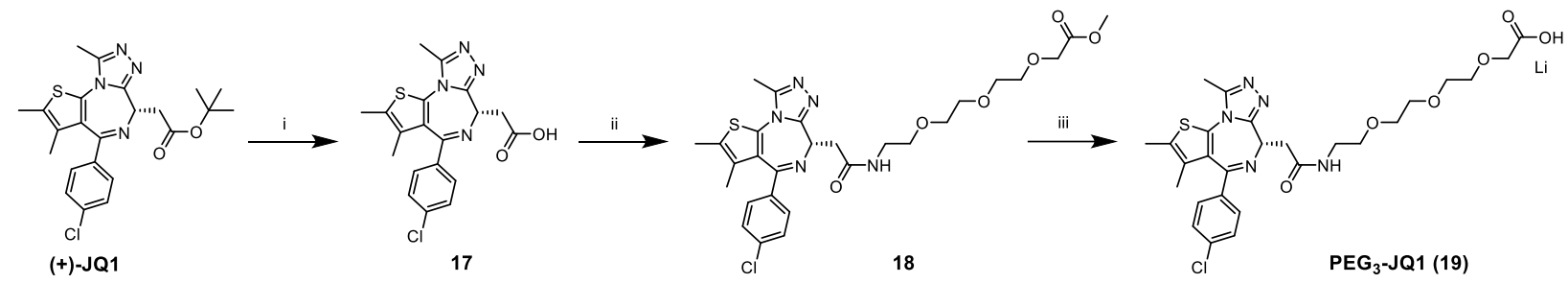

Supplemental scheme 2. Reagents and conditions: i) TFA $20 \%$ in DCM, rt, 81\%; ii) $\mathrm{NH}_{2}-\mathrm{PEG}_{3}$ linker, TBTU, DIPEA in DMF, rt, 52\%; iii) Satd. LiOH in dioxane/water, rt, $88 \%$

\section{Synthesis of ct-MZ1 (3)}

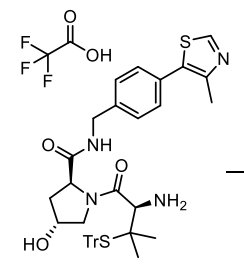

20

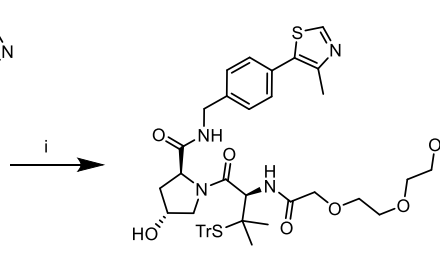

21

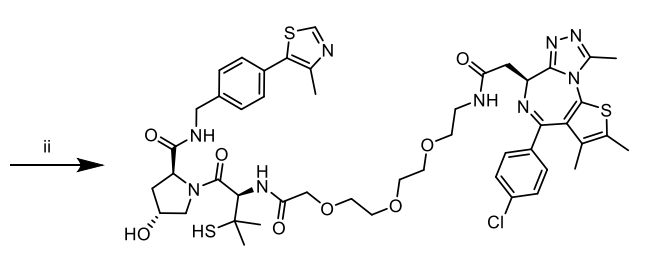

MZ1 analog (1)

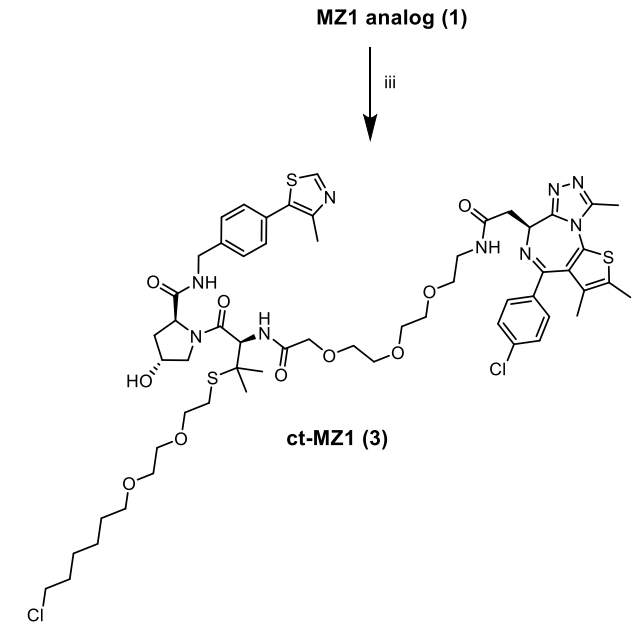

Supplemental scheme 3. Reagents and conditions: Compound $\mathbf{2 0}$ was synthesized according to literature procedures; ${ }^{1}$ i) Compound PEG ${ }_{3}-\mathrm{JQ1}$ (19), HATU, HOAT, DIPEA in DMF, rt, 31\%; ii) TIPS/TFA 5\% in DCM, rt, $65 \%$; iii) Compound 2, DBU in DMF, rt, 5\% 


\section{Synthesis of chloroalkane (ct) amine (23)}

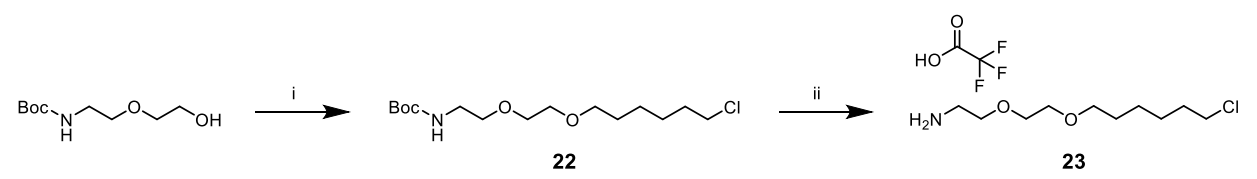

Supplemental scheme 8. Reagents and conditions: i) 1-Chloro-6-iodohexne, $\mathrm{NaH}$ in DMF, $0^{\circ} \mathrm{C}$ to rt, $55 \%$; ii) TFA $10 \%$ in DCM, rt, quantitative

Synthesis of ct-PEG $-J Q 1(6)$
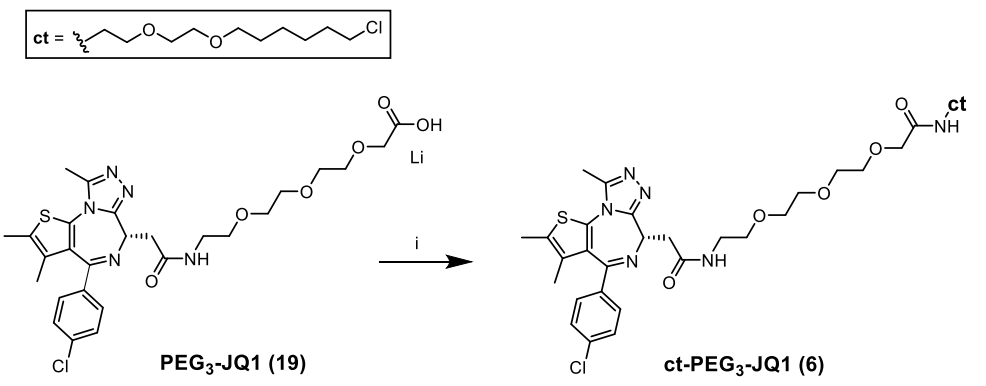

Supplemental scheme 5. Reagents and conditions: PEG $-J Q 1$ (19) was synthesized according to supplemental scheme 2; i) Compound 23, TBTU, DIPEA in DMF, rt, 36\%

\section{Synthesis of ct-JQ1 (7)}

$$
\mathrm{ct}=\stackrel{\sim}{\sim} \sim \sim_{\mathrm{O}} \sim \mathrm{Cl}
$$

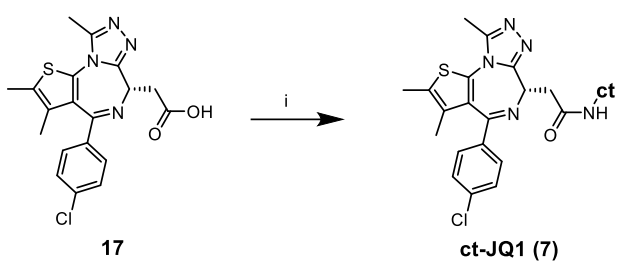

Supplemental scheme 6. Reagents and conditions: Compound 17 was synthesized according to supplemental scheme 2; i) Compound 23, TBTU, DIPEA in DMF, rt, 15\%

\section{Synthesis of ct-S-VHL (4)}

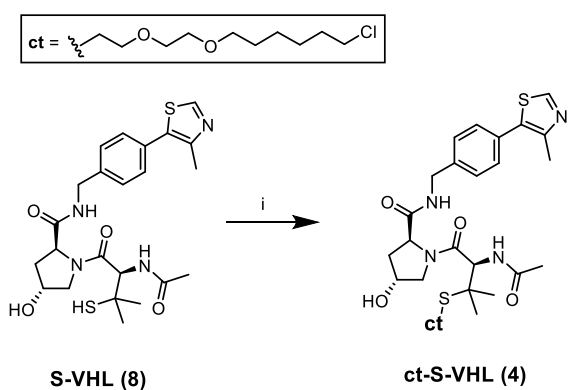

Supplemental scheme 7. Reagents and conditions: S-VHL (8) was synthesized according to literature procedures; ${ }^{1,3}$ i) Compound 23, DBU in DMF, rt, 18\% 


\section{Synthesis of ct-alkylz linker (24)}

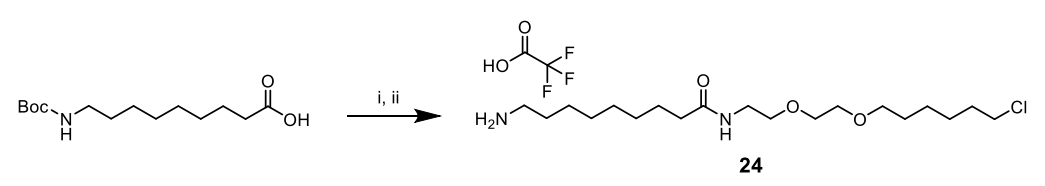

Supplemental scheme 9. Reagents and conditions: i) Compound 23, TBTU, DIPEA in DMF, rt; ii) TFA 20\% in DCM, rt, 70\% over two steps

\section{Synthesis of ct-VHL (5), ct-PEG 6 -VHL (11), and ct-PEG $2-\mathrm{VHL}$ (12), and ct-alkyl 2 -VHL (13)}

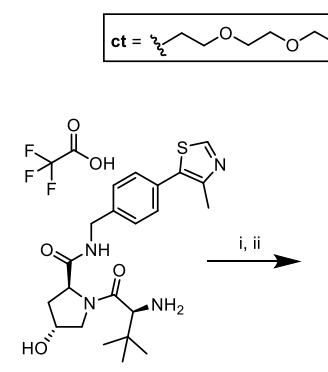

25

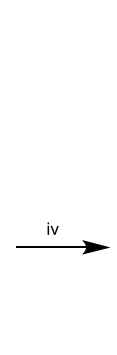

26

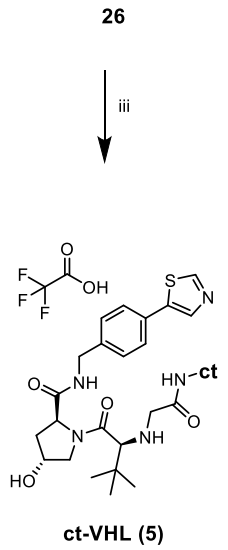

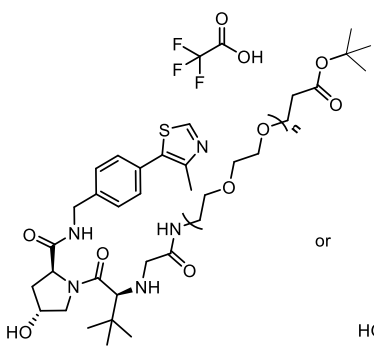

27: $\mathbf{n}=\mathbf{3}$ 28: $n=1$

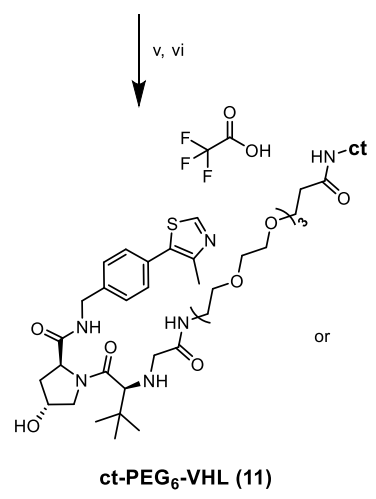

${ }^{\circ} \mathrm{O}^{\circ}$

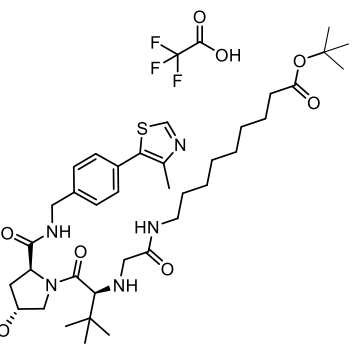

ct-alkyl 2 -VHL (13)

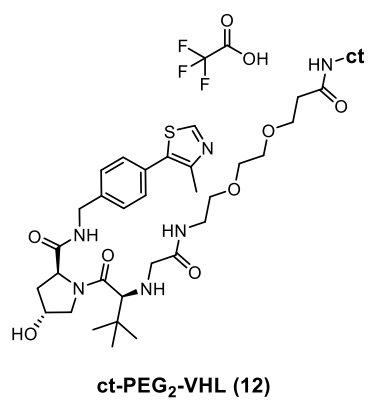

Supplemental scheme 10. Reagents and conditions: Compound 25 was synthesized according to literature procedures; ; 3 i) tert-butyl 2-bromoacetate, $\mathrm{K}_{2} \mathrm{CO}_{3}$ in $\mathrm{ACN}, 80^{\circ} \mathrm{C}, 27 \%$; ii) $20 \%$ TFA in DCM, $11 \%$ over two steps; iii) Compound 23, TBTU, DIPEA in DMF, rt, $13 \%$; iv) $\mathrm{NH}_{2}-\mathrm{PEG}_{6}$ or $\mathrm{NH}_{2}-\mathrm{PEG}_{2}$ linker or Compound 24, TBTU, DIPEA in DMF, rt, 6-37\%; v) TFA 20\% in DCM, rt; vi) Compound 23, TBTU, DIPEA in DMF, rt, 30-38\% 


\section{Synthesis of ct-O-Pom (9) and ct-N-Pom (10)}
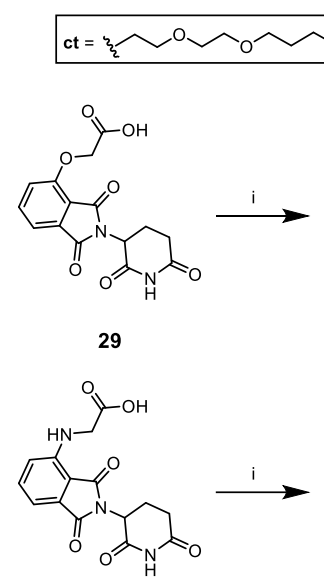

30

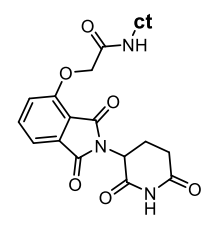

ct-O-Pom (9)

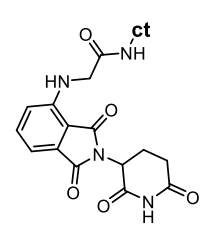

ct-N-Pom (10)

Supplemental scheme 11. Reagents and conditions: Compounds $\mathbf{2 9}$ and $\mathbf{3 0}$ were synthesized according to literature procedures; ${ }^{5}$ i) Compound 29 or $\mathbf{3 0}$, compound $\mathbf{2 3}$, TBTU, DIPEA in DMF, $13-57 \%$.

\section{Synthetic Procedures}

\section{2-(2-((triisopropylsilyl)oxy)ethoxy)ethan-1-ol (14)}<smiles>OCCOCCO[SnH3]</smiles>

TIPSCl (4.94 mL, 1.0 Eq, $22 \mathrm{mmol}$ ) and imidazole (1.50 g, $1.0 \mathrm{Eq}, 22.0 \mathrm{mmol})$ were dissolved in DCM (50 $\mathrm{mL})$. A solution of 2,2'-oxybis(ethan-1-ol) $(4.70 \mathrm{~g}, 3.8 \mathrm{~mL}, 2.0 \mathrm{Eq}, 44.0 \mathrm{mmol})$ in DCM (20 mL) was added dropwise at $\mathrm{rt}$, and the reaction was left to stir at rt overnight. After $22 \mathrm{~h}$, the reaction was quenched by the addition of water and was washed with $10 \% \mathrm{HCl}$, satd. $\mathrm{NaHCO}_{3}$, and brine $3 \mathrm{X}$ each. The organic layer was then dried over $\mathrm{Na}_{2} \mathrm{SO}_{4}$, filtered, and concentrated under reduced pressure. The resulting crude product was purified via flash chromatography (0-100\%, EtOAc in hexanes) to yield the desired product, compound 14, as a clear colorless oil $(2.10 \mathrm{~g}, 36 \%)$.

${ }^{1} \mathrm{H}$ NMR $\left(400 \mathrm{MHz}, \mathrm{MeOD}-d_{4}\right) \delta 3.87(\mathrm{dd}, J=5.8,4.7 \mathrm{~Hz}, 2 \mathrm{H}), 3.68-3.64(\mathrm{~m}, 2 \mathrm{H}), 3.62-3.58(\mathrm{~m}, 4 \mathrm{H}), 1.16$ $-1.13(\mathrm{~m}, 1 \mathrm{H}), 1.12-1.06(\mathrm{~m}, 2 \mathrm{H})$.

${ }^{13} \mathrm{C}$ NMR $\left(101 \mathrm{MHz}, \mathrm{MeOD}-d_{4}\right) \delta 73.82,64.27,62.28,18.42,13.20$ (One carbon not observed). 


\section{6-chloro-3,3-diisopropyl-2-methyl-4,7,10-trioxa-3-silahexadecane (15)}<smiles>ClCCCCCCCOCCOCCO[InH]</smiles>

To a solution of $\mathrm{NaH}$ ( $60 \%$ in mineral oil, $0.28 \mathrm{~g}, 1.5 \mathrm{Eq}, 6.9 \mathrm{mmol})$ in anhydrous DMF ( $3 \mathrm{~mL})$ and THF ( 3 $\mathrm{mL})$ at $0^{\circ} \mathrm{C}$ under nitrogen was added compound $14(1.21 \mathrm{~g}, 1.0 \mathrm{Eq}, 4.6 \mathrm{mmol}$. After 40 minutes, 1-chloro6-iodohexane $(1.30 \mathrm{~g}, 0.8 \mathrm{~mL}, 1.1 \mathrm{Eq}, 5.1 \mathrm{mmol})$ was added, and the reaction was warmed to rt and left to stir overnight. After $19 \mathrm{~h}$, the reaction was quenched by the addition of water, diluted with $1 \mathrm{M} \mathrm{HCl}$, and extracted with DCM $3 \mathrm{X}$. The combined organic layers were then washed with bine, dried over $\mathrm{Na}_{2} \mathrm{SO}_{4}$, filtered, and concentrated under reduced pressure. The resulting crude product was purified via flash chromatography (0-100\% EtOAc in hexanes) to yield the desired product, compound 15, as a clear colorless oil (635.7 mg, 36\%).

${ }^{1} \mathrm{H}$ NMR $\left(400 \mathrm{MHz}, \mathrm{MeOD}-d_{4}\right) \delta 3.85(\mathrm{t}, J=5.2 \mathrm{~Hz}, 2 \mathrm{H}), 3.66-3.62(\mathrm{~m}, 2 \mathrm{H}), 3.60-3.52(\mathrm{~m}, 6 \mathrm{H}), 3.47(\mathrm{t}, J=$ $6.5 \mathrm{~Hz}, 2 \mathrm{H}), 1.78(\mathrm{p}, J=6.8 \mathrm{~Hz}, 2 \mathrm{H}), 1.59(\mathrm{p}, J=6.7 \mathrm{~Hz}, 2 \mathrm{H}), 1.52-1.37(\mathrm{~m}, 4 \mathrm{H}), 1.16-1.13(\mathrm{~m}, 1 \mathrm{H}), 1.12-$ $1.06(\mathrm{~m}, 2 \mathrm{H})$.

${ }^{13} \mathrm{C}$ NMR $\left(101 \mathrm{MHz}, \mathrm{MeOD}-d_{4}\right) \delta$ 73.80, 72.08, 71.78, 71.25, 64.21, 45.53, 33.74, 30.58, 27.74, 26.51, 18.62, 13.11.

\section{2-(2-((6-chlorohexyl)oxy)ethoxy)ethan-1-ol (16)}<smiles>OCCOCCOCCCCCCCl</smiles>

To a solution of compound 15 (200 mg, $1 \mathrm{Eq}, 525 \mu \mathrm{mol})$ in THF (1 mL) at rt was added TBAF (182 $\mu \mathrm{L}, 1.2$ $\mathrm{Eq}, 630 \mu \mathrm{mol})$. The reaction was left to stir at $\mathrm{rt}$ for $3 \mathrm{~h}$, before being quenched with water and extracted with EtOAc 3X. The combined organic layers were then washed with brine, dried over $\mathrm{Na}_{2} \mathrm{SO}_{4}$, filtered, and concentrated under reduced pressure. The resulting crude product was purified via flash chromatography $(0-100 \%$ EtOAc in hexanes) to yield the desired product, compound 16, as a clear colorless oil (93.4 mg, 79\%).

${ }^{1} \mathrm{H}$ NMR $\left(400 \mathrm{MHz}, \mathrm{MeOD}-d_{4}\right) \delta 3.68-3.61(\mathrm{~m}, 4 \mathrm{H}), 3.61-3.54(\mathrm{~m}, 6 \mathrm{H}), 3.49(\mathrm{t}, J=6.6 \mathrm{~Hz}, 2 \mathrm{H}), 1.83-1.71$ $(\mathrm{m}, 2 \mathrm{H}), 1.64-1.56(\mathrm{~m}, 2 \mathrm{H}), 1.52-1.35(\mathrm{~m}, 4 \mathrm{H})$.

${ }^{13} \mathrm{C}$ NMR $\left(101 \mathrm{MHz}, \mathrm{MeOD}-d_{4}\right) \delta$ 73.66, 72.18, 71.39, 71.20, 62.21, 45.68, 33.73, 30.50, 27.71, 26.45. 


\section{2-(2-((6-chlorohexyl)oxy)ethoxy)ethyl 4-methylbenzenesulfonate (2)}<smiles>O=S(=O)(O)CCOCCOCCCCCCCl</smiles>

To a solution of compound $16(93.4 \mathrm{mg}, 1.0 \mathrm{Eq}, 416 \mu \mathrm{mol})$ in $\mathrm{DCM}(400 \mu \mathrm{L})$ at rt was added $\mathrm{TsCl}(95.1 \mathrm{mg}$, $1.2 \mathrm{Eq}, 499 \mu \mathrm{mol})$ and $\operatorname{DMAP}(5.1 \mathrm{mg}, 0.1 \mathrm{Eq}, 42 \mu \mathrm{mol})$. The reaction was left to stir at rt overnight. The reaction was then quenched with water and extracted with $\mathrm{DCM} 3 \mathrm{X}$. The combined organic layers were washed with brine, dried over $\mathrm{Na}_{2} \mathrm{SO}_{4}$, filtered, and concentrated under reduced pressure. The resulting crude product was purified via flash chromatography (0-100\% EtOAc in hexanes) to yield the desired product, compound $\mathbf{2}$, as a clear colorless oil (105.5 mg, 67.0\%).

${ }^{1} \mathrm{H}$ NMR $\left(400 \mathrm{MHz}, \mathrm{MeOD}-d_{4}\right) \delta 7.79(\mathrm{~d}, J=8.3 \mathrm{~Hz}, 2 \mathrm{H}), 7.44(\mathrm{~d}, J=8.0 \mathrm{~Hz}, 2 \mathrm{H}), 4.17-4.13(\mathrm{~m}, 2 \mathrm{H}), 3.67-$ $3.64(\mathrm{~m}, 2 \mathrm{H}), 3.57-3.52(\mathrm{~m}, 4 \mathrm{H}), 3.52-3.48(\mathrm{~m}, 2 \mathrm{H}), 3.44(\mathrm{t}, J=6.5 \mathrm{~Hz}, 2 \mathrm{H}), 2.45(\mathrm{~s}, 3 \mathrm{H}), 1.79-1.71(\mathrm{~m}$, $2 \mathrm{H}), 1.56(\mathrm{p}, J=6.8 \mathrm{~Hz}, 2 \mathrm{H}), 1.49-1.41(\mathrm{~m}, 2 \mathrm{H}), 1.41-1.33(\mathrm{~m}, 2 \mathrm{H})$.

${ }^{13} \mathrm{C}$ NMR $\left(101 \mathrm{MHz}, \mathrm{MeOD}-d_{4}\right) \delta 146.42,134.47,131.03,129.03,72.15,71.55,71.07,70.89,69.73,45.72$, $33.72,30.52,27.70,26.45,21.60$.

(S)-2-(4-(4-chlorophenyl)-2,3,9-trimethyl-6H-thieno[3,2-f][1,2,4]triazolo[4,3-a][1,4]diazepin-6-yl)acetic acid (17)

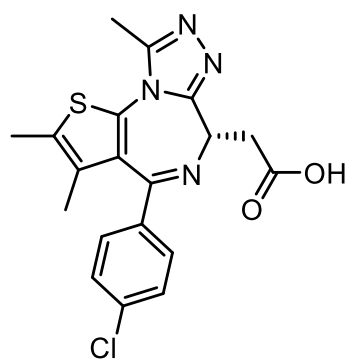

To a solution of (+)-JQ1 (tert-butyl (S)-2-(4-(4-chlorophenyl)-2,3,9-trimethyl-6H-thieno[3,2$f][1,2,4]$ triazolo[4,3-a][1,4]diazepin-6-yl)acetate, $50.0 \mathrm{mg}, 1.0 \mathrm{Eq}, 109 \mu \mathrm{mol})$ in DCM $(800 \mu \mathrm{L})$ at rt was added TFA $(200 \mu \mathrm{L})$. The reaction was left to stir at rt. After $4 \mathrm{~h}$, the reaction was concentrated under reduced pressure. To remove residual TFA, the product was dissolved in DCM $(3 \mathrm{~mL})$ and concentrated under reduced pressure $3 \mathrm{X}$ to yield the desired product, compound 17 , as a yellow residue $(35.5 \mathrm{mg}$, 81\%). ESI-MS (m/z): [M+H+] calcd. for $\mathrm{C}_{19} \mathrm{H}_{18} \mathrm{ClN}_{4} \mathrm{O}_{2} \mathrm{~S}, 401.08$; found 401.10.

${ }^{1} \mathrm{H} \mathrm{NMR}\left(400 \mathrm{MHz}, \mathrm{CDCl}_{3}\right) \delta 7.42(\mathrm{~d}, J=8.6 \mathrm{~Hz}, 2 \mathrm{H}), 7.32(\mathrm{~d}, J=8.7 \mathrm{~Hz}, 2 \mathrm{H}), 4.61(\mathrm{t}, J=7.0 \mathrm{~Hz}, 1 \mathrm{H}), 3.71$ (dd, $J=17.0,6.8 \mathrm{~Hz}, 1 \mathrm{H}), 3.60(\mathrm{dd}, J=16.9,7.1 \mathrm{~Hz}, 1 \mathrm{H}), 2.67(\mathrm{~s}, 3 \mathrm{H}), 2.40(\mathrm{~s}, 3 \mathrm{H}), 1.68(\mathrm{~s}, 3 \mathrm{H})$.

${ }^{13} \mathrm{C}$ NMR $\left(101 \mathrm{MHz}, \mathrm{CDCl}_{3}\right) \delta 173.77,164.08,155.29,149.95,136.87,136.33,131.91,131.13,130.96$, $130.53,129.92,128.70,53.71,36.75,14.41,13.11,11.71$. 
Methyl (S)-1-(4-(4-chlorophenyl)-2,3,9-trimethyl-6H-thieno[3,2-f][1,2,4]triazolo[4,3-a][1,4]diazepin-6yl)-2-oxo-6,9,12-trioxa-3-azatetradecan-14-oate (18)

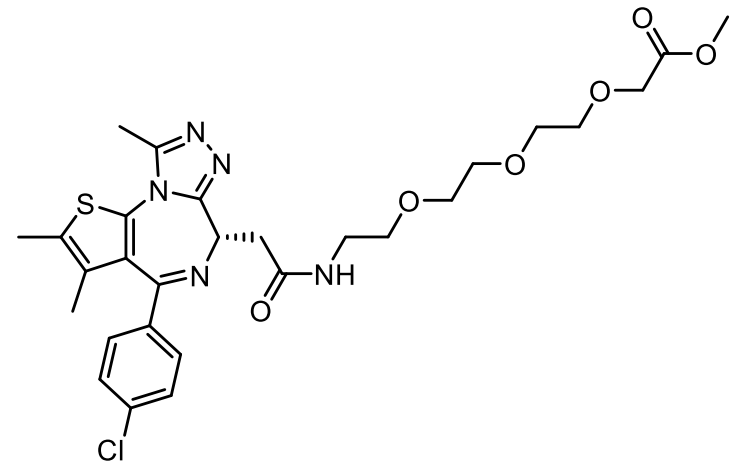

To a solution of compound 17 (37.0 mg, $1.3 \mathrm{Eq}, 115 \mu \mathrm{mol})$ in DMF (500 $\mu \mathrm{L})$ at rt was added TBTU (37.0 $\mathrm{mg}, 1.3 \mathrm{Eq}, 115 \mu \mathrm{mol})$ and DIPEA $(34.3 \mathrm{mg}, 46.3 \mu \mathrm{L}, 3.0 \mathrm{Eq}, 266 \mu \mathrm{mol})$. In a separate flask, DIPEA (11.4 $\mathrm{mg}, \quad 15.4 \mu \mathrm{L}, 1.0 \mathrm{Eq}, 89 \mu \mathrm{mol})$ was added to a solution of methyl 2-(2-(2-(2aminoethoxy)ethoxy)ethoxy)acetate 2,2,2-trifluoroacetate $(29.7 \mathrm{mg}, 1.0 \mathrm{Eq}, 89 \mu \mathrm{mol})$ in DMF (500 $\mu \mathrm{L})$ at $\mathrm{rt}$; after 5-10 $\mathrm{min}$, the solution was added to the main reaction mixture, and the reaction was left to stir at rt. After $1 \mathrm{~h}$, the reaction was concentrated under reduced pressure and purified via flash chromatography $(0-10 \% \mathrm{MeOH}$ in $\mathrm{DCM})$ to yield the desired product, compound 18 , as a clear yellow oil (28.0 mg, 52\%). ESI-MS (m/z): [M+H'] calcd. for $\mathrm{C}_{28} \mathrm{H}_{35} \mathrm{ClN}_{5} \mathrm{O}_{6} \mathrm{~S}, 604.19$; found 604.20.

${ }^{1} \mathrm{H}$ NMR $\left(400 \mathrm{MHz}, \mathrm{MeOD}-d_{4}\right) \delta 7.48-7.39(\mathrm{~m}, 4 \mathrm{H}), 4.63(\mathrm{dd}, J=9.0,5.2 \mathrm{~Hz}, 1 \mathrm{H}), 4.15(\mathrm{~s}, 2 \mathrm{H}), 3.70(\mathrm{~s}, 3 \mathrm{H})$, $3.70-3.64(\mathrm{~m}, 8 \mathrm{H}), 3.62(\mathrm{t}, J=5.7 \mathrm{~Hz}, 2 \mathrm{H}), 3.49-3.42(\mathrm{~m}, 3 \mathrm{H}), 3.33-3.32(\mathrm{~m}, 1 \mathrm{H}), 3.30-3.26(\mathrm{~m}, 1 \mathrm{H})$, $2.69(\mathrm{~s}, 3 \mathrm{H}), 2.45(\mathrm{~s}, 3 \mathrm{H}), 1.70(\mathrm{~s}, 3 \mathrm{H})$.

${ }^{13} \mathrm{C}$ NMR $\left(101 \mathrm{MHz}, \mathrm{MeOD}-d_{4}\right) \delta$ 172.92, 172.72, 166.14, 157.04, 152.14, 138.14, 137.94, 133.51, 133.20, $132.03,132.00,131.36,129.78,71.84,71.58,71.55,71.30,70.61,69.14,55.20,40.54,38.75,14.41,12.93$, 11.60 . 
(S)-1-(4-(4-chlorophenyl)-2,3,9-trimethyl-6H-thieno[3,2-f][1,2,4]triazolo[4,3-a][1,4]diazepin-6-yl)-2oxo-6,9,12-trioxa-3-azatetradecan-14-oic acid, lithium salt (PEG $-J Q 1,19)$

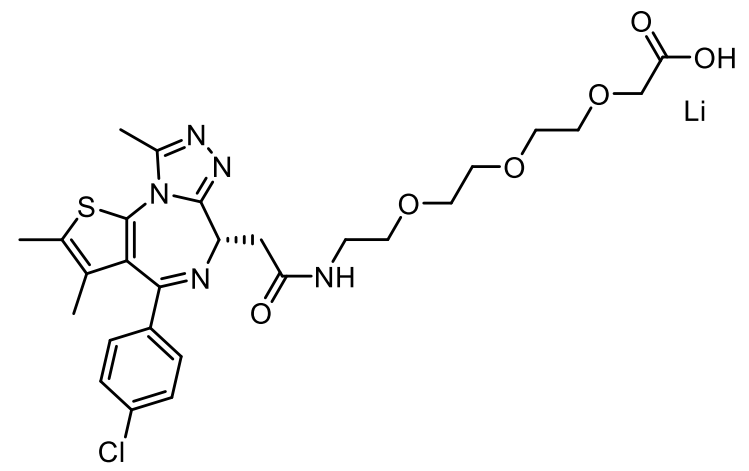

To a solution of compound 18 (28.0 mg, $1.0 \mathrm{Eq}, 46 \mu \mathrm{mol})$ in 1,4-dioxane $(500 \mu \mathrm{L})$ and water $(500 \mu \mathrm{L})$ at $\mathrm{rt}$ was added satd. $\mathrm{LiOH}$. The reaction was left to stir at rt. After $30 \mathrm{~min}$, the reaction was concentrated under reduced pressure to yield the desired product, PEG $_{3}-\mathrm{JQ1}$ (19), as a clear yellow oil (24.0 mg, 87\%). ESI-MS $(\mathrm{m} / \mathrm{z}):\left[\mathrm{M}+\mathrm{H}^{+}\right]$calcd. for $\mathrm{C}_{27} \mathrm{H}_{33} \mathrm{ClN}_{5} \mathrm{O}_{6} \mathrm{~S}, 590.18$; found 590.20.

${ }^{1} \mathrm{H}$ NMR $\left(400 \mathrm{MHz}, \mathrm{CDCl}_{3}\right) \delta 7.49(\mathrm{t}, J=5.5 \mathrm{~Hz}, 1 \mathrm{H}), 7.42-7.29(\mathrm{~m}, 4 \mathrm{H}), 4.71(\mathrm{dd}, J=7.6,6.6 \mathrm{~Hz}, 1 \mathrm{H}), 4.17$ $(\mathrm{d}, J=3.9 \mathrm{~Hz}, 1 \mathrm{H}), 3.84-3.79(\mathrm{~m}, 1 \mathrm{H}), 3.77-3.74(\mathrm{~m}, 1 \mathrm{H}), 3.72(\mathrm{~d}, J=5.0 \mathrm{~Hz}, 3 \mathrm{H}), 3.69(\mathrm{~s}, 5 \mathrm{H}), 3.67-3.63$ $(\mathrm{m}, 2 \mathrm{H}), 3.60-3.56(\mathrm{~m}, 1 \mathrm{H}), 3.52-3.48(\mathrm{~m}, 1 \mathrm{H}), 3.44(\mathrm{dd}, J=15.0,6.7 \mathrm{~Hz}, 1 \mathrm{H}), 2.66(\mathrm{~s}, 3 \mathrm{H}), 2.40(\mathrm{~s}, 3 \mathrm{H})$, $1.67(\mathrm{~s}, 3 \mathrm{H})$.

${ }^{13} \mathrm{C}$ NMR $\left(101 \mathrm{MHz}, \mathrm{CDCl}_{3}\right) \delta 172.64,170.37,164.13,155.52,150.01,136.99,136.46,131.66,131.38$, $131.22,131.11,130.02,128.83$, 71.18, 70.78, 70.64, 70.39, 69.85, 68.87, 54.38, 39.41, 38.63, 14.51, 13.23, 11.83. 
$(2 S, 4 R)-1-((R)-2$-amino-3-methyl-3-(tritylthio)butanoyl)-4-hydroxy- $N$-(4-(4-methylthiazol-5yl)benzyl)pyrrolidine-2-carboxamide hydrochloride (20)

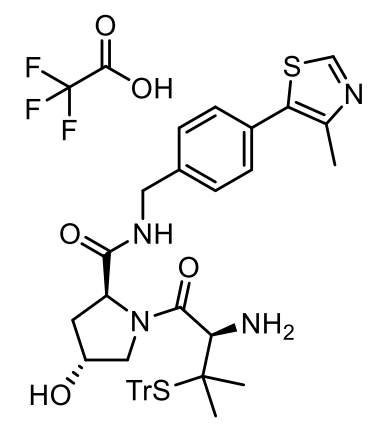

Compound 20 was synthesized according to literature procedures. ${ }^{1,3}$ Obtained $30.0 \mathrm{mg}, 12 \%$ over two steps. ESI-MS (m/z): [M+H+ $\mathrm{H}^{+}$calcd. for $\mathrm{C}_{40} \mathrm{H}_{43} \mathrm{~N}_{4} \mathrm{O}_{3} \mathrm{~S}_{2}$, 691.27; found 243.10 ([ $\left.\mathrm{Tr}+\mathrm{H}^{+}\right]$calcd. for $\mathrm{C}_{19} \mathrm{H}_{15}, 243.12$ and 449.20 ([M-Tr] calcd. $\mathrm{C}_{21} \mathrm{H}_{28} \mathrm{~N}_{4} \mathrm{O}_{3} \mathrm{~S}_{2}$ for 449.16 ).

${ }^{1} \mathrm{H}$ NMR $\left(400 \mathrm{MHz}, \mathrm{CDCl}_{3}\right) \delta 8.93(\mathrm{~s}, 1 \mathrm{H}), 8.71(\mathrm{t}, J=6.0 \mathrm{~Hz}, 1 \mathrm{H}), 7.72-7.66(\mathrm{~m}, 6 \mathrm{H}), 7.42-7.39(\mathrm{~m}, 4 \mathrm{H})$, $7.39-7.34(\mathrm{~m}, 6 \mathrm{H}), 7.30-7.25(\mathrm{~m}, 4 \mathrm{H}), 4.53-4.44(\mathrm{~m}, 2 \mathrm{H}), 4.40(\mathrm{~s}, 1 \mathrm{H}), 4.31-4.24(\mathrm{~m}, 1 \mathrm{H}), 3.08(\mathrm{dd}, J=$ 3.7, $11.1 \mathrm{~Hz}, 1 \mathrm{H}), 2.79(\mathrm{~d}, J=11.1 \mathrm{~Hz}, 1 \mathrm{H}), 2.52(\mathrm{~s}, 1 \mathrm{H}), 2.47(\mathrm{~s}, 3 \mathrm{H}), 2.21-2.12(\mathrm{~m}, 1 \mathrm{H}), 1.97-1.88(\mathrm{~m}$, $1 \mathrm{H}), 1.50(\mathrm{~s}, 3 \mathrm{H}), 1.40(\mathrm{~s}, 3 \mathrm{H})$.

${ }^{13} \mathrm{C}$ NMR $\left(101 \mathrm{MHz}, \mathrm{CDCl}_{3}\right) \delta 173.66,166.33,153.01,148.82,145.70,140.18,133.48,131.44,130.94$, $130.36,129.33,128.84,128.84,128.35,70.77,69.77,61.16,58.30,57.34,54.65,43.63,38.91,26.28$, $25.83,15.70$. 
$(2 S, 4 R)-1-((R)-17-((S)-4-(4-c h l o r o p h e n y l)-2,3,9-t r i m e t h y l-6 H$-thieno[3,2-f][1,2,4]triazolo[4,3a][1,4] diazepin-6-yl)-4,16-dioxo-2-(2-(tritylthio)propan-2-yl)-6,9,12-trioxa-3,15-diazaheptadecanoyl)4-hydroxy-N-(4-(4-methylthiazol-5-yl)benzyl)pyrrolidine-2-carboxamide (21)

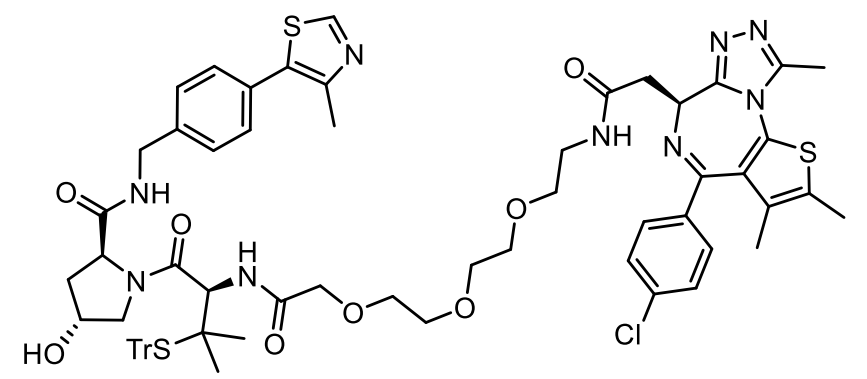

To a solution of PEG ${ }_{3} \mathrm{JQ1}(19)(15.2 \mathrm{mg}, 1.0 \mathrm{Eq}, 26 \mu \mathrm{mol})$ in DMF $(150 \mu \mathrm{L})$ at rt was added HATU $(9.8 \mathrm{mg}$, $1.0 \mathrm{Eq}, 26 \mu \mathrm{mol})$ and HOAT $(3.5 \mathrm{mg}, 1.0 \mathrm{Eq}, 26 \mu \mathrm{mol})$, followed by DIPEA $(5.0 \mathrm{mg}, 6.7 \mu \mathrm{L}, 1.5 \mathrm{Eq}, 39 \mu \mathrm{mol})$. In a separate flask, DIPEA ( $5.0 \mathrm{mg}, 6.7 \mu \mathrm{L}, 1.5 \mathrm{Eq}, 39 \mu \mathrm{mol})$ was added to a solution of compound 20 (20.7 $\mathrm{mg}, 1.0 \mathrm{Eq}, 26 \mu \mathrm{mol})$ in DMF (150 $\mu \mathrm{L})$; after $20 \mathrm{~min}$, the solution was added to the main reaction mixture, and the reaction was left to stir at rt. After $5 \mathrm{~h}$, the reaction was concentrated under reduced pressure and purified via preparative HPLC (20-100\%, MeOH in water containing $0.1 \% \mathrm{TFA})$ to yield the desired product, compound 21, as a clear yellow oil $(10.0 \mathrm{mg}, 31 \%)$. ESI-MS $(\mathrm{m} / \mathrm{z}):\left[\mathrm{M}+\mathrm{H}^{+}\right]$calcd. for $\mathrm{C}_{67} \mathrm{H}_{73} \mathrm{ClN}_{9} \mathrm{O}_{8} \mathrm{~S}_{3}, 1262.44$; found 243.10 ( $\left[\mathrm{Tr}+\mathrm{H}^{+}\right]$calcd. for $\left.\mathrm{C}_{19} \mathrm{H}_{15}, 243.12\right)$.

${ }^{1} \mathrm{H}$ NMR $\left(400 \mathrm{MHz}, \mathrm{MeOD}-d_{4}\right) \delta 8.97(\mathrm{~s}, 1 \mathrm{H}), 7.55(\mathrm{dd}, J=8.3,1.2 \mathrm{~Hz}, 5 \mathrm{H}), 7.49-7.36(\mathrm{~m}, 6 \mathrm{H}), 7.36(\mathrm{~s}, 3 \mathrm{H})$, $7.28-7.13(\mathrm{~m}, 10 \mathrm{H}), 4.65(\mathrm{dd}, J=8.9,5.3 \mathrm{~Hz}, 1 \mathrm{H}), 4.51(\mathrm{t}, J=8.2 \mathrm{~Hz}, 1 \mathrm{H}), 4.44-4.39(\mathrm{~m}, 1 \mathrm{H}), 4.30(\mathrm{~s}, 2 \mathrm{H})$, $4.16-3.99(\mathrm{~m}, 3 \mathrm{H}), 3.76-3.49(\mathrm{~m}, 13 \mathrm{H}), 3.51-3.38(\mathrm{~m}, 4 \mathrm{H}), 2.71(\mathrm{~s}, 3 \mathrm{H}), 2.44(\mathrm{~s}, 6 \mathrm{H}), 2.21-2.10(\mathrm{~m}$, $1 \mathrm{H}), 2.00$ (ddd, $J=13.2,8.7,4.7 \mathrm{~Hz}, 1 \mathrm{H}), 1.68(\mathrm{~s}, 3 \mathrm{H}), 1.22(\mathrm{~s}, 3 \mathrm{H}), 1.09(\mathrm{~s}, 3 \mathrm{H})$.

${ }^{13} \mathrm{C}$ NMR $\left(101 \mathrm{MHz}, \mathrm{MeOD}-d_{4}\right) \delta$ 174.25, 172.72, 172.14, 170.41, 166.37, 156.92, 153.16, 148.45, 146.10, 140.30, 138.18, 137.78, 133.57, 133.45, 132.17, 131.99, 131.46, 131.24, 131.09, 130.37, 129.84, 129.06, $128.81,128.73,128.61,128.02,127.87,72.27,71.71,71.60,71.40,71.19,70.82,70.67,69.55,61.01$, $58.26,58.14,55.83,55.03,43.48,40.60,38.85,38.49,26.96,26.05,15.62,14.44,12.96,11.59$. 
$(2 S, 4 R)-1-((R)-17-((S)-4-(4-c h l o r o p h e n y))-2,3,9-$ trimethyl-6H-thieno[3,2-f][1,2,4]triazolo[4,3a][1,4] diazepin-6-yl)-2-(2-mercaptopropan-2-yl)-4,16-dioxo-6,9,12-trioxa-3,15-diazaheptadecanoyl)-4hydroxy- $N$-(4-(4-methylthiazol-5-yl)benzyl)pyrrolidine-2-carboxamide (MZ1 analog, 1)<smiles>Cc1ncsc1-c1ccc(CNC(=O)[C@@H]2C[C@@H](O)CN2C(=O)[C@H](NC(=O)COCCOCCOCCNC(=O)C[C@@H]2N=C(c3ccc(Cl)cc3)c3c(sc(C)c3C)-n3c(C)nnc32)C(C)(C)S)cc1</smiles>

To a solution of compound 21 (15.5 mg, 1.0 Eq, $12 \mu \mathrm{mol})$ was dissolved in DCM ( $285 \mu \mathrm{L}$ ) at rt was added TIPS $(15 \mu \mathrm{L})$ and TFA $(15 \mu \mathrm{L})$. The reaction was left to stir at rt. After 30 minutes, the reaction was concentrated under reduced pressure and purified via flash chromatography $(0-15 \% \mathrm{MeOH}$ in $\mathrm{DCM})$ to yield the desired, MZ1 analog (1), as a clear yellow oil (8.2 mg, 65\%). ESI-MS $(\mathrm{m} / \mathrm{z}):\left[\mathrm{M}+\mathrm{H}^{+}\right]$calcd. for $\mathrm{C}_{48} \mathrm{H}_{59} \mathrm{ClN}_{9} \mathrm{O}_{8} \mathrm{~S}_{3}, 1020.33$; found 1020.10 .

${ }^{1} \mathrm{H}$ NMR $\left(400 \mathrm{MHz}, \mathrm{MeOD}-d_{4}\right) \delta 8.82(\mathrm{~s}, 1 \mathrm{H}), 7.43-7.33(\mathrm{~m}, 8 \mathrm{H}), 4.86(\mathrm{~s}, 1 \mathrm{H}), 4.60-4.51(\mathrm{~m}, 2 \mathrm{H}), 4.50-$ $4.44(\mathrm{~m}, 2 \mathrm{H}), 4.31(\mathrm{~d}, J=15.4 \mathrm{~Hz}, 1 \mathrm{H}), 4.04(\mathrm{~d}, J=4.1 \mathrm{~Hz}, 2 \mathrm{H}), 3.94-3.84(\mathrm{~m}, 2 \mathrm{H}), 3.71-3.59(\mathrm{~m}, 9 \mathrm{H}), 3.55$ $(\mathrm{t}, J=5.7 \mathrm{~Hz}, 2 \mathrm{H}), 3.44-3.37(\mathrm{~m}, 3 \mathrm{H}), 2.64(\mathrm{~s}, 3 \mathrm{H}), 2.42(\mathrm{~s}, 3 \mathrm{H}), 2.40(\mathrm{~s}, 3 \mathrm{H}), 2.24-2.17(\mathrm{~m}, 1 \mathrm{H}), 2.04$ (ddd, $J=13.3,9.1,4.5 \mathrm{~Hz}, 1 \mathrm{H}), 1.65(\mathrm{~s}, 3 \mathrm{H}), 1.40(\mathrm{~s}, 3 \mathrm{H}), 1.35(\mathrm{~s}, 3 \mathrm{H})$.

${ }^{13} \mathrm{C}$ NMR $\left(101 \mathrm{MHz}, \mathrm{MeOD}-d_{4}\right) \delta$ 174.29, 172.90, 172.22, 170.62, 166.13, 157.02, 152.82, 152.13, 149.06, 140.17, 138.11, 137.95, 133.50, 133.37, 133.20, 132.04, 131.99, 131.54, 131.36, 130.38, 129.79, 129.02, 72.24, 71.72, 71.59, 71.41, 71.13, 70.98, 70.71, 60.97, 58.56, 58.08, 55.19, 47.67, 43.74, 40.60, 39.05, $38.73,30.14,29.18,15.88,14.43,12.93,11.61$. 
$(2 S, 4 R)-1-((R)-2-(2-((2-(2-((6-c h l o r o h e x y)) o x y)$ ethoxy)ethyl)thio)propan-2-yl)-17-((S)-4-(4chlorophenyl)-2,3,9-trimethyl-6H-thieno[3,2-f][1,2,4]triazolo[4,3-a][1,4]diazepin-6-yl)-4,16-dioxo6,9,12-trioxa-3,15-diazaheptadecanoyl)-4-hydroxy- $N$-(4-(4-methylthiazol-5-yl)benzyl)pyrrolidine-2carboxamide (ct-MZ1, 3)

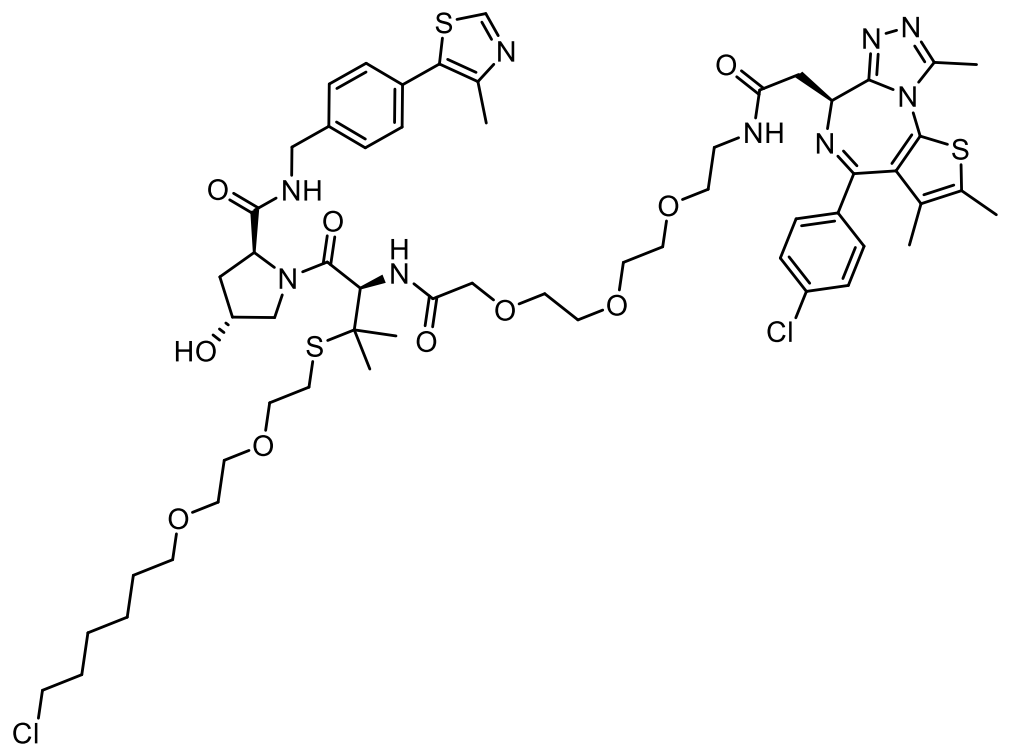

To a solution of MZ1 analog (1) $(8.2 \mathrm{mg}, 1.0 \mathrm{Eq}, 8 \mu \mathrm{mol})$ in DMF $(100 \mu \mathrm{L})$ at rt was added DBU (1.3 mg, 1.1 Eq, $9 \mu \mathrm{mol})$, followed by a solution of compound $2(3.3 \mathrm{mg}, 1.1 \mathrm{Eq}, 9 \mu \mathrm{mol})$ in DMF $(100 \mu \mathrm{L})$. The reaction was left to stir at rt. After $30 \mathrm{~min}$, the reaction was cooled to $0^{\circ} \mathrm{C}$ and treated with $5 \% \mathrm{KHSO}_{4}$ to adjust the $\mathrm{pH}$ to 3-4. The reaction was then concentrated under reduced pressure, and the resulting crude product was purified via preparative HPLC (30-100\% ACN in water containing $0.1 \%$ TFA) to yield the desired product, ct-MZ1 (3), as a clear yellow oil (0.53 mg, 5\%). ESI-MS $(\mathrm{m} / \mathrm{z})$ : $\left[\mathrm{M}+\mathrm{H}^{+}\right]$calcd. for $\mathrm{C}_{58} \mathrm{H}_{78} \mathrm{Cl}_{2} \mathrm{~N}_{9} \mathrm{O}_{10} \mathrm{~S}_{3}$, 1226.43; found 613. $90\left(\left[\mathrm{M} / 2+\mathrm{H}^{+}\right]\right.$calcd. for $\left.\mathrm{C}_{58} \mathrm{H}_{78} \mathrm{Cl}_{2} \mathrm{~N}_{9} \mathrm{O}_{10} \mathrm{~S}_{3}, 613.75\right)$.

${ }^{1} \mathrm{H}$ NMR $\left(400 \mathrm{MHz}, \mathrm{MeOD}-d_{4}\right) \delta 8.95(\mathrm{~s}, 1 \mathrm{H}), 7.48-7.39(\mathrm{~m}, 8 \mathrm{H}), 4.94(\mathrm{~d}, J=0.4 \mathrm{~Hz}, 1 \mathrm{H}), 4.68-4.64(\mathrm{~m}$, $1 \mathrm{H}), 4.60(\mathrm{t}, J=8.1 \mathrm{~Hz}, 1 \mathrm{H}), 4.51-4.47(\mathrm{~m}, 2 \mathrm{H}), 4.41(\mathrm{~s}, 1 \mathrm{H}), 4.08(\mathrm{~s}, 2 \mathrm{H}), 3.90(\mathrm{~d}, J=2.7 \mathrm{~Hz}, 2 \mathrm{H}), 3.76-$ $3.65(\mathrm{~m}, 8 \mathrm{H}), 3.62-3.56(\mathrm{~m}, 3 \mathrm{H}), 3.56-3.52(\mathrm{~m}, 4 \mathrm{H}), 3.52-3.47(\mathrm{~m}, 3 \mathrm{H}), 3.47-3.40(\mathrm{~m}, 5 \mathrm{H}), 2.79(\mathrm{t}, J=$ $6.6 \mathrm{~Hz}, 2 \mathrm{H}), 2.71(\mathrm{~s}, 3 \mathrm{H}), 2.48(\mathrm{~s}, 3 \mathrm{H}), 2.45(\mathrm{~s}, 3 \mathrm{H}), 2.29-2.22(\mathrm{~m}, 1 \mathrm{H}), 2.09$ (ddd, $J=13.4,9.1,4.5 \mathrm{~Hz}, 1 \mathrm{H}$ ), $1.75(\mathrm{p}, J=14.1,7.2 \mathrm{~Hz}, 2 \mathrm{H}), 1.70(\mathrm{~s}, 3 \mathrm{H}), 1.55(\mathrm{p}, J=6.7 \mathrm{~Hz}, 2 \mathrm{H}), 1.48-1.33(\mathrm{~m}, 10 \mathrm{H})$. 


\section{Tert-butyl (2-(2-((6-chlorohexyl)oxy)ethoxy)ethyl)carbamate (22)}<smiles>CC(C)(C)OC(=O)NCCOCCOCCCCCCCl</smiles>

To a solution of tert-butyl (2-(2-hydroxyethoxy)ethyl)carbamate $(500.0 \mathrm{mg}, 471 \mu \mathrm{L}, 1.0 \mathrm{Eq}, 2.4 \mathrm{mmol})$ in DMF $(30 \mathrm{~mL})$ at $0^{\circ} \mathrm{C}$ was added $\mathrm{NaH}(60 \%$ in mineral oil, $0.13 \mathrm{~g}, 1.3 \mathrm{Eq}, 3.2 \mathrm{mmol})$. The reaction was left to stir at $0^{\circ} \mathrm{C}$ for $30 \mathrm{~min}$, after which 1-chloro-6-iodohexane $(901.0 \mathrm{mg}, 555 \mu \mathrm{L}, 1.5 \mathrm{Eq}, 3.7 \mathrm{mmol})$ was added at $0^{\circ} \mathrm{C}$. The reaction was left to stir at $0^{\circ} \mathrm{C}$ for an additional $30 \mathrm{~min}$, before being warmed to $\mathrm{rt}$ and left to stir at rt overnight. After $16 \mathrm{~h}$, the reaction was quenched at $0^{\circ} \mathrm{C}$ with $1 \mathrm{M} \mathrm{HCl}$ and extracted with EtOAc $3 \mathrm{X}$. The combined organic layers were then washed with brine, dried over $\mathrm{Na}_{2} \mathrm{SO}_{4}$, filtered, and concentrated under reduced pressure. The resulting crude product was purified via flash chromatography (0-100\% EtOAc in hexanes) to yield the desired product, compound 22 , as a clear colorless oil (434.5 mg, $55 \%)$.

${ }^{1} \mathrm{H}$ NMR $\left(400 \mathrm{MHz}, \mathrm{MeOD}-d_{4}\right) \delta 3.62-3.54(\mathrm{~m}, 6 \mathrm{H}), 3.53-3.46(\mathrm{~m}, 4 \mathrm{H}), 3.22(\mathrm{t}, J=5.6 \mathrm{~Hz}, 2 \mathrm{H}), 1.77(\mathrm{p}$, $2 \mathrm{H}), 1.60(\mathrm{p}, J=14.0,6.7 \mathrm{~Hz}, 2 \mathrm{H}), 1.52-1.36(\mathrm{~m}, 13 \mathrm{H})$.

${ }^{13} \mathrm{C}$ NMR $\left(100 \mathrm{MHz}, \mathrm{MeOD}-d_{4}\right) \delta 158.29,79.96,72.16,71.19,71.14,71.00,45.66,41.24,33.71,30.50$, $28.79,27.70,26.45$.

\section{2-(2-((6-chlorohexyl)oxy)ethoxy)ethan-1-amine 2,2,2-trifluoroacetate (23)}

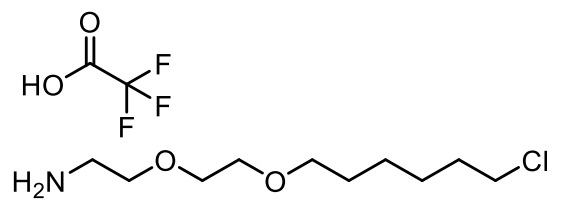

To a solution of compound $22(429.0 \mathrm{mg}, 1.0 \mathrm{Eq}, 1.3 \mathrm{mmol})$ in DCM (30 mL) at rt was added TFA (3 mL). The reaction was left to stir at $\mathrm{rt}$. After $2.5 \mathrm{~h}$, the reaction was concentrated under reduced pressure. To remove residual TFA, the product was dissolved in DCM and concentrated under reduced pressure 2-3X to yield the desired product, compound $\mathbf{2 3}$, as a clear colorless oil (quantitative yield).

${ }^{1} \mathrm{H}$ NMR $\left(400 \mathrm{MHz}, \mathrm{MeOD}-d_{4}\right) \delta 3.72-3.68(\mathrm{~m}, 2 \mathrm{H}), 3.68-3.64(\mathrm{~m}, 2 \mathrm{H}), 3.64-3.60(\mathrm{~m}, 2 \mathrm{H}), 3.56(\mathrm{t}, J=$ $6.6 \mathrm{~Hz}, 2 \mathrm{H}), 3.50(\mathrm{t}, J=6.6 \mathrm{~Hz}, 2 \mathrm{H}), 3.12(\mathrm{t}, J=5.0 \mathrm{~Hz}, 2 \mathrm{H}), 1.76(\mathrm{p}, 2 \mathrm{H}), 1.61(\mathrm{p}, J=14.1,6.8 \mathrm{~Hz}, 2 \mathrm{H}), 1.52$ $-1.35(\mathrm{~m}, 4 \mathrm{H})$.

${ }^{13} \mathrm{C}$ NMR $\left(100 \mathrm{MHz}, \mathrm{MeOD}-d_{4}\right) \delta 72.26,71.31,71.11,67.83,45.66,40.65,33.70,30.47,27.71,26.42$. 
(S)-N-(24-chloro-11-oxo-3,6,9,15,18-pentaoxa-12-azatetracosyl)-2-(4-(4-chlorophenyl)-2,3,9-trimethyl$6 H$-thieno[3,2-f][1,2,4]triazolo[4,3-a][1,4]diazepin-6-yl)acetamide (ct-PEG ${ }_{3}-\mathrm{JQ1}, 6$ )
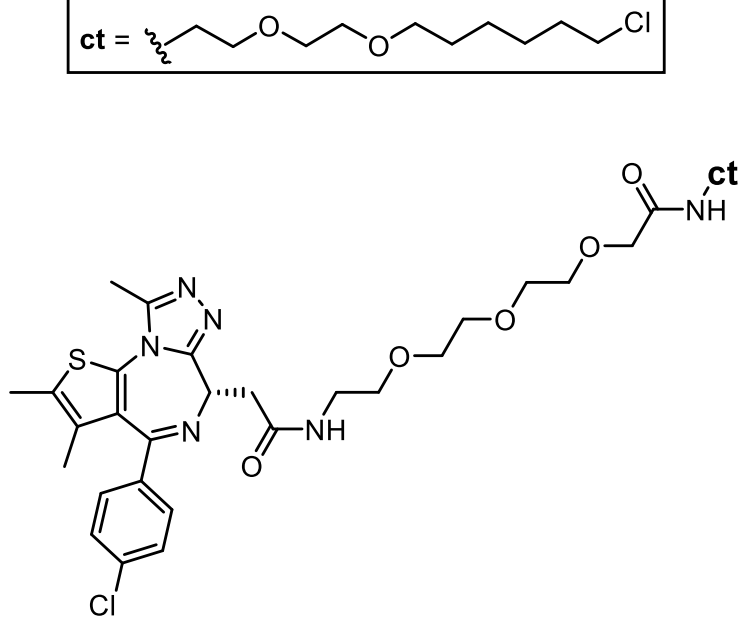

To a solution of PEG PQ1 $^{-\mathrm{JQ}}(\mathbf{1 9})(6.0 \mathrm{mg}, 1.0 \mathrm{Eq}, 10 \mu \mathrm{mol})$ in DMF $(4.5 \mathrm{~mL})$ was added TBTU $(3.6 \mathrm{mg}, 1.1 \mathrm{Eq}$, $11 \mu \mathrm{mol})$ and DIPEA $(2.0 \mathrm{mg}, 2.7 \mu \mathrm{L}, 1.5 \mathrm{Eq}, 15 \mu \mathrm{mol})$. In a separate flask, DIPEA (2.0 mg, $2.7 \mu \mathrm{L}, 1.5 \mathrm{Eq}, 15$ $\mu \mathrm{mol})$ was added to a solution of compound $23(6.9 \mathrm{mg}, 2.0 \mathrm{Eq}, 20 \mu \mathrm{mol})$ in DMF (500 $\mu \mathrm{L})$; after 5-10 min, the solution was added to the main reaction mixture, and the reaction was left to stir at rt overnight. After $18 \mathrm{~h}$, the reaction was quenched with water and diluted with EtOAc. The organic layer was washed with water $2 \mathrm{X}$ and brine, dried over $\mathrm{Na}_{2} \mathrm{SO}_{4}$, filtered, and concentrated under reduced pressure. The resulting crude product was purified via preparative HPLC (10-100\% ACN in water containing $0.1 \%$ TFA) to yield the desired product, ct-PEG $-\mathrm{JQ1}(6)$, as a clear yellow (2.9 mg, 36\%). ESI-MS $(\mathrm{m} / \mathrm{z}):\left[\mathrm{M}+\mathrm{H}^{+}\right]$calcd. for $\mathrm{C}_{37} \mathrm{H}_{53} \mathrm{Cl}_{2} \mathrm{~N}_{6} \mathrm{O}_{7} \mathrm{~S}$, 795.30; found 795.10.

${ }^{1} \mathrm{H}$ NMR $\left(400 \mathrm{MHz}, \mathrm{MeOD}-\mathrm{d}_{4}\right) \delta 7.49-7.40(\mathrm{~m}, 4 \mathrm{H}), 4.65(\mathrm{dd}, J=8.9,5.3 \mathrm{~Hz}, 1 \mathrm{H}), 4.00(\mathrm{~s}, 2 \mathrm{H}), 3.69(\mathrm{~d}, J=$ $3.5 \mathrm{~Hz}, 8 \mathrm{H}), 3.62(\mathrm{t}, \mathrm{J}=5.4 \mathrm{~Hz}, 2 \mathrm{H}), 3.60-3.51(\mathrm{~m}, 9 \mathrm{H}), 3.49-3.40(\mathrm{~m}, 7 \mathrm{H}), 2.71(\mathrm{~s}, 3 \mathrm{H}), 2.46(\mathrm{~s}, 3 \mathrm{H}), 1.78$ $-1.70(\mathrm{~m}, 5 \mathrm{H}), 1.57(\mathrm{p}, J=13.9,6.7 \mathrm{~Hz}, 2 \mathrm{H}), 1.48-1.41(\mathrm{~m}, 2 \mathrm{H}), 1.41-1.34(\mathrm{~m}, 2 \mathrm{H})$. 
(S)-N-(2-(2-((6-chlorohexyl)oxy)ethoxy)ethyl)-2-(4-(4-chlorophenyl)-2,3,9-trimethyl-6H-thieno[3,2$f][1,2,4]$ triazolo[4,3-a][1,4]diazepin-6-yl)acetamide (ct-JQ1, 7)
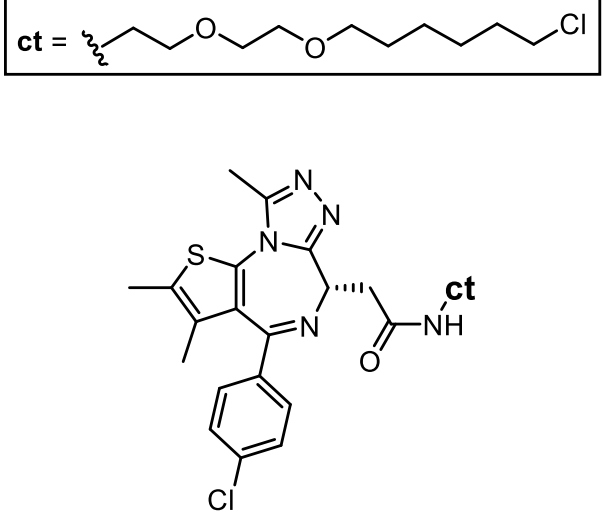

To a solution of compound 17 (17.5 mg, $1.0 \mathrm{Eq}, 44 \mu \mathrm{mol})$ in DMF (1.5 mL) was added TBTU (15.4 mg, 1.1 Eq, $48 \mu \mathrm{mol})$ and DIPEA ( $8.5 \mathrm{mg}, 11.4 \mu \mathrm{L}, 1.5 \mathrm{Eq}, 66 \mu \mathrm{mol})$. In a separate flask, DIPEA (8.5 mg, $11.4 \mu \mathrm{L}, 1.5$ Eq, $66 \mu \mathrm{mol})$ was added to a solution of compound $23(29.5 \mathrm{mg}, 2.0 \mathrm{Eq}, 87 \mu \mathrm{mol})$ in DMF (500 $\mu \mathrm{L})$; after 5-10 $\mathrm{min}$, the solution was added to the main reaction mixture, and the reaction was left to stir at rt overnight. After $18 \mathrm{~h}$, the reaction was quenched with water and diluted with EtOAc. The organic layer was washed with water $2 \mathrm{X}$ and brine, dried using a phase separator, and concentrated under reduced pressure. The resulting crude product was purified via flash chromatography $(0-10 \% \mathrm{MeOH}$ in $\mathrm{DCM})$ to yield the desired product, ct-JQ1 (7), as a yellow solid (4.0 mg, 15\%). ESI-MS (m/z): $\left[\mathrm{M}+\mathrm{H}^{+}\right]$calcd. for $\mathrm{C}_{29} \mathrm{H}_{38} \mathrm{Cl}_{2} \mathrm{~N}_{5} \mathrm{O}_{3} \mathrm{~S}$, 606.20; found 606.20.

${ }^{1} \mathrm{H}$ NMR $\left(400 \mathrm{MHz}\right.$, MeOD- $\left.d_{4}\right) \delta 7.48-7.39(\mathrm{~m}, 4 \mathrm{H}), 4.63(\mathrm{dd}, J=9.2,5.0 \mathrm{~Hz}, 1 \mathrm{H}), 3.67-3.58(\mathrm{~m}, 6 \mathrm{H}), 3.53$ $-3.38(\mathrm{~m}, 8 \mathrm{H}), 2.69(\mathrm{~s}, 3 \mathrm{H}), 2.45(\mathrm{~s}, 3 \mathrm{H}), 1.74-1.66(\mathrm{~m}, 5 \mathrm{H}), 1.62-1.54(\mathrm{~m}, 2 \mathrm{H}), 1.45-1.33(\mathrm{~m}, 4 \mathrm{H})$.

${ }^{13} \mathrm{C}$ NMR $\left(101 \mathrm{MHz}, \mathrm{MeOD}-d_{4}\right) \delta 172.89,166.11,157.02,152.14,138.12,137.94,133.49,133.20,132.02$, $132.00,131.38,129.77,72.27,71.34,71.21,70.62$, 55.18, 48.36, 45.69, 40.54, 38.78, 33.71, 30.57, 27.73, $26.49,14.42,12.93,11.62$. 
$(2 S, 4 R)-1-((R)-2$-acetamido-3-mercapto-3-methylbutanoyl)-4-hydroxy- $N$-(4-(4-methylthiazol-5yl)benzyl)pyrrolidine-2-carboxamide (S-VHL, 8)

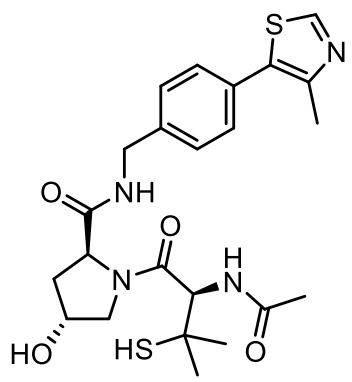

S-VHL (8) was synthesized according to literature procedures. ${ }^{1,3}$ Obtained $53.5 \mathrm{mg}, 69.0 \%$. ESI-MS $(\mathrm{m} / \mathrm{z})$ : $\left[\mathrm{M}+\mathrm{H}^{+}\right]$calcd. for $\mathrm{C}_{23} \mathrm{H}_{31} \mathrm{~N}_{4} \mathrm{O}_{4} \mathrm{~S}_{2}$, 491.17; found 491.20 .

${ }^{1} \mathrm{H}$ NMR $\left(400 \mathrm{MHz}, \mathrm{MeOD}-\mathrm{d}_{4}\right) \delta 9.25(\mathrm{~s}, 1 \mathrm{H}), 7.53-7.41(\mathrm{~m}, 4 \mathrm{H}), 4.90(\mathrm{~s}, 1 \mathrm{H}), 4.61-4.48(\mathrm{~m}, 3 \mathrm{H}), 4.39(\mathrm{~d}$, $J=15.5 \mathrm{~Hz}, 1 \mathrm{H}), 4.00-3.94(\mathrm{~m}, 1 \mathrm{H}), 3.88(\mathrm{~d}, J=11.2 \mathrm{~Hz}, 1 \mathrm{H}), 2.51(\mathrm{~s}, 3 \mathrm{H}), 2.25$ (ddd, $J=13.1,7.7,0.9 \mathrm{~Hz}$, 1H), 2.08 (ddd, $J=13.3,9.0,4.5 \mathrm{~Hz}, 1 \mathrm{H}), 2.01(\mathrm{~s}, 3 \mathrm{H}), 1.42(\mathrm{~s}, 3 \mathrm{H}), 1.40(\mathrm{~s}, 3 \mathrm{H})$.

${ }^{13} \mathrm{C}$ NMR $\left(101 \mathrm{MHz}, \mathrm{MeOD}-d_{4}\right) \delta$ 174.40, 173.07, 171.10, 154.12, 146.70, 140.99, 134.81, 130.39, 130.28, $129.19,70.95,60.95,59.84,58.04,47.14,43.67,39.04,29.86,28.95,22.35,14.86$. 
(2S,4R)-1-((R)-2-acetamido-3-((2-(2-((6-chlorohexyl)oxy)ethoxy)ethyl)thio)-3-methylbutanoyl)-4hydroxy- $\mathrm{N}$-(4-(4-methylthiazol-5-yl)benzyl)pyrrolidine-2-carboxamide (ct-S-VHL, 4)

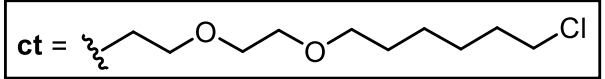<smiles>CC(=O)N[C@H](C(=O)N1C[C@H](O)C[C@H]1C(=O)NCc1ccc(-c2scnc2C)cc1)C(C)(C)SCl</smiles>

To a solution of S-VHL (8) $(14.5 \mathrm{mg}, 1.0 \mathrm{Eq}, 30 \mu \mathrm{mol})$ in DMF (700 $\mu \mathrm{L})$ at rt was added DBU $(5.0 \mathrm{mg}, 4.9 \mu \mathrm{L}$, $1.1 \mathrm{Eq}, 33 \mu \mathrm{mol})$, followed by compound $2(12.3 \mathrm{mg}, 1.1 \mathrm{Eq}, 33 \mu \mathrm{mol})$. The reaction was left to stir at rt. After $1 \mathrm{~h}$, the reaction was cooled to $0^{\circ} \mathrm{C}$ and treated with $5 \% \mathrm{KHSO} 4$ to adjust the $\mathrm{pH}$ to $3-4$. The reaction was then concentrated under reduced pressure, and the resulting crude product was purified via preparative HPLC (20-100\% ACN in water containing 0.1\% TFA) to yield the desired product, ct-S-VHL (4), as a clear yellow oil (3.8 mg, 18\%). ESI-MS $(\mathrm{m} / \mathrm{z})$ : $\left[\mathrm{M}+\mathrm{H}^{+}\right]$calcd. for $\mathrm{C}_{33} \mathrm{H}_{50} \mathrm{ClN}_{4} \mathrm{O}_{6} \mathrm{~S}_{2}, 697.28$; found 697.20.

${ }^{1} \mathrm{H}$ NMR $\left(400 \mathrm{MHz}, \mathrm{MeOD}-\mathrm{d}_{4}\right) \delta 8.95(\mathrm{~s}, 1 \mathrm{H}), 7.50-7.39(\mathrm{~m}, 4 \mathrm{H}), 4.94(\mathrm{~s}, 1 \mathrm{H}), 4.57(\mathrm{t}, 1 \mathrm{H}), 4.53-4.45(\mathrm{~m}$, $2 \mathrm{H}), 4.45(\mathrm{~d}, J=6.6 \mathrm{~Hz}, 2 \mathrm{H}), 3.92(\mathrm{~d}, J=2.9 \mathrm{~Hz}, 2 \mathrm{H}), 3.63-3.47(\mathrm{~m}, 9 \mathrm{H}), 3.44(\mathrm{t}, J=6.5 \mathrm{~Hz}, 2 \mathrm{H}), 2.78(\mathrm{t}, J=$ $6.8 \mathrm{~Hz}, 2 \mathrm{H}$ ), $2.49(\mathrm{~s}, 3 \mathrm{H}), 2.27$ (ddd, $J=13.2,7.8,2.5 \mathrm{~Hz}, 1 \mathrm{H}$ ), 2.10 (ddd, $J=13.3,9.0,4.5 \mathrm{~Hz}, 1 \mathrm{H}), 2.01(\mathrm{~s}$, $3 \mathrm{H}), 1.81-1.69(\mathrm{~m}, 2 \mathrm{H}), 1.56(\mathrm{dt}, J=14.1,6.7 \mathrm{~Hz}, 2 \mathrm{H}), 1.51-1.32(\mathrm{~m}, 11 \mathrm{H})$.

${ }^{13} \mathrm{C}$ NMR $\left(101 \mathrm{MHz}, \mathrm{MeOD}-d_{4}\right) \delta$ 174.26, 173.06, 171.38, 153.08, 148.68, 140.29, 131.39, 130.40, 129.51, 129.20, 72.16, 71.54, 71.31, 71.13, 70.91, 61.06, 57.91, 57.19, 45.70, 43.59, 39.11, 33.77, 30.57, 29.38, $27.74,26.52,25.99,25.81,22.31,15.69$. 
$(2 S, 4 R)-1-((S)-2$-amino-3,3-dimethylbutanoyl)-4-hydroxy-N-(4-(4-methylthiazol-5yl)benzyl)pyrrolidine-2-carboxamide (25)<smiles>Cc1ncsc1-c1ccc(CNC(=O)[C@@H]2C[C@@H](O)CN2C(=O)C(N)C(C)(C)C)cc1</smiles>

Compound 25 was synthesized according to literature procedures. ${ }^{3,4}$ Obtained $870.5 \mathrm{mg}, 27 \%$. ESI-MS $(\mathrm{m} / \mathrm{z}):\left[\mathrm{M}+\mathrm{H}^{+}\right]$cald. for $\mathrm{C}_{22} \mathrm{H}_{31} \mathrm{~N}_{4} \mathrm{O}_{3} \mathrm{~S}, 431.20$; found 431.20.

${ }^{1} \mathrm{H}$ NMR $\left(400 \mathrm{MHz}, \mathrm{MeOD}-d_{4}\right) \delta 9.01(\mathrm{~s}, 1 \mathrm{H}), 7.45$ (dd, $\left.J=8.2,21.4 \mathrm{~Hz}, 4 \mathrm{H}\right), 4.67$ (dd, $\left.J=7.7,9.5 \mathrm{~Hz}, 1 \mathrm{H}\right), 4.58$ $-4.52(\mathrm{~m}, 2 \mathrm{H}), 4.36(\mathrm{~d}, J=15.5 \mathrm{~Hz}, 1 \mathrm{H}), 4.05(\mathrm{~s}, 1 \mathrm{H}), 3.82(\mathrm{~d}, J=11.3 \mathrm{~Hz}, 1 \mathrm{H}), 3.71(\mathrm{dd}, J=3.5,11.2 \mathrm{~Hz}$, $1 \mathrm{H}), 2.34-2.26(\mathrm{~m}, 1 \mathrm{H}), 2.09$ (ddd, $J=4.2,9.6,13.4 \mathrm{~Hz}, 1 \mathrm{H}), 1.13(\mathrm{~s}, 9 \mathrm{H})$.

${ }^{13} \mathrm{C}$ NMR $\left(101 \mathrm{MHz}, \mathrm{MeOD}-d_{4}\right) \delta$ 174.02, 168.58, 153.27, 148.28, 140.43, 133.83, 131.13, 130.36, 128.96, $71.15,60.98,60.35,58.04,43.69,39.06,35.78,26.64,15.48$.

(2S,4R)-1-((S)-2-amino-3,3-dimethylbutanoyl)-4-hydroxy-N-(4-(4-methylthiazol-5yl)benzyl)pyrrolidine-2-carboxamide 2,2,2-trifluoroacetate (26)<smiles>Cc1ncsc1-c1ccc(CNC(=O)[C@@H]2C[C@@H](O)C[C@H]2C(=O)[C@H](NCC(=O)O)C(C)(C)C)cc1</smiles>

To a solution of compound $25(400.0 \mathrm{mg}, 1.0 \mathrm{Eq}, 734 \mu \mathrm{mol})$ in $\mathrm{ACN}(2.9 \mathrm{~mL})$ at rt was added $\mathrm{K}_{2} \mathrm{CO}_{3}(305.0$ $\mathrm{mg}, 3.0 \mathrm{Eq}, 2.2 \mathrm{mmol})$, followed by tert-butyl 2-bromoacetate (158 mg, $119 \mu \mathrm{L}, 1.1 \mathrm{Eq}, 808 \mu \mathrm{mol})$. The reaction was refluxed at $80^{\circ} \mathrm{C}$ for $1 \mathrm{~h}$. The reaction was cooled to $\mathrm{rt}$ and concentrated under reduced pressure, and the resulting crude intermediate tert-butyl ((S)-1-((2S,4R)-4-hydroxy-2-((4-(4-methylthiazol5-yl)benzyl)carbamoyl)pyrrolidin-1-yl)-3,3-dimethyl-1-oxobutan-2-yl)glycinate was purified via flash chromatography (0-10\% $\mathrm{MeOH}$ in DCM) and concentrated under reduced pressure to yield a clear oil (302.0 mg), which was dissolved in 20\% TFA in DCM (4 mL) for $4 \mathrm{~h}$. The reaction was concentrated under reduced pressure and the product was purified by reverse phase flash chromatography $(10-100 \%$ ACN in water containing $0.1 \%$ TFA) to yield the desired product, compound $\mathbf{2 6}$, as a clear oil $(40.3 \mathrm{mg}, 11 \%$ over 2 steps). ESI-MS (m/z): [M+H $\mathrm{H}^{+}$calcd. for $\mathrm{C}_{33} \mathrm{H}_{50} \mathrm{ClN}_{4} \mathrm{O}_{6} \mathrm{~S}_{2}, 489.21$; found 489.20.

${ }^{1} \mathrm{H}$ NMR $\left(400 \mathrm{MHz}, \mathrm{MeOD}-d_{4}\right) \delta 8.88(\mathrm{~s}, 1 \mathrm{H}), 7.49-7.40(\mathrm{~m}, 4 \mathrm{H}), 4.67(\mathrm{t}, J=8.2 \mathrm{~Hz}, 1 \mathrm{H}), 4.54(\mathrm{~d}, J=8.2 \mathrm{~Hz}$, $1 \mathrm{H}), 4.38(\mathrm{~d}, J=15.6 \mathrm{~Hz}, 1 \mathrm{H}), 3.73(\mathrm{~d}, J=2.9 \mathrm{~Hz}, 2 \mathrm{H}), 3.33(\mathrm{~s}, 1 \mathrm{H}), 3.18(\mathrm{~d}, J=2.6 \mathrm{~Hz}, 2 \mathrm{H}), 2.48(\mathrm{~s}, 3 \mathrm{H}), 2.23$ (ddd, $J=2.2,7.8,13.0 \mathrm{~Hz}, 1 \mathrm{H}$ ), 2.12 (ddd, $J=4.5,7.4,13.1 \mathrm{~Hz}, 1 \mathrm{H}$ ), $1.47(\mathrm{~s}, 9 \mathrm{H}), 10.3(\mathrm{~s}, 9 \mathrm{H}$ ). 
(2S,4R)-1-((S)-2-(tert-butyl)-18-chloro-5-oxo-9,12-dioxa-3,6-diazaoctadecanoyl)-4-hydroxy-N-(4-(4methylthiazol-5-yl)benzyl)pyrrolidine-2-carboxamide 2,2,2-trifluoroacetate (ct-VHL, 5)
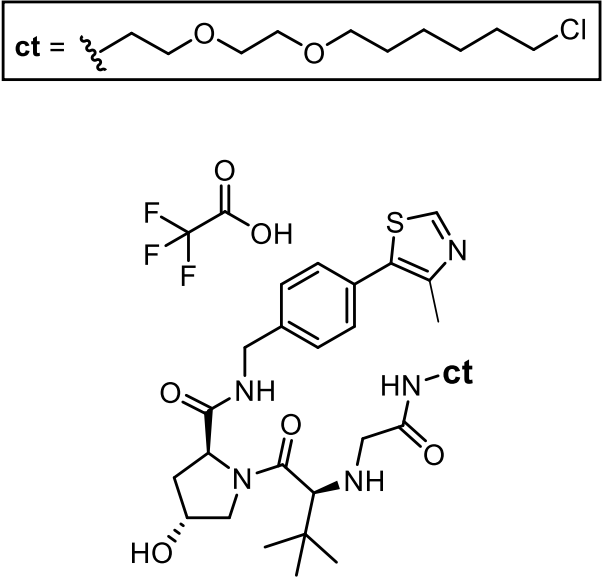

To a solution of compound $26(8.3 \mathrm{mg}, 1.0 \mathrm{Eq}, 17 \mu \mathrm{mol})$ in DMF $(1.5 \mathrm{~mL})$ was added TBTU $(6.0 \mathrm{mg}, 1.1 \mathrm{Eq}$, $19 \mu \mathrm{mol}$ ) and DIPEA (3.3 mg, $4.5 \mu \mathrm{L}, 1.5 \mathrm{Eq}, 25 \mu \mathrm{mol})$. In a separate flask, DIPEA (3.3 mg, $4.5 \mu \mathrm{L}, 1.5 \mathrm{Eq}, 25$ $\mu \mathrm{mol})$ was added to a solution of compound $23(11.0 \mathrm{mg}, 2.0 \mathrm{Eq}, 34 \mu \mathrm{mol})$ in DMF (500 $\mu \mathrm{L})$; after 5-10 $\mathrm{min}$, the solution was added to the main reaction mixture, and the reaction was left to stir at rt overnight. After $24 \mathrm{~h}$, the reaction was quenched with water and diluted with EtOAc. The organic layer was washed with water $2 \mathrm{X}$ and brine, dried using a phase separator, and concentrated under reduced pressure. The resulting crude product was purified via preparative HPLC (10-100\% ACN in water containing $0.1 \%$ TFA) to yield the desired product, ct-VHL (5), as a clear colorless oil (1.8 mg, 13\%). ESI-MS ( $\mathrm{m} / \mathrm{z}):\left[\mathrm{M}+\mathrm{H}^{+}\right]$calcd. for $\mathrm{C}_{34} \mathrm{H}_{53} \mathrm{ClN}_{5} \mathrm{O}_{6} \mathrm{~S}, 694.33$; found 694.20.

${ }^{1} \mathrm{H}$ NMR $\left(400 \mathrm{MHz}, \mathrm{MeOD}-d_{4}\right) \delta 8.94(\mathrm{~d}, J=2.6 \mathrm{~Hz}, 1 \mathrm{H}), 7.51-7.40(\mathrm{~m}, 4 \mathrm{H}), 4.69(\mathrm{t}, 1 \mathrm{H}), 4.60-4.50(\mathrm{~m}$, $2 \mathrm{H}), 4.35(\mathrm{dd}, J=15.5,4.1 \mathrm{~Hz}, 1 \mathrm{H}), 4.25(\mathrm{~s}, 1 \mathrm{H}), 3.82(\mathrm{~d}, J=16.0 \mathrm{~Hz}, 1 \mathrm{H}), 3.70-3.66(\mathrm{~m}, 1 \mathrm{H}), 3.65-3.52$ $(\mathrm{m}, 10 \mathrm{H}), 3.49(\mathrm{t}, J=6.5 \mathrm{~Hz}, 2 \mathrm{H}), 3.47-3.42(\mathrm{~m}, 2 \mathrm{H}), 2.49(\mathrm{~d}, J=7.0 \mathrm{~Hz}, 3 \mathrm{H}), 2.31(\mathrm{dd}, J=13.4,7.6 \mathrm{~Hz}, 1 \mathrm{H})$, $2.11(\mathrm{ddd}, J=13.4,9.6,4.1 \mathrm{~Hz}, 1 \mathrm{H}), 1.77(\mathrm{p}, J=14.0,6.8 \mathrm{~Hz}, 2 \mathrm{H}), 1.60(\mathrm{p}, J=6.8 \mathrm{~Hz}, 2 \mathrm{H}), 1.52-1.34(\mathrm{~m}$, $4 \mathrm{H}), 1.20(\mathrm{~d}, J=3.8 \mathrm{~Hz}, 9 \mathrm{H})$.

${ }^{13} \mathrm{C}$ NMR $\left(101 \mathrm{MHz}, \mathrm{MeOD}-d_{4}\right) \delta 173.73,167.07,166.06,153.06,140.29,130.69,130.39,128.95,72.25$, 71.22 , 71.19, 71.06, 70.33, 67.87, 58.32, 45.68, 43.70, 40.58, 39.16, 36.43, 33.73, 30.49, 27.72, 26.86, $26.72,26.47,15.67$. 
Tert-butyl (S)-3-((2S,4R)-4-hydroxy-2-((4-(4-methylthiazol-5-yl)benzyl)carbamoyl)pyrrolidine-1carbonyl)-2,2-dimethyl-6-oxo-10,13-dioxa-4,7-diazahexadecan-16-oate (27)

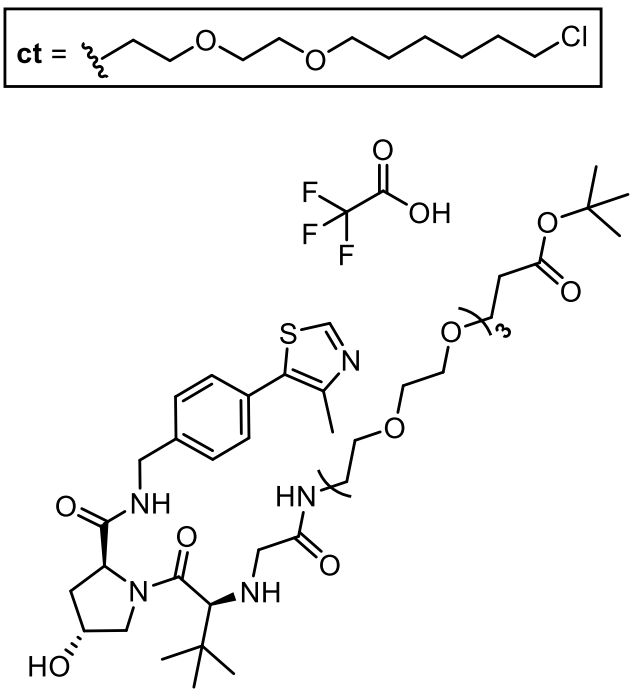

To a solution of compound 26 (18.1 mg, 1.0 Eq, $37 \mu \mathrm{mol})$ in DMF $(500 \mu \mathrm{L})$ was added TBTU $(15.4 \mathrm{mg}, 1.3$ $\mathrm{Eq}, 48 \mu \mathrm{mol})$ and DIPEA (6.2 mg, $8.4 \mu \mathrm{L}, 1.3 \mathrm{Eq}, 48 \mu \mathrm{mol})$. After 5-10 min, a solution of tert-butyl 1-amino3,6,9,12,15,18-hexaoxahenicosan-21-oate $(15.2 \mathrm{mg}, 1.0 \mathrm{Eq}, 37 \mu \mathrm{mol})$ in DMF (500 $\mu \mathrm{L})$ was added, and the reaction was left to stir at rt overnight. After $16 \mathrm{~h}$, the reaction was concentrated under reduced pressure, and the resulting crude product was purified via preparative HPLC (10-100\% ACN in water containing $0.1 \%$ TFA) to yield the desired product, compound 27 , as a clear yellow oil (11.9 mg, 37\%). ESI-MS (m/z): [M+H'] calcd. for $\mathrm{C}_{43} \mathrm{H}_{70} \mathrm{~N}_{5} \mathrm{O}_{12} \mathrm{~S}$, 880.47; found 880.30.

${ }^{1} \mathrm{H}$ NMR $\left(400 \mathrm{MHz}\right.$, Methanol- $\left.d_{4}\right) \delta 9.04(\mathrm{~s}, 1 \mathrm{H}), 7.52-7.40(\mathrm{~m}, 4 \mathrm{H}), 4.70(\mathrm{dd}, J=9.4,7.6 \mathrm{~Hz}, 1 \mathrm{H}), 4.60-$ $4.51(\mathrm{~m}, 2 \mathrm{H}), 4.35(\mathrm{~d}, J=15.6 \mathrm{~Hz}, 1 \mathrm{H}), 4.26(\mathrm{~s}, 1 \mathrm{H}), 3.84(\mathrm{~d}, J=16.1 \mathrm{~Hz}, 1 \mathrm{H}), 3.71-3.67(\mathrm{~m}, 3 \mathrm{H}), 3.66-3.57$ $(\mathrm{m}, 24 \mathrm{H}), 3.45(\mathrm{q}, J=5.3 \mathrm{~Hz}, 2 \mathrm{H}), 2.51-2.44(\mathrm{~m}, 5 \mathrm{H}), 2.35-2.28(\mathrm{~m}, 1 \mathrm{H}), 2.10(\mathrm{ddd}, J=13.5,9.5,4.2 \mathrm{~Hz}$, $1 \mathrm{H}), 1.45(\mathrm{~d}, J=1.9 \mathrm{~Hz}, 9 \mathrm{H}), 1.20(\mathrm{~d}, J=3.9 \mathrm{~Hz}, 9 \mathrm{H})$.

${ }^{13} \mathrm{C}$ NMR $\left(100 \mathrm{MHz}\right.$, Methanol- $\left.d_{4}\right) \delta 173.74,172.79,167.04,166.05,153.40,140.51,131.05,130.67$, $130.37,129.44,128.99,81.75,71.54,71.52,71.50,71.49,71.47,71.46,71.38,71.20,71.04,70.27,67.89$, $67.84,61.06,58.32,47.91,43.68,40.59,39.15,37.23,36.41,36.38,28.37,26.86,26.73,15.41$. 
Tert-butyl (S)-3-((2S,4R)-4-hydroxy-2-((4-(4-methylthiazol-5-yl)benzyl)carbamoyl)pyrrolidine-1carbonyl)-2,2-dimethyl-6-oxo-10,13,16,19,22,25-hexaoxa-4,7-diazaoctacosan-28-oate 2,2,2trifluoroacetate (ct-PEG 6 -VHL, 11)

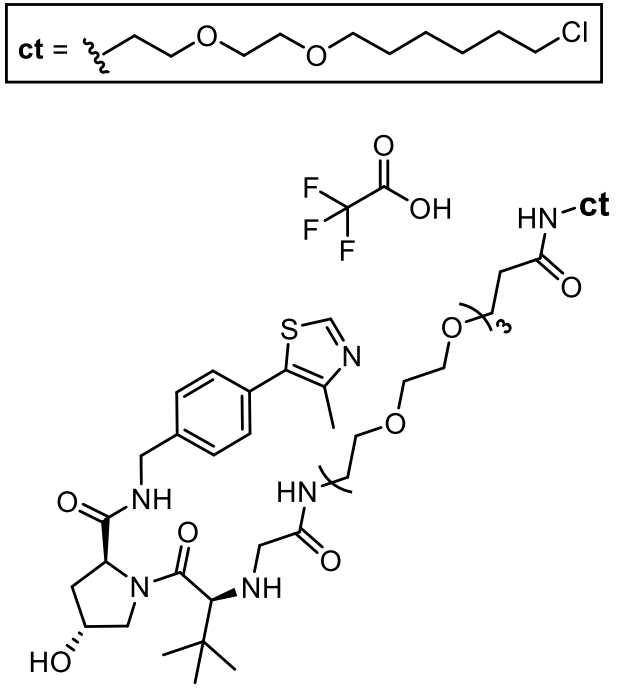

To a solution of compound $27(30.7 \mathrm{mg}, 1.0 \mathrm{Eq}, 35 \mu \mathrm{mol})$ in DCM (800 $\mu \mathrm{L})$ at rt was added TFA (200 $\mu \mathrm{L})$. The reaction was left to stir at rt. After $1 \mathrm{~h}$, the reaction was concentrated under reduced pressure and dissolved in DMF (500 $\mu \mathrm{L})$. To this solution was added TBTU (12.3 mg, $1.1 \mathrm{Eq}, 38 \mu \mathrm{mol})$ and DIPEA (6.8 mg, $9.1 \mu \mathrm{L}, 1.5 \mathrm{Eq}, 52 \mu \mathrm{mol})$. In a separate flask, DIPEA (6.8 mg, $9.1 \mu \mathrm{L}, 1.5 \mathrm{Eq}, 52 \mu \mathrm{mol})$ was added to a solution of compound 23 (23.6 mg, $2.0 \mathrm{Eq}, 70 \mu \mathrm{mol})$ in DMF (500 $\mu \mathrm{L}$ ); after 5-10 min, the solution was added to the main reaction mixture, and the reaction was left to stir at rt overnight. After $19 \mathrm{~h}$, the reaction was concentrated under reduced pressure. The resulting crude product was purified via preparative HPLC (10$100 \% \mathrm{ACN}$ in water containing $0.1 \%$ TFA) to yield the desired product, ct-PEG ${ }_{6}$-VHL (11), as a clear yellow oil (15.3 mg, 38\%). ESI-MS (m/z): [M+H $\mathrm{H}^{+}$calcd. for $\mathrm{C}_{49} \mathrm{H}_{82} \mathrm{ClN}_{6} \mathrm{O}_{13} \mathrm{~S}, 1029.53$; found 1029.40 .

${ }^{1} \mathrm{H}$ NMR $\left(400 \mathrm{MHz}, \mathrm{MeOD}-d_{4}\right) \delta 9.01(\mathrm{~d}, J=4.1 \mathrm{~Hz}, 1 \mathrm{H}), 7.52-7.40(\mathrm{~m}, 4 \mathrm{H}), 4.70(\mathrm{dd}, J=9.3,7.6 \mathrm{~Hz}, 1 \mathrm{H})$, $4.60-4.50(\mathrm{~m}, 2 \mathrm{H}), 4.35(\mathrm{~d}, J=15.6 \mathrm{~Hz}, 1 \mathrm{H}), 4.27(\mathrm{~s}, 1 \mathrm{H}), 3.84(\mathrm{~d}, J=16.1 \mathrm{~Hz}, 1 \mathrm{H}), 3.74-3.67(\mathrm{~m}, 4 \mathrm{H}), 3.66$ $-3.57(\mathrm{~m}, 28 \mathrm{H}), 3.56-3.52(\mathrm{~m}, 4 \mathrm{H}), 3.50-3.44(\mathrm{~m}, 3 \mathrm{H}), 3.37(\mathrm{t}, J=5.6 \mathrm{~Hz}, 2 \mathrm{H}), 2.51-2.42(\mathrm{~m}, 5 \mathrm{H}), 2.35$ $-2.28(\mathrm{~m}, 1 \mathrm{H}), 2.11(\mathrm{td}, J=9.4,4.8 \mathrm{~Hz}, 1 \mathrm{H}), 1.76(\mathrm{p}, J=14.6,6.7 \mathrm{~Hz}, 2 \mathrm{H}), 1.59(\mathrm{p}, J=6.7 \mathrm{~Hz}, 2 \mathrm{H}), 1.51-$ $1.43(\mathrm{~m}, 2 \mathrm{H}), 1.43-1.34(\mathrm{~m}, 2 \mathrm{H}), 1.20(\mathrm{~d}, J=3.8 \mathrm{~Hz}, 9 \mathrm{H})$.

${ }^{13} \mathrm{C}$ NMR $\left(100 \mathrm{MHz}, \mathrm{MeOD}-d_{4}\right) \delta$ 173.97, 173.73, 167.04, 166.06, 153.27, 140.44, 131.19, 130.67, 130.37, $129.43,128.98,72.21,71.55,71.54,71.52,71.50,71.48,71.47,71.44,71.32,71.29,71.21,71.19,71.04$, $70.55,70.28,68.28,67.84,61.06,58.32,47.91,45.71,43.69,40.60,40.41,39.16,37.57,36.42,33.74$, $30.54,27.73,26.87,26.73,26.48,15.52$. 
Tert-butyl (S)-3-((2S,4R)-4-hydroxy-2-((4-(4-methylthiazol-5-yl)benzyl)carbamoyl)pyrrolidine-1carbonyl)-2,2-dimethyl-6-oxo-10,13-dioxa-4,7-diazahexadecan-16-oate 2,2,2-trifluoroacetate (28)

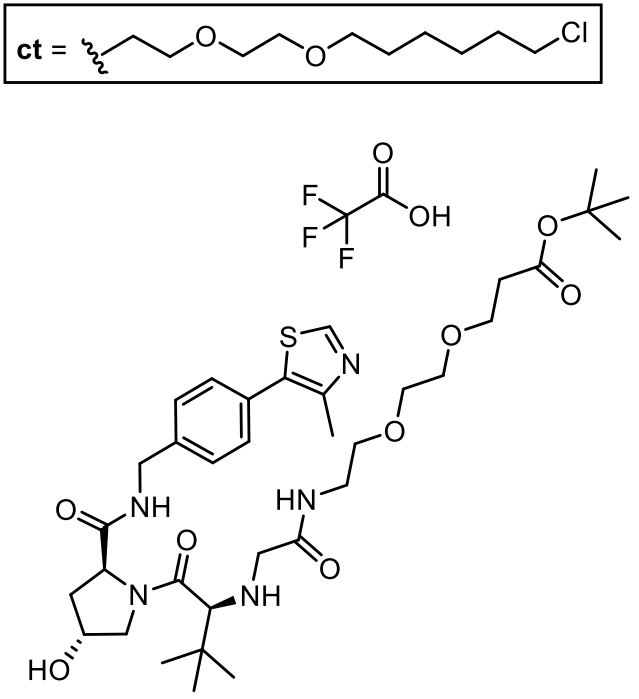

To a solution of compound 26 (14.3 mg, 1.0 Eq, $29.3 \mu \mathrm{mol})$ in DMF (500 $\mu \mathrm{L})$ at rt was added TBTU (10.3 $\mathrm{mg}, 1.1 \mathrm{Eq}, 32 \mu \mathrm{mol})$ and DIPEA $(4.9 \mathrm{mg}, 6.6 \mu \mathrm{L}, 1.3 \mathrm{Eq}, 38 \mu \mathrm{mol})$. After 5-10 min, a solution of tert-butyl 3-(2-(2-aminoethoxy)ethoxy)propanoate $(6.8 \mathrm{mg}, 1 \mathrm{Eq}, 29 \mu \mathrm{mol})$ in DMF $(500 \mu \mathrm{L})$ was added, and the reaction was left to stir at $\mathrm{rt}$ overnight. After $24 \mathrm{~h}$, the reaction was quenched with water and diluted with EtOAc. The organic layer was washed with water $2 \mathrm{X}$ and brine, dried using a phase separator, and concentrated under reduced pressure. The resulting crude product was purified via preparative HPLC (10$100 \% \mathrm{ACN}$ in water containing $0.1 \% \mathrm{TFA}$ ) to yield the desired product, compound $\mathbf{2 8}$, as a clear colorless oil (4.4 mg, 21\%). ESI-MS (m/z): [M+H $\mathrm{H}^{+}$calcd. for $\mathrm{C}_{35} \mathrm{H}_{54} \mathrm{~N}_{5} \mathrm{O}_{8} \mathrm{~S}, 704.36$; found 704.30.

${ }^{1} \mathrm{H}$ NMR $\left(400 \mathrm{MHz}, \mathrm{MeOD}-d_{4}\right) \delta 8.94(\mathrm{~d}, J=2.7 \mathrm{~Hz}, 1 \mathrm{H}), 7.51-7.40(\mathrm{~m}, 4 \mathrm{H}), 4.69(\mathrm{dd}, J=9.6,7.7 \mathrm{~Hz}, 1 \mathrm{H})$, $4.57(\mathrm{~d}, J=15.5 \mathrm{~Hz}, 1 \mathrm{H}), 4.54-4.50(\mathrm{~m}, 1 \mathrm{H}), 4.35(\mathrm{~d}, J=15.5 \mathrm{~Hz}, 1 \mathrm{H}), 4.25(\mathrm{~s}, 1 \mathrm{H}), 3.83(\mathrm{~d}, J=16.1 \mathrm{~Hz}, 1 \mathrm{H})$, $3.72-3.53(\mathrm{~m}, 11 \mathrm{H}), 3.44(\mathrm{q}, J=4.9 \mathrm{~Hz}, 2 \mathrm{H}), 2.51-2.47(\mathrm{~m}, 5 \mathrm{H}), 2.31$ (dd, $J=13.4,7.6 \mathrm{~Hz}, 1 \mathrm{H}), 2.11$ (ddd, $J=13.4,9.6,4.1 \mathrm{~Hz}, 1 \mathrm{H}), 1.44(\mathrm{~d}, J=10.0 \mathrm{~Hz}, 9 \mathrm{H}), 1.20(\mathrm{~d}, J=3.8 \mathrm{~Hz}, 9 \mathrm{H})$.

${ }^{13} \mathrm{C}$ NMR (101 MHz, Methanol- $\left.d_{4}\right) \delta 173.74,172.82,167.07,166.05,153.06,140.30,131.42,130.39$, $128.95,71.39,71.16,71.06,70.31,67.92,61.07,58.32,43.70,40.59,39.17,37.17,36.43,28.36,26.86$, $26.72,15.66$. 
(2S,4R)-1-((S)-2-(tert-butyl)-28-chloro-5,15-dioxo-9,12,19,22-tetraoxa-3,6,16-triazaoctacosanoyl)-4hydroxy-N-(4-(4-methylthiazol-5-yl)benzyl)pyrrolidine-2-carboxamide 2,2,2-trifluoroacetate (ct-PEG ${ }_{2}^{-}$ VHL, 12)

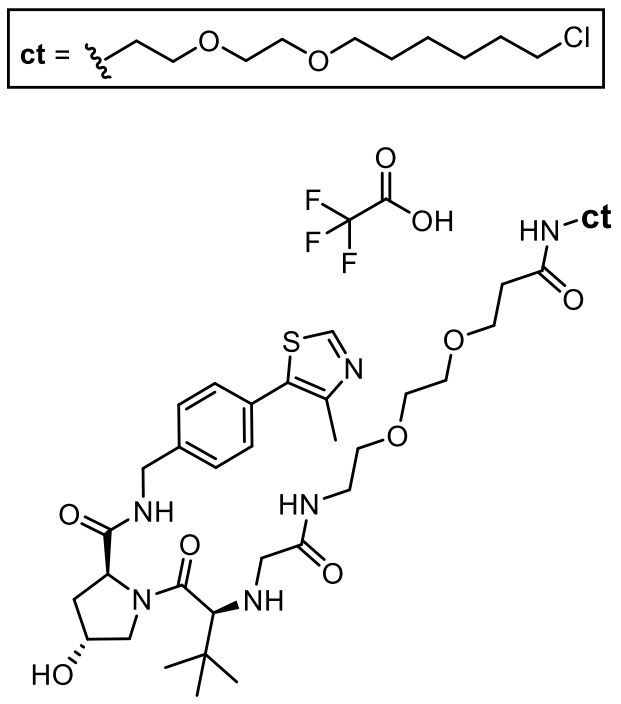

To a solution of compound $28(4.0 \mathrm{mg}, 1.0 \mathrm{Eq}, 6 \mu \mathrm{mol})$ in DCM $(800 \mu \mathrm{L})$ at rt was added TFA (200 $\mu \mathrm{L})$. The reaction was left to stir at $\mathrm{rt}$. After $1 \mathrm{~h}$, the reaction was concentrated under reduced pressure and redissolved in DMF $(500 \mu \mathrm{L})$. To this solution was added TBTU $(2.4 \mathrm{mg}, 1.2 \mathrm{Eq}, 7 \mu \mathrm{mol})$ and DIPEA (1.6 mg, $2.2 \mu \mathrm{L}, 2.0 \mathrm{Eq}, 12 \mu \mathrm{mol})$. In a separate flask, DIPEA (1.6 mg, $2.2 \mu \mathrm{L}, 2.0 \mathrm{Eq}, 12 \mu \mathrm{mol})$ was added to a solution of compound 23 (4.2 mg, 2.0 Eq, $12 \mu \mathrm{mol})$ in DMF (500 $\mu \mathrm{L})$; after 5-10 min, the solution was added to the main reaction mixture, and the reaction was left to stir at $\mathrm{rt}$ overnight. After $2 \mathrm{~h}$, the reaction was concentrated under reduced pressure, and the resulting crude product was purified via preparative HPLC (10-100\% ACN in water containing 0.1\% TFA) to yield the desired product, ct-PEG $\mathbf{2}-\mathbf{V H L}_{\mathbf{1 2}}$ (12), as a clear colorless oil (1.8 mg, 30\%). ESI-MS (m/z): [M+H+ calcd. for $\mathrm{C}_{41} \mathrm{H}_{66} \mathrm{ClN}_{6} \mathrm{O} \mathrm{O}_{9} \mathrm{~S}, 853.42$; found 853.30.

${ }^{1} \mathrm{H}$ NMR $\left(400 \mathrm{MHz}, \mathrm{MeOD}-d_{4}\right) \delta 8.93(\mathrm{~d}, J=3.7 \mathrm{~Hz}, 1 \mathrm{H}), 7.51-7.40(\mathrm{~m}, 4 \mathrm{H}), 4.72-4.66(\mathrm{~m}, 1 \mathrm{H}), 4.57(\mathrm{~d}, J$ $=15.4 \mathrm{~Hz}, 1 \mathrm{H}), 4.54-4.50(\mathrm{~m}, 1 \mathrm{H}), 4.35(\mathrm{~d}, J=15.6 \mathrm{~Hz}, 1 \mathrm{H}), 4.26(\mathrm{~s}, 1 \mathrm{H}), 3.84(\mathrm{~d}, J=16.1 \mathrm{~Hz}, 1 \mathrm{H}), 3.74(\mathrm{t}$, $J=6.2 \mathrm{~Hz}, 2 \mathrm{H}), 3.71-3.66(\mathrm{~m}, 2 \mathrm{H}), 3.62-3.52(\mathrm{~m}, 15 \mathrm{H}), 3.51-3.43(\mathrm{~m}, 4 \mathrm{H}), 3.37(\mathrm{t}, J=5.6 \mathrm{~Hz}, 2 \mathrm{H}), 2.50$ $-2.41(\mathrm{~m}, 5 \mathrm{H}), 2.31(\mathrm{dd}, J=13.4,7.6 \mathrm{~Hz}, 1 \mathrm{H}), 2.11(\mathrm{ddd}, J=13.5,9.6,4.2 \mathrm{~Hz}, 1 \mathrm{H}), 1.76(\mathrm{p}, J=6.7 \mathrm{~Hz}, 2 \mathrm{H})$, $1.59(\mathrm{p}, J=6.7 \mathrm{~Hz}, 2 \mathrm{H}), 1.51-1.43(\mathrm{~m}, 2 \mathrm{H}), 1.43-1.35(\mathrm{~m}, 2 \mathrm{H}), 1.20(\mathrm{~d}, J=3.8 \mathrm{~Hz}, 9 \mathrm{H})$.

${ }^{13} \mathrm{C}$ NMR $\left(101 \mathrm{MHz}\right.$, MeOD- $\left.d_{4}\right) \delta 173.72,153.00,131.48,130.38,128.94,72.24,71.29,71.28,71.22,71.19$, $70.55,70.31,68.24,45.70,40.46$, 36.43, 33.74, 30.53, 27.74, 26.87, 26.73, 26.48, 15.72 (4 aliphatic peaks not observed, 1 aromatic peak not observed). 


\section{9-amino-N-(2-(2-((6-chlorohexyl)oxy)ethoxy)ethyl)nonanamide 2,2,2-trifluoroacetate (24)}

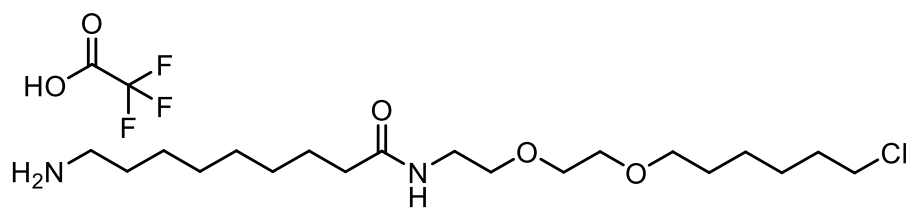

To a solution of 9-((tert-butoxycarbonyl)amino)nonanoic acid $(25.0 \mathrm{mg}, 1.0 \mathrm{Eq}, 92 \mu \mathrm{mol})$ in DMF (1 mL) was added TBTU (32.3 mg, 1.1 Eq, $101 \mu \mathrm{mol})$ and DIPEA (17.7 mg, $24.0 \mu \mathrm{L}, 1.5 \mathrm{Eq}, 137 \mu \mathrm{mol})$. In a separate flask, DIPEA (17.7 mg, $24.0 \mu \mathrm{L}, 1.5 \mathrm{Eq}, 137 \mu \mathrm{mol})$ was added to a solution of compound 23 (61.8 mg, 2.0 Eq, $183 \mu \mathrm{mol})$ in DMF (500 $\mu \mathrm{L})$; after 5-10 min, the solution was added to the main reaction mixture, and the reaction was left to stir at $\mathrm{rt}$. After $2 \mathrm{~h}$, the reaction was concentrated under reduced pressure and dissolved in DCM $(1.6 \mathrm{~mL})$. TFA $(400 \mu \mathrm{L})$ was added, and the reaction was left to stir at rt. After $2 \mathrm{~h}$, the resulting crude product was purified via flash chromatography (0-10\% $\mathrm{MeOH}$ in DCM) to yield the desired product, compound $\mathbf{2 4}$, as a clear colorless oil $(30.5 \mathrm{mg}, 68 \%)$. ESI-MS $(\mathrm{m} / \mathrm{z}):\left[\mathrm{M}+\mathrm{H}^{+}\right]$calcd. for $\mathrm{C}_{19} \mathrm{H}_{40} \mathrm{ClN}_{2} \mathrm{O}_{3}, 379.26$; found 379.30 .

${ }^{1} \mathrm{H}$ NMR (400 MHz, MeOD- $\left.d_{4}\right) \delta 3.62-3.46(\mathrm{~m}, 10 \mathrm{H}), 3.35(\mathrm{t}, J=5.5 \mathrm{~Hz}, 2 \mathrm{H}), 2.91(\mathrm{t}, J=7.6 \mathrm{~Hz}, 2 \mathrm{H}), 2.20$ (td, $J=7.5,2.8 \mathrm{~Hz}, 2 \mathrm{H}), 1.76(\mathrm{p}, 2 \mathrm{H}), 1.69-1.56(\mathrm{~m}, 6 \mathrm{H}), 1.52-1.31(\mathrm{~m}, 12 \mathrm{H})$. 
(2S,4R)-1-((S)-2-(tert-butyl)-28-chloro-5,15-dioxo-19,22-dioxa-3,6,16-triazaoctacosanoyl)-4-hydroxy- $N$ (4-(4-methylthiazol-5-yl)benzyl)pyrrolidine-2-carboxamide 2,2,2-trifluoroacetate (ct-alkyl 2 -VHL, 13)

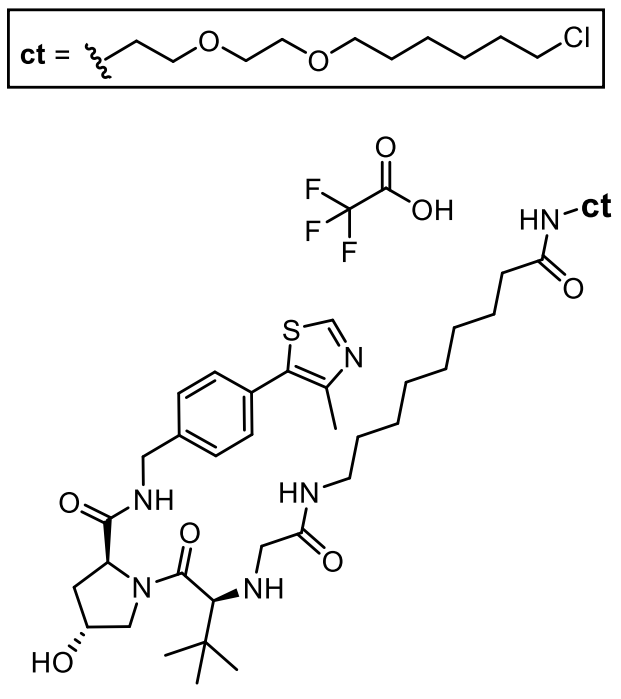

To a solution of compound 26 (17.5 mg, $1.0 \mathrm{Eq}, 36 \mu \mathrm{mol})$ in DMF (500 uL) at rt was added TBTU (12.7 mg, $1.1 \mathrm{Eq}, 39 \mu \mathrm{mol})$ and DIPEA (13.9 mg, $18.7 \mu \mathrm{L}, 3.0 \mathrm{Eq}, 107 \mu \mathrm{mol})$. In a separate flask, DIPEA (6.9 mg, 9.4 $\mu \mathrm{L}, 1.5 \mathrm{Eq}, 54 \mu \mathrm{mol})$ was added to a solution of compound $24(17.7 \mathrm{mg}, 1.0 \mathrm{Eq}, 36 \mu \mathrm{mol})$ in DMF (500 $\mu \mathrm{L})$; after 5-10 min, the solution was added to the main reaction mixture, and the reaction was left to stir at $\mathrm{rt}$ overnight. After $16 \mathrm{~h}$, the reaction was concentrated under reduced pressure, and the resulting crude product was purified via preparative HPLC (10-100\% ACN in water containing $0.1 \%$ TFA) to yield the desired product, ct-alkyl $\mathbf{2}_{2}$-VHL (13), as a clear yellow (2.1 mg, 6\%). ESI-MS (m/z): $\left[\mathrm{M}+\mathrm{H}^{+}\right]$calcd. for $\mathrm{C}_{43} \mathrm{H}_{70} \mathrm{ClN}_{6} \mathrm{O}_{7} \mathrm{~S}$, 849.46; found 849.40.

${ }^{1} \mathrm{H}$ NMR $\left(400 \mathrm{MHz}, \mathrm{MeOD}-d_{4}\right) \delta 8.90(\mathrm{~d}, J=6.9 \mathrm{~Hz}, 1 \mathrm{H}), 8.80(\mathrm{t}, J=6.1 \mathrm{~Hz}, 1 \mathrm{H}), 7.51-7.39(\mathrm{~m}, 4 \mathrm{H}), 4.69$ (dd, $J=9.4,7.5 \mathrm{~Hz}, 1 \mathrm{H}), 4.60-4.50(\mathrm{~m}, 2 \mathrm{H}), 4.35(\mathrm{dd}, J=15.4,5.3 \mathrm{~Hz}, 1 \mathrm{H}), 4.25(\mathrm{~s}, 1 \mathrm{H}), 3.79(\mathrm{~d}, J=16.1$ $\mathrm{Hz}, 1 \mathrm{H}), 3.71(\mathrm{dd}, J=11.2,3.5 \mathrm{~Hz}, 1 \mathrm{H}), 3.64(\mathrm{~d}, J=13.5 \mathrm{~Hz}, 2 \mathrm{H}), 3.60-3.46(\mathrm{~m}, 10 \mathrm{H}), 3.37-3.33(\mathrm{~m}, 2 \mathrm{H})$, $3.28-3.19(\mathrm{~m}, 2 \mathrm{H}), 2.48(\mathrm{~d}, J=8.8 \mathrm{~Hz}, 3 \mathrm{H}), 2.31(\mathrm{dd}, J=13.3,7.8 \mathrm{~Hz}, 1 \mathrm{H}), 2.19(\mathrm{t}, J=7.5 \mathrm{~Hz}, 2 \mathrm{H}), 2.15-$ $2.07(\mathrm{~m}, 1 \mathrm{H}), 1.76(\mathrm{p}, 2 \mathrm{H}), 1.63-1.31(\mathrm{~m}, 18 \mathrm{H}), 1.20(\mathrm{~d}, J=4.5 \mathrm{~Hz}, 9 \mathrm{H})$.

${ }^{13} \mathrm{C}$ NMR $\left(100 \mathrm{MHz}, \mathrm{MeOD}-d_{4}\right) \delta 130.37,128.92,72.23,71.24,71.19,70.58,45.69,40.34,36.46,33.76$, $30.54,30.33,30.19,30.18,30.15,27.90,27.75,26.94,26.73,26.49,15.77$. 


\section{2-((2-(2,6-dioxopiperidin-3-yl)-1,3-dioxoisoindolin-4-yl)oxy)acetic acid (29)}<smiles>O=C(O)COc1cccc2c1C(=O)N(C1CCC(=O)NC1=O)C2=O</smiles>

Compound 29 was synthesized according to literature procedures. ${ }^{5}$ Obtained $3.9 \mathrm{mg}, 13 \%$. ESI-MS $(\mathrm{m} / \mathrm{z})$ : $\left[\mathrm{M}+\mathrm{H}^{+}\right]$calcd. for $\mathrm{C}_{15} \mathrm{H}_{12} \mathrm{~N}_{2} \mathrm{O}_{7}, 333.06$; found 333.10.

${ }^{1} \mathrm{H}$ NMR (400 MHz, DMSO-d $\left.d_{6}\right) \delta 11.11(\mathrm{~s}, 1 \mathrm{H}), 7.79$ (dd, $\left.J=7.4,8.4 \mathrm{~Hz}, 1 \mathrm{H}\right), 7.47$ (d, $J=7.2 \mathrm{~Hz}, 1 \mathrm{H}$ ), 7.39 (d, $J=8.6 \mathrm{~Hz}, 1 \mathrm{H}), 5.11(\mathrm{dd}, J=5.4,12.9 \mathrm{~Hz}, 1 \mathrm{H}), 4.99(\mathrm{~s}, 2 \mathrm{H}), 2.94-2.83(\mathrm{~m}, 1 \mathrm{H}), 2.64-2.52(\mathrm{~m}, 2 \mathrm{H}), 2.08-$ $2.00(\mathrm{~m}, 1 \mathrm{H})$.

N-(2-(2-((6-chlorohexyl)oxy)ethoxy)ethyl)-2-((2-(2,6-dioxopiperidin-3-yl)-1,3-dioxoisoindolin-4yl)oxy)acetamide (ct-O-Pom, 9)
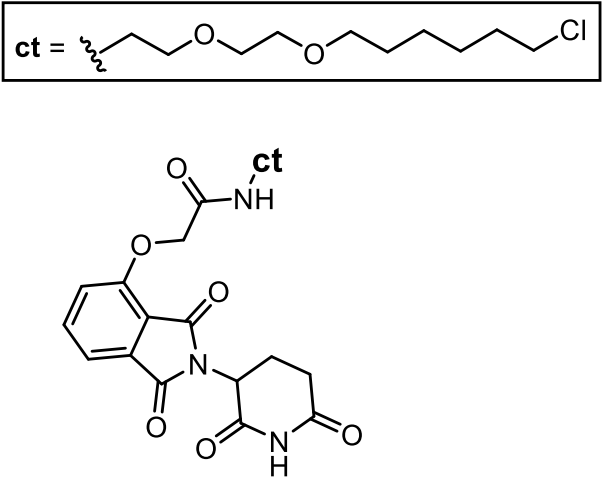

To a solution of compound $29(20.0 \mathrm{mg}, 1.1 \mathrm{Eq}, 60 \mu \mathrm{mol})$ in DMF $(0.5 \mathrm{~mL})$ at rt was added TBTU $(21.0 \mathrm{mg}$, $1.2 \mathrm{Eq}, 66 \mu \mathrm{mol})$ and DIPEA $(21.0 \mathrm{mg}, 29.0 \mu \mathrm{L}, 3.0 \mathrm{Eq}, 0.2 \mathrm{mmol})$, followed by addition of compound $23(18.0 \mathrm{mg}, 1.0 \mathrm{Eq}, 55 \mu \mathrm{mol})$ after 5-10 min, and the reaction was left to stir at rt overnight. After $16 \mathrm{~h}$, the reaction was concentrated under reduced pressure, and the resulting crude product was purified via preparative HPLC (10-100\% ACN in water containing 0.1\% TFA) to yield the desired product, ct-0-Pom (9), as a white solid (3.9 mg, 13\%). ESI-MS (m/z): $\left[\mathrm{M}+\mathrm{H}^{+}\right]$calcd. for $\mathrm{C}_{25} \mathrm{H}_{32} \mathrm{ClN}_{3} \mathrm{O}_{8}$, 538.19; found 539.20.

${ }^{1} \mathrm{H}$ NMR $\left(400 \mathrm{MHz}, \mathrm{MeOD}-d_{4}\right) \delta 7.85-7.78(\mathrm{~m}, 1 \mathrm{H}), 7.55(\mathrm{~d}, J=7.3 \mathrm{~Hz}, 1 \mathrm{H}), 7.44(\mathrm{~d}, J=8.5 \mathrm{~Hz}, 1 \mathrm{H}), 5.13$ $(\mathrm{dd}, J=5.5,12.6 \mathrm{~Hz}, 1 \mathrm{H}), 4.78(\mathrm{~s}, 2 \mathrm{H}), 3.64-3.60(\mathrm{~m}, 4 \mathrm{H}), 3.60-3.56(\mathrm{~m}, 2 \mathrm{H}), 3.55-3.48(\mathrm{~m}, 4 \mathrm{H}), 3.45(\mathrm{t}$, $J=6.5 \mathrm{~Hz}, 2 \mathrm{H}), 2.92-2.82(\mathrm{~m}, 1 \mathrm{H}), 2.79-2.66(\mathrm{~m}, 2 \mathrm{H}), 2.20-2.09(\mathrm{~m}, 1 \mathrm{H}), 1.76-1.67(\mathrm{~m}, 2 \mathrm{H}), 1.59-$ $1.50(\mathrm{~m}, 2 \mathrm{H}), 1.46-1.30(\mathrm{~m}, 4 \mathrm{H})$.

${ }^{13} \mathrm{C}$ NMR $\left(100 \mathrm{MHz}, \mathrm{MeOD}-d_{4}\right) \delta 174.56,171.32,170.03,156.27,138.22,135.02,121.65,119.30,117.95$, $72.25,71.46,71.24,70.34,69.31,50.60,45.74,40.24$, 3.77, 32.34, 30.60, 27.76, 26.51, 23.71 (2 aromatic peaks not observed). 


\section{(2-(2,6-dioxopiperidin-3-yl)-1,3-dioxoisoindolin-4-yl)glycine (30)}

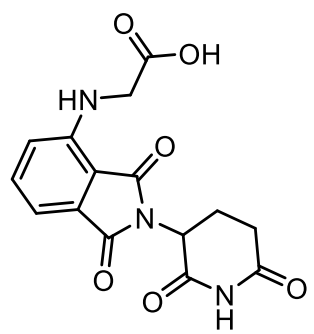

Compound 30 was synthesized according to literature procedures. ${ }^{5}$ Obtained $25.0 \mathrm{mg}, 10 \%$. ESI-MS $(\mathrm{m} / \mathrm{z})$ : $\left[\mathrm{M}+\mathrm{H}^{+}\right]$calcd. for $\mathrm{C}_{15} \mathrm{H}_{13} \mathrm{~N}_{3} \mathrm{O}_{6}, 332.08$; found 332.10.

${ }^{1} \mathrm{H}$ NMR $\left(400 \mathrm{MHz}, \mathrm{MeOD}-d_{4}\right) \delta 7.57(\mathrm{dd}, J=7.2,8.5 \mathrm{~Hz}, 1 \mathrm{H}), 7.11(\mathrm{~d}, J=7.3 \mathrm{~Hz}, 1 \mathrm{H}), 6.96(\mathrm{~d}, J=8.6 \mathrm{~Hz}$, $1 \mathrm{H}), 5.07(\mathrm{dd}, J=5.5,12.5 \mathrm{~Hz}, 1 \mathrm{H}), 4.12(\mathrm{~s}, 2 \mathrm{H}), 2.90-2.81(\mathrm{~m}, 1 \mathrm{H}), 2.79-2.68(\mathrm{~m}, 2 \mathrm{H}), 2.16-2.07(\mathrm{~m}$, $1 \mathrm{H})$.

N-(2-(2-((6-chlorohexyl)oxy)ethoxy)ethyl)-2-((2-(2,6-dioxopiperidin-3-yl)-1,3-dioxoisoindolin-4yl)amino)acetamide (ct-N-Pom, 10)
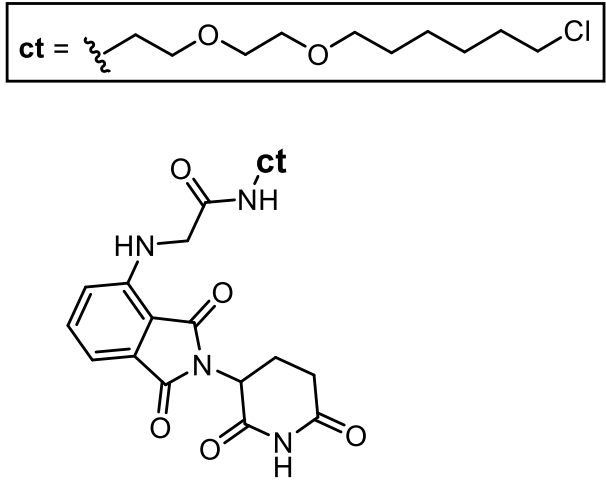

To a solution of compound 30 (5.0 mg, $1.1 \mathrm{Eq}, 15 \mu \mathrm{mol})$ in DMF $(0.1 \mathrm{~mL})$ at rt was added TBTU $(5.3 \mathrm{mg}, 1.2 \mathrm{Eq}, 16 \mu \mathrm{mol})$ and DIPEA $(5.0 \mathrm{mg}, 7.0 \mu \mathrm{L}, 3.0 \mathrm{Eq}, 41 \mu \mathrm{mol})$, followed by addition of compound 23 (5.0 mg, $1.0 \mathrm{Eq}, 14 \mu \mathrm{mol})$ after 5-10 min, and the reaction was left to stir at rt overnight. After $16 \mathrm{~h}$, the reaction was concentrated under reduced pressure, and the resulting crude product was purified via preparative HPLC (10-100\% ACN in water containing $0.1 \%$ TFA) to yield the desired product, ct-N-Pom (10), as a yellow solid (4.2 mg, 57\%). ESI-MS (m/z): [M+H'] calcd. for $\mathrm{C}_{25} \mathrm{H}_{33} \mathrm{ClN}_{4} \mathrm{O}_{7}, 537.20$; found 537.20.

${ }^{1} \mathrm{H}$ NMR $\left(400 \mathrm{MHz}, \mathrm{MeOD}-d_{4}\right) \delta 7.58(\mathrm{dd}, J=7.3,8.4 \mathrm{~Hz}, 1 \mathrm{H}), 7.13(\mathrm{~d}, J=7.2 \mathrm{~Hz}, 1 \mathrm{H}), 6.90(\mathrm{~d}, J=8.5 \mathrm{~Hz}$, $1 \mathrm{H}), 5.08(\mathrm{dd}, J=5.5,12.5 \mathrm{~Hz}, 1 \mathrm{H}), 4.01(\mathrm{~s}, 2 \mathrm{H}), 3.57-3.48(\mathrm{~m}, 7 \mathrm{H}), 3.46-3.38(\mathrm{~m}, 4 \mathrm{H}), 2.92-2.81(\mathrm{~m}$, $1 \mathrm{H}), 2.79-2.68(\mathrm{~m}, 2 \mathrm{H}), 2.15-2.08(\mathrm{~m}, 1 \mathrm{H}), 1.78-1.70(\mathrm{~m}, 2 \mathrm{H}), 1.60-1.51(\mathrm{~m}, 2 \mathrm{H}), 1.49-1.31(\mathrm{~m}, 4 \mathrm{H})$.

${ }^{13} \mathrm{C}$ NMR $\left(100 \mathrm{MHz}, \mathrm{MeOD}-d_{4}\right) \delta 174.65,172.05,171.49,170.38,169.17,147.37,137.26,133.93,118.16$, $112.83,112.49$, 72.22, 71.22, 71.17, 70.48, 50.25, 46.96., 45.71, 40.34, 33.74, 32.21, 30.51, 27.73, 26.47, 23.81. 


\section{NMR Spectra}

14, ${ }^{1} \mathrm{H}-\mathrm{NMR}$ and ${ }^{13} \mathrm{C}-\mathrm{NMR}$ in $\mathrm{CD}_{3} \mathrm{OD}$

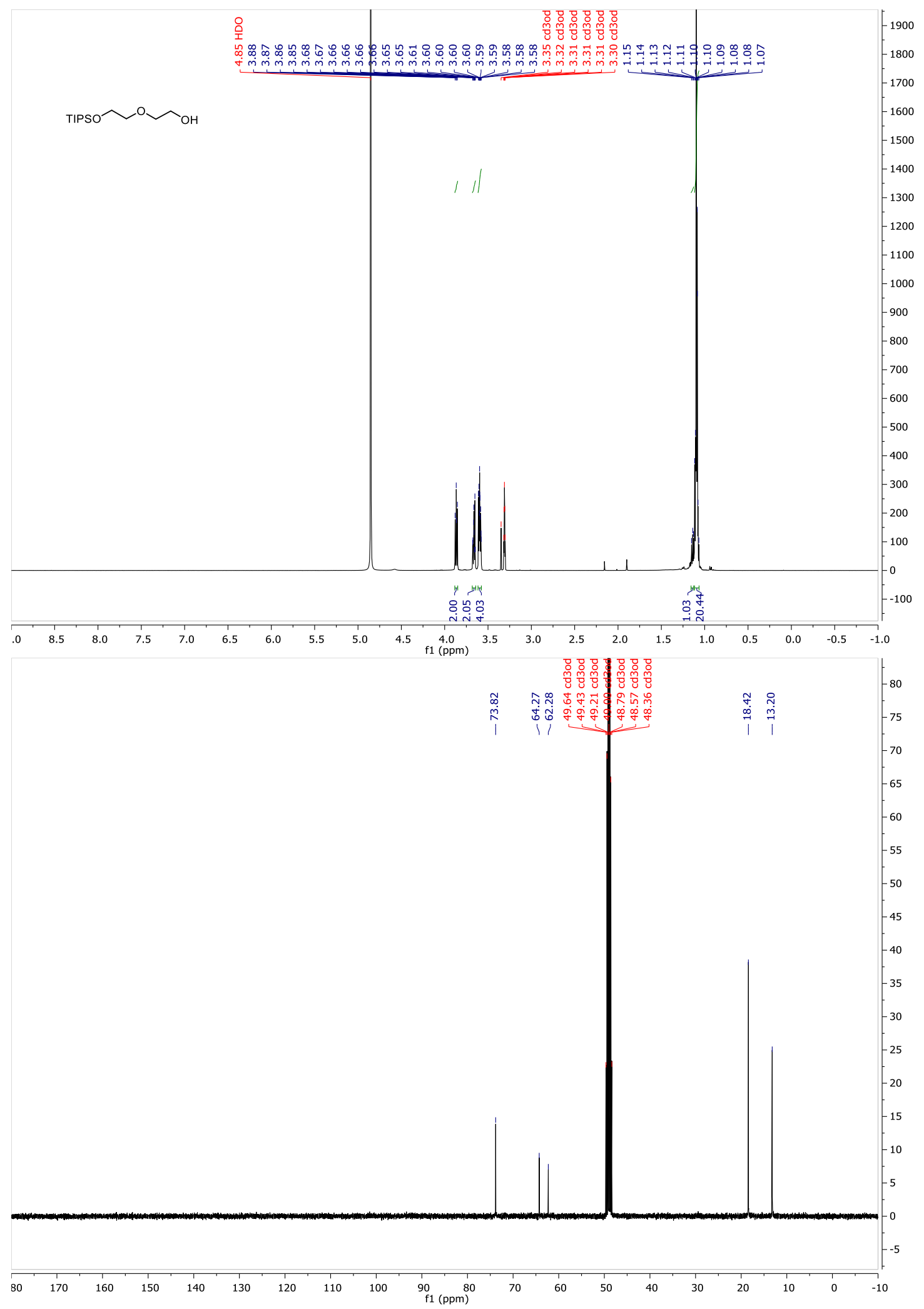


15, ${ }^{1} \mathrm{H}-\mathrm{NMR}$ and ${ }^{13} \mathrm{C}-\mathrm{NMR}$ in $\mathrm{CD}_{3} \mathrm{OD}$

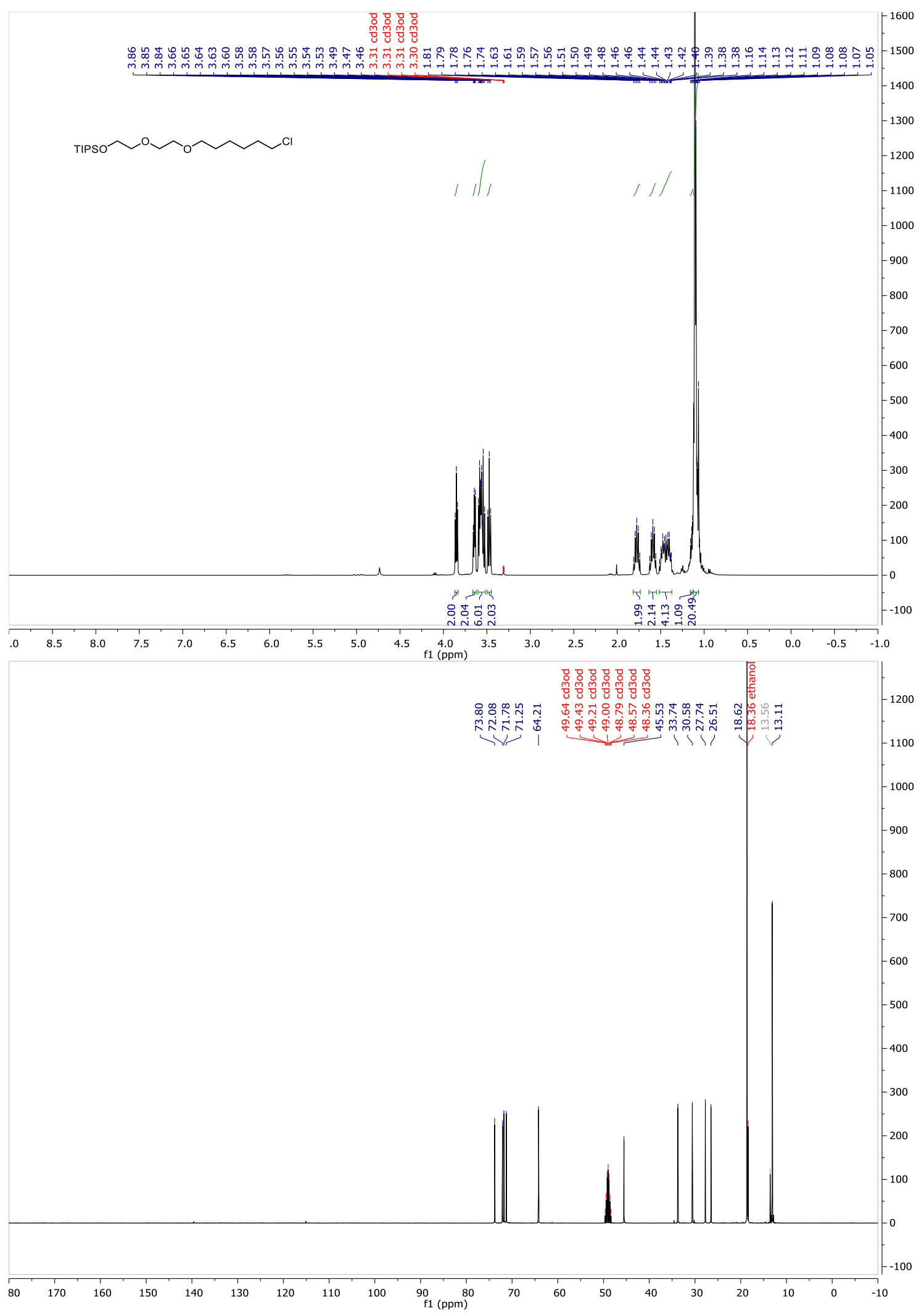




\section{6, ${ }^{1} \mathrm{H}-\mathrm{NMR}$ and ${ }^{13} \mathrm{C}-\mathrm{NMR}$ in $\mathrm{CD}_{3} \mathrm{OD}$}

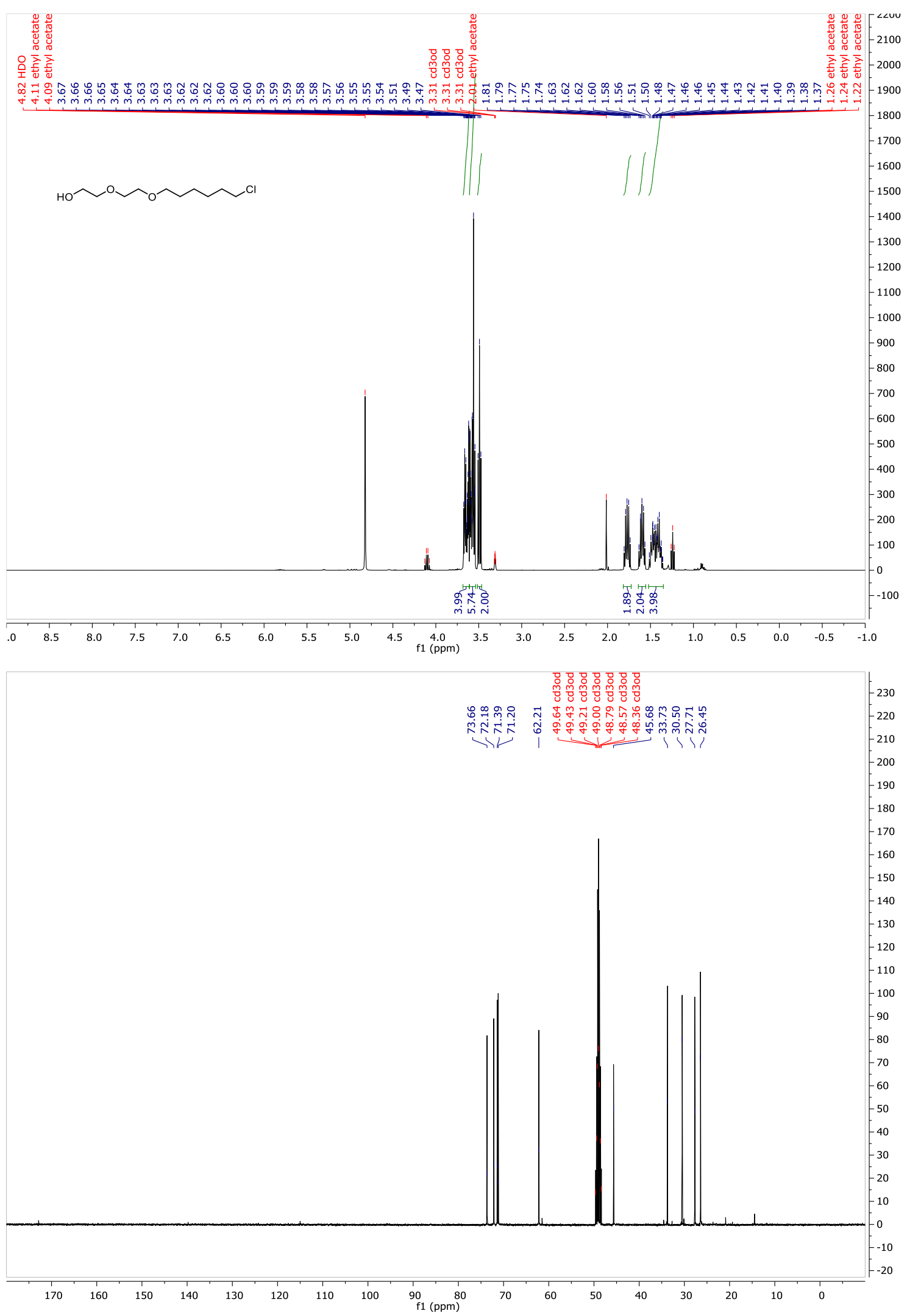




\section{2, ${ }^{1} \mathrm{H}-\mathrm{NMR}$ and ${ }^{13} \mathrm{C}-\mathrm{NMR}$ in $\mathrm{CD}_{3} \mathrm{OD}$}

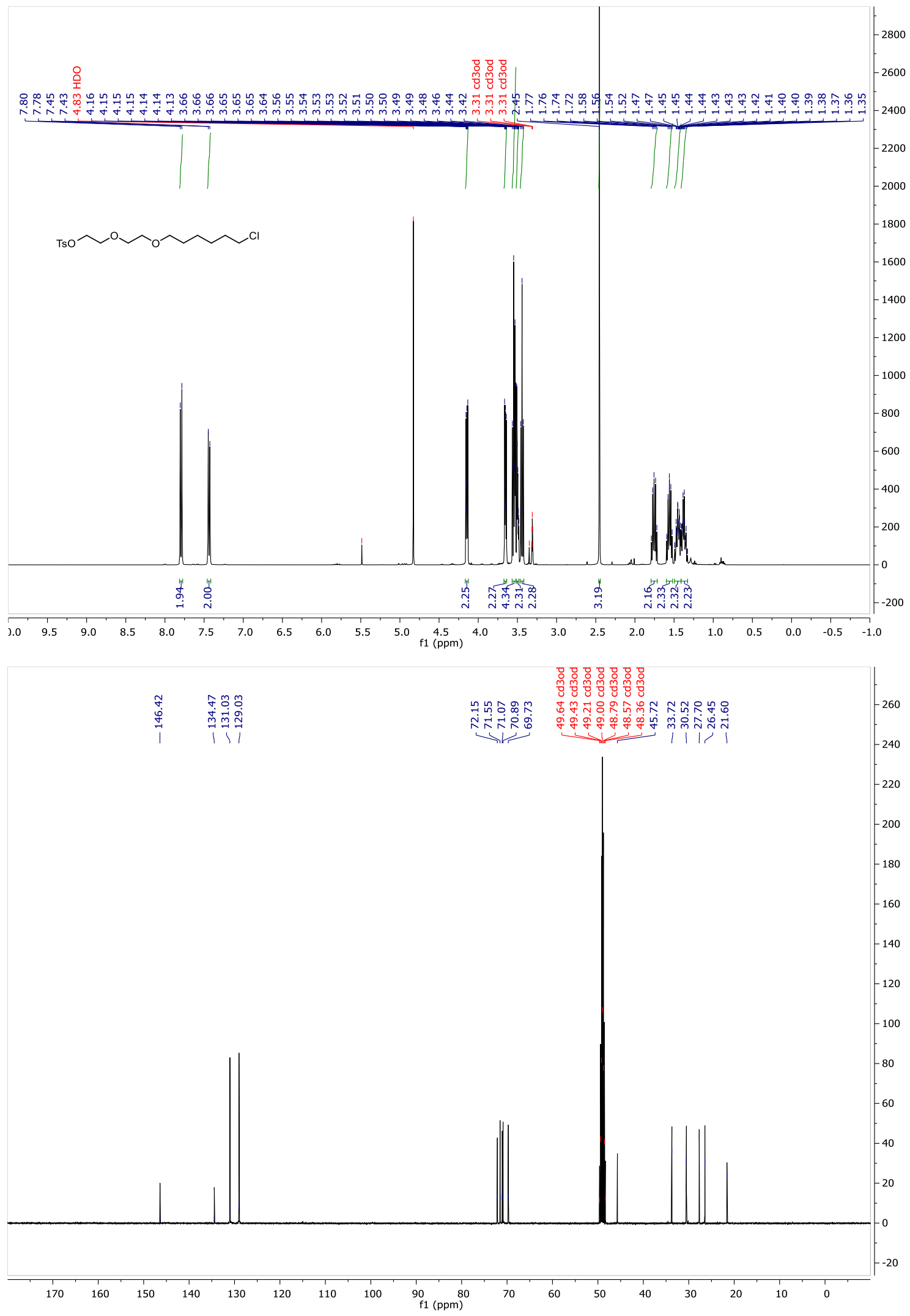


17, ${ }^{1} \mathrm{H}-\mathrm{NMR}$ and ${ }^{13} \mathrm{C}-\mathrm{NMR}$ in $\mathrm{CDCl}_{3}$
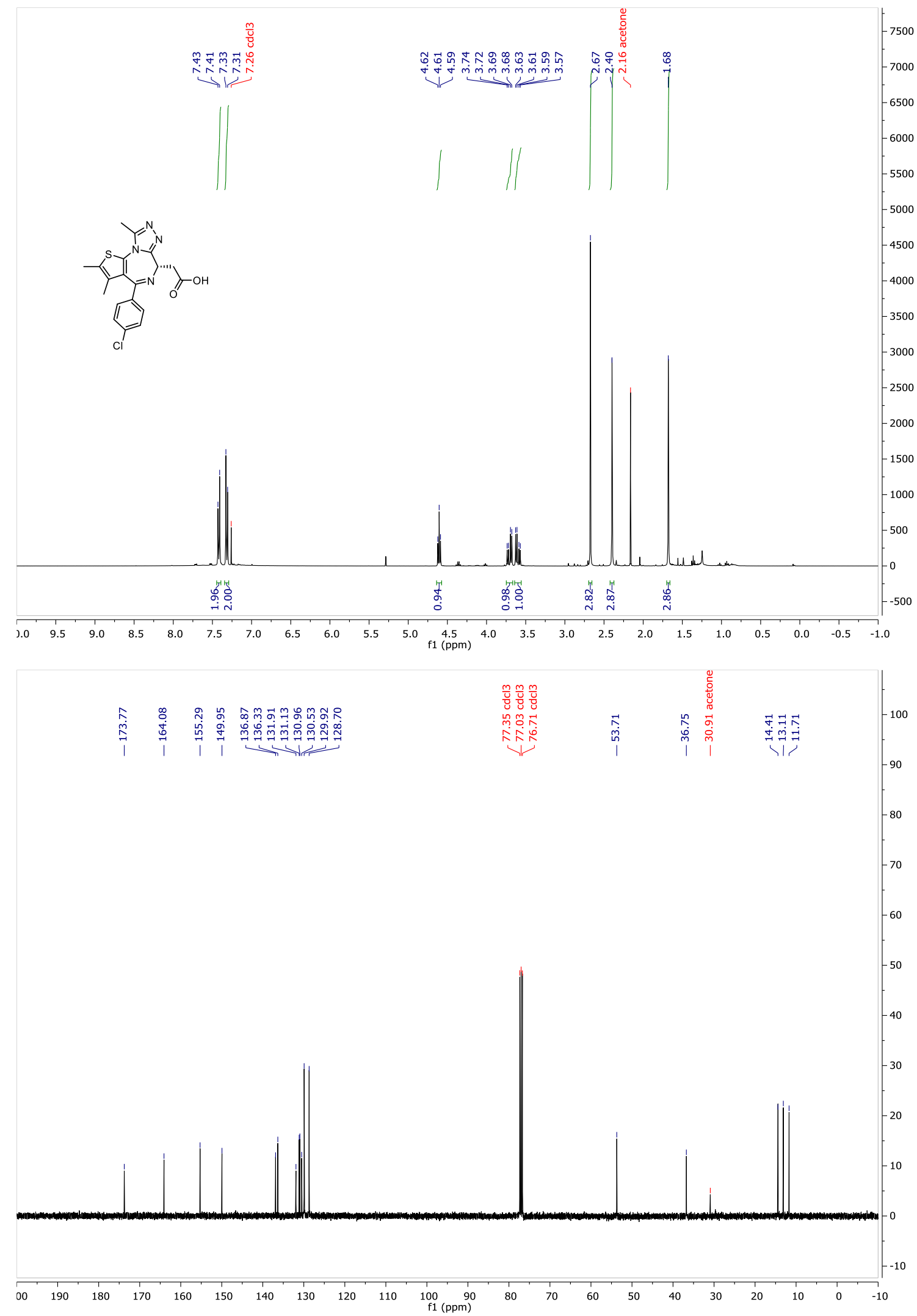
18, ${ }^{1} \mathrm{H}-\mathrm{NMR}$ and ${ }^{13} \mathrm{C}-\mathrm{NMR}$ in $\mathrm{CD}_{3} \mathrm{OD}$

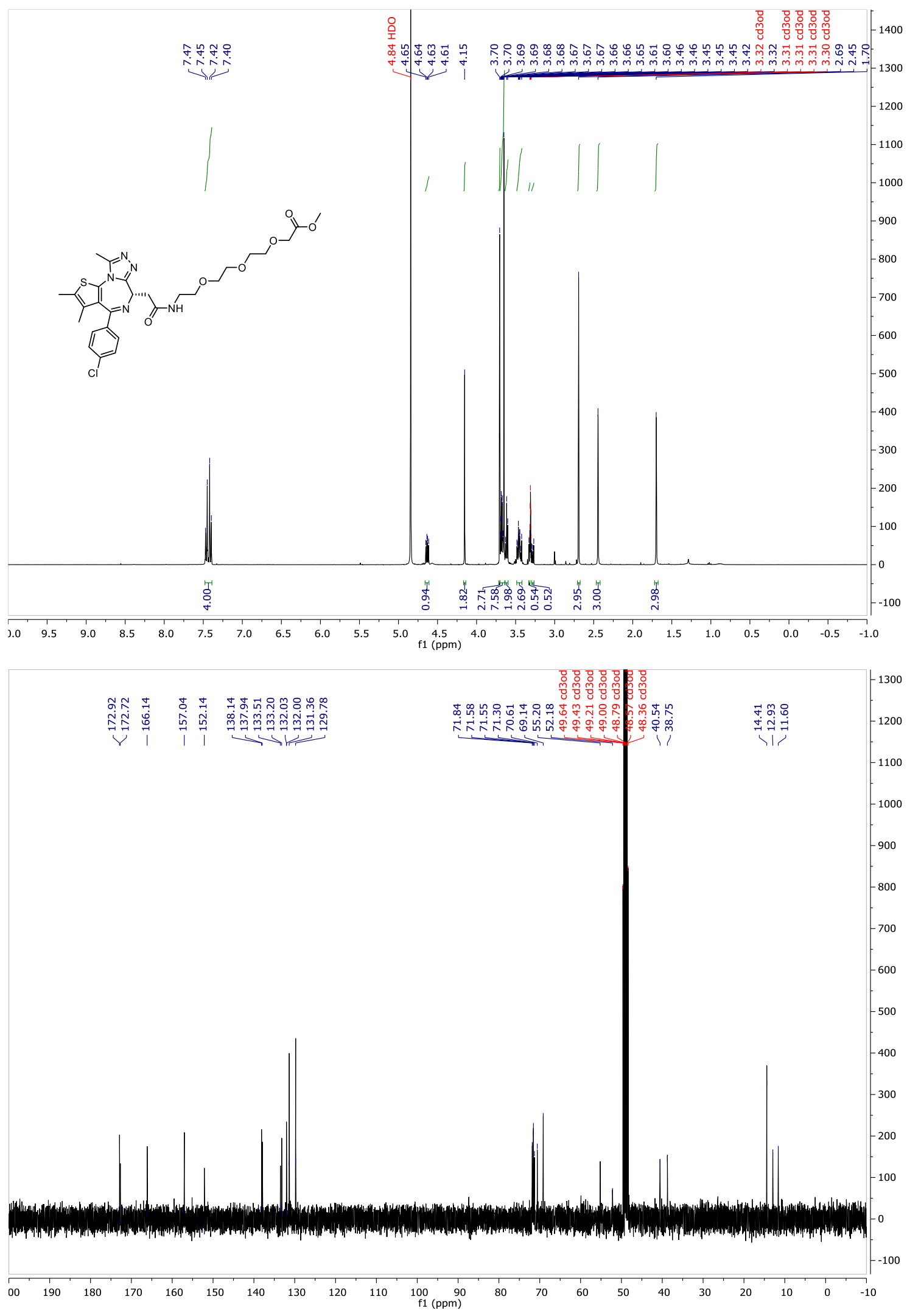


PEG - JQ1 (19), ${ }^{1} \mathrm{H}-\mathrm{NMR}$ and ${ }^{13} \mathrm{C}-\mathrm{NMR}$ in $\mathrm{CDCl}_{3}$

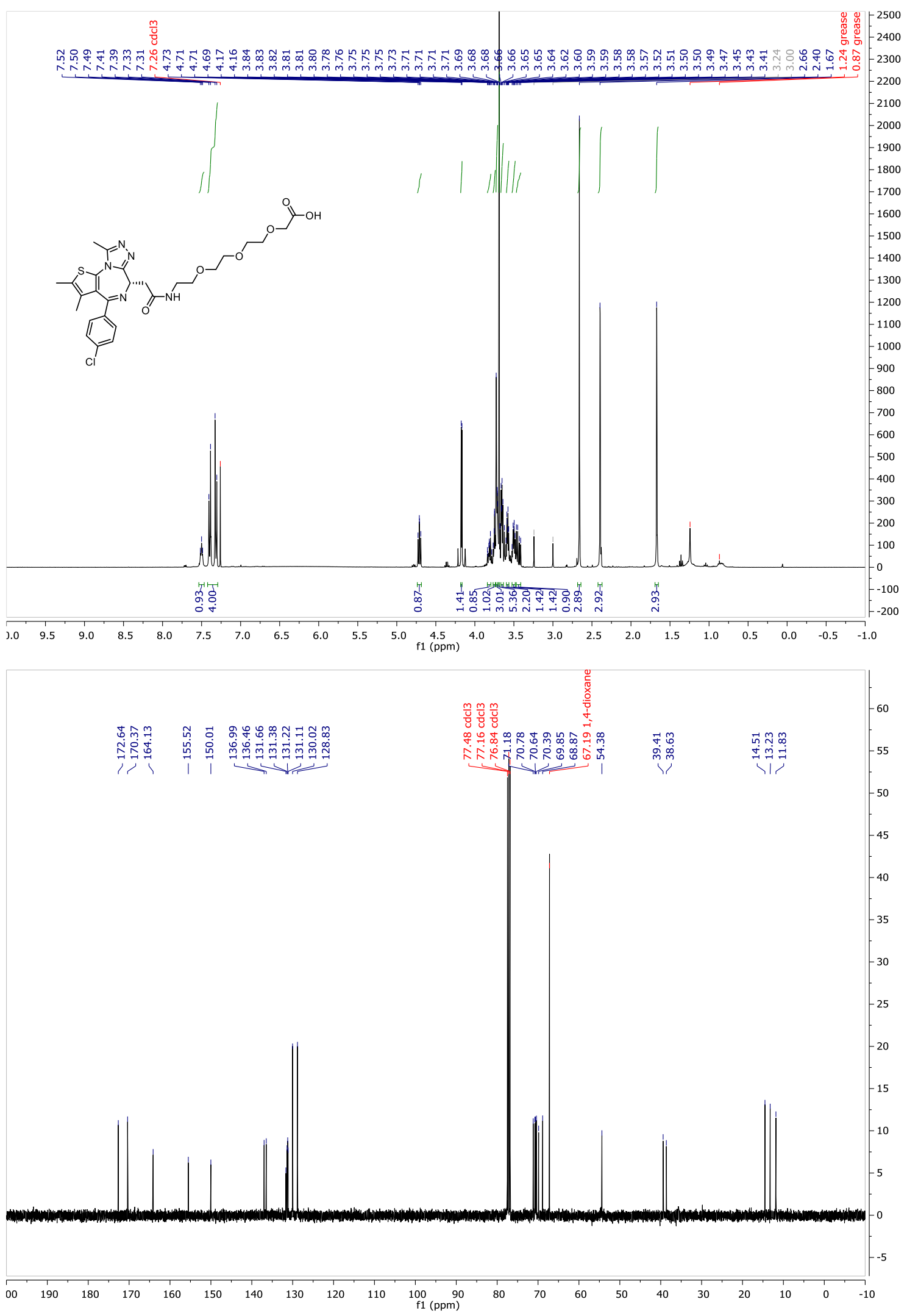


20, ${ }^{1} \mathrm{H}-\mathrm{NMR}$ and ${ }^{13} \mathrm{C}-\mathrm{NMR}$ in $\mathrm{CD}_{3} \mathrm{OD}$
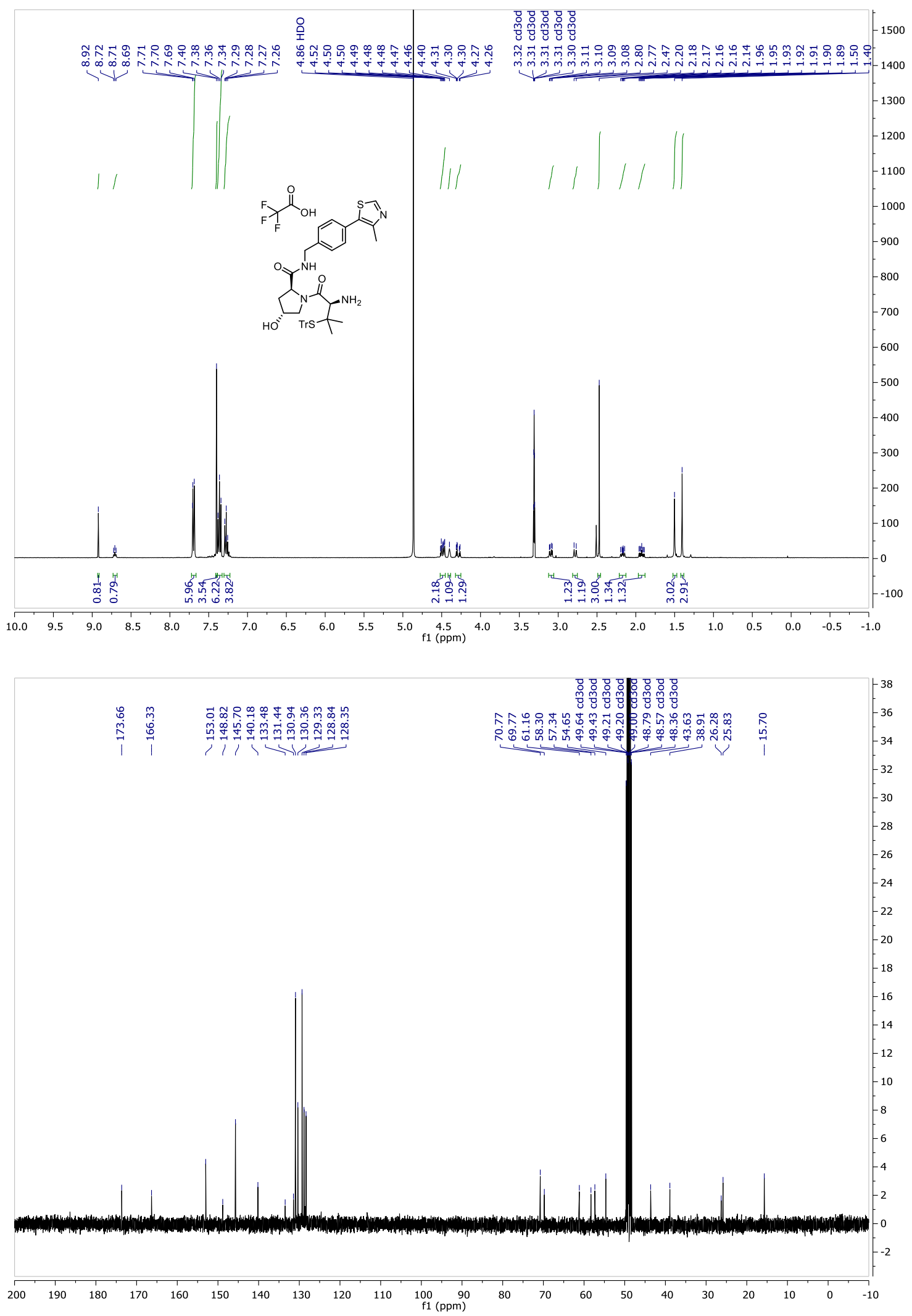
21, ${ }^{1} \mathrm{H}-\mathrm{NMR}$ and ${ }^{13} \mathrm{C}-\mathrm{NMR}$ in $\mathrm{CD}_{3} \mathrm{OD}$
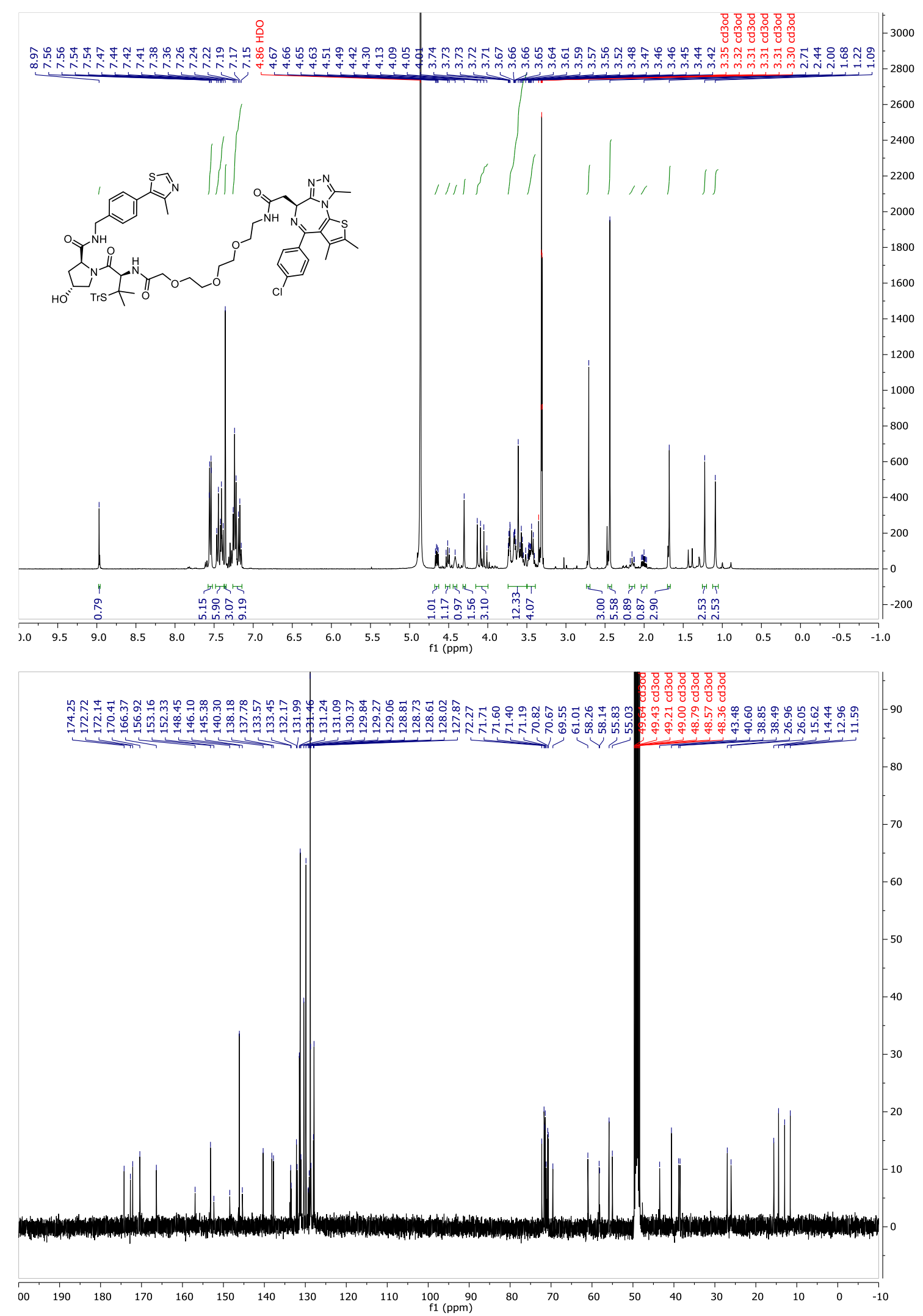
MZ1 analog (1), ${ }^{1} \mathrm{H}-\mathrm{NMR}$ and ${ }^{13} \mathrm{C}-\mathrm{NMR}$ in $\mathrm{CD}_{3} \mathrm{OD}$

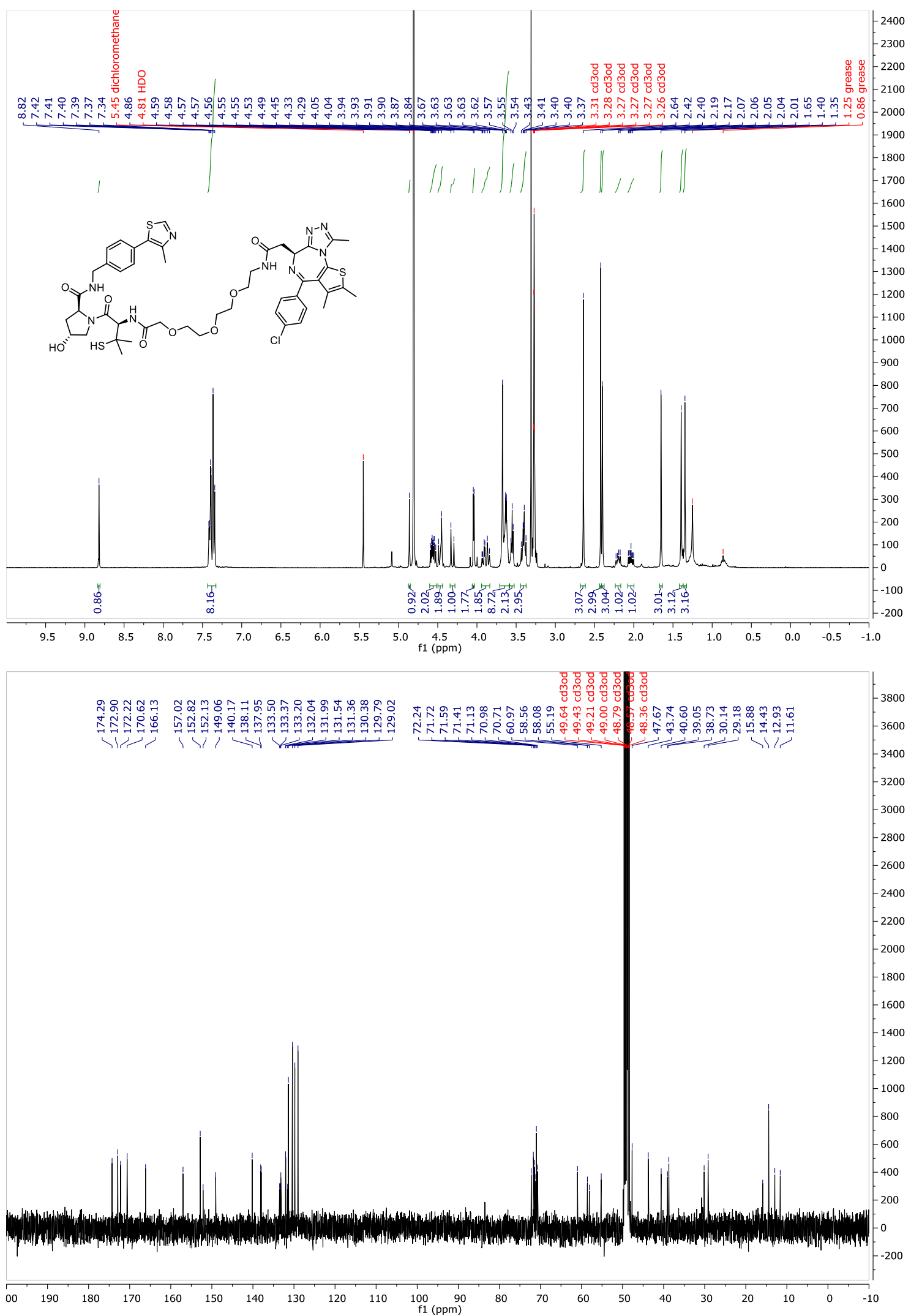


ct-MZ1 (3), ${ }^{1} \mathrm{H}-\mathrm{NMR}$ in $\mathrm{CD}_{3} \mathrm{OD}$
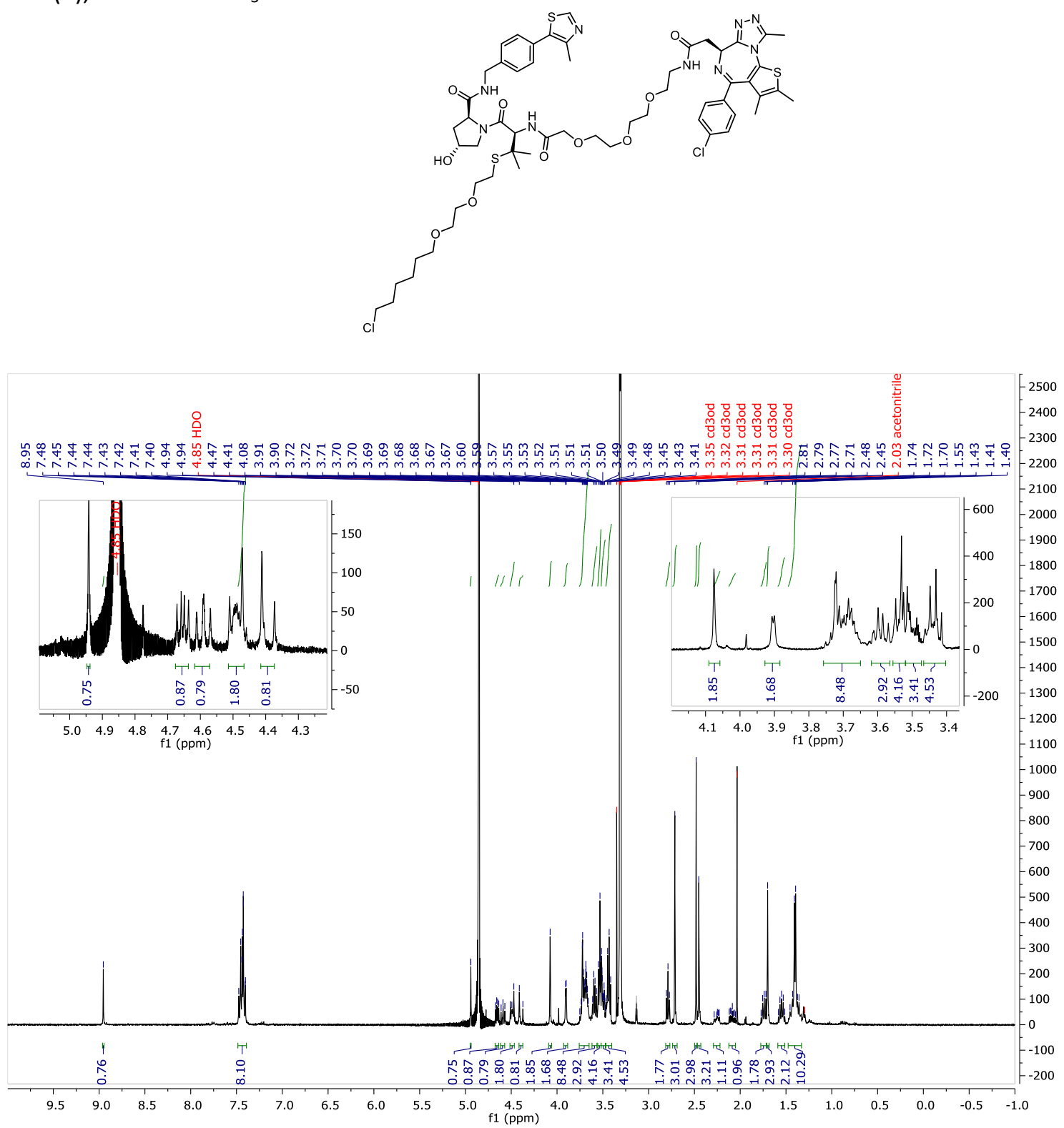
22, ${ }^{1} \mathrm{H}-\mathrm{NMR}$ and ${ }^{13} \mathrm{C}-\mathrm{NMR}$ in $\mathrm{CD}_{3} \mathrm{OD}$

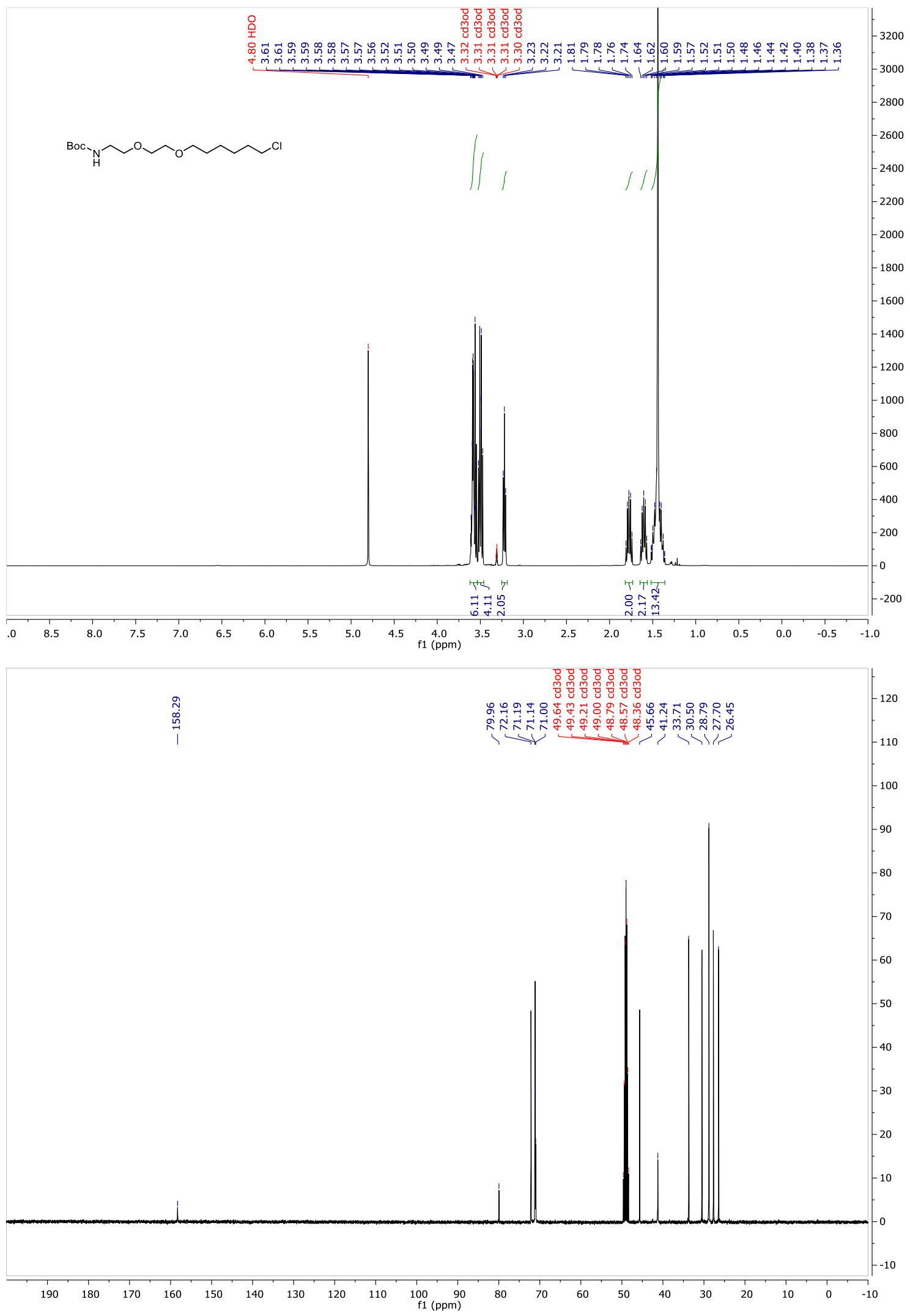


23, ${ }^{1} \mathrm{H}-\mathrm{NMR}$ and ${ }^{13} \mathrm{C}-\mathrm{NMR}$ in $\mathrm{CD}_{3} \mathrm{OD}$

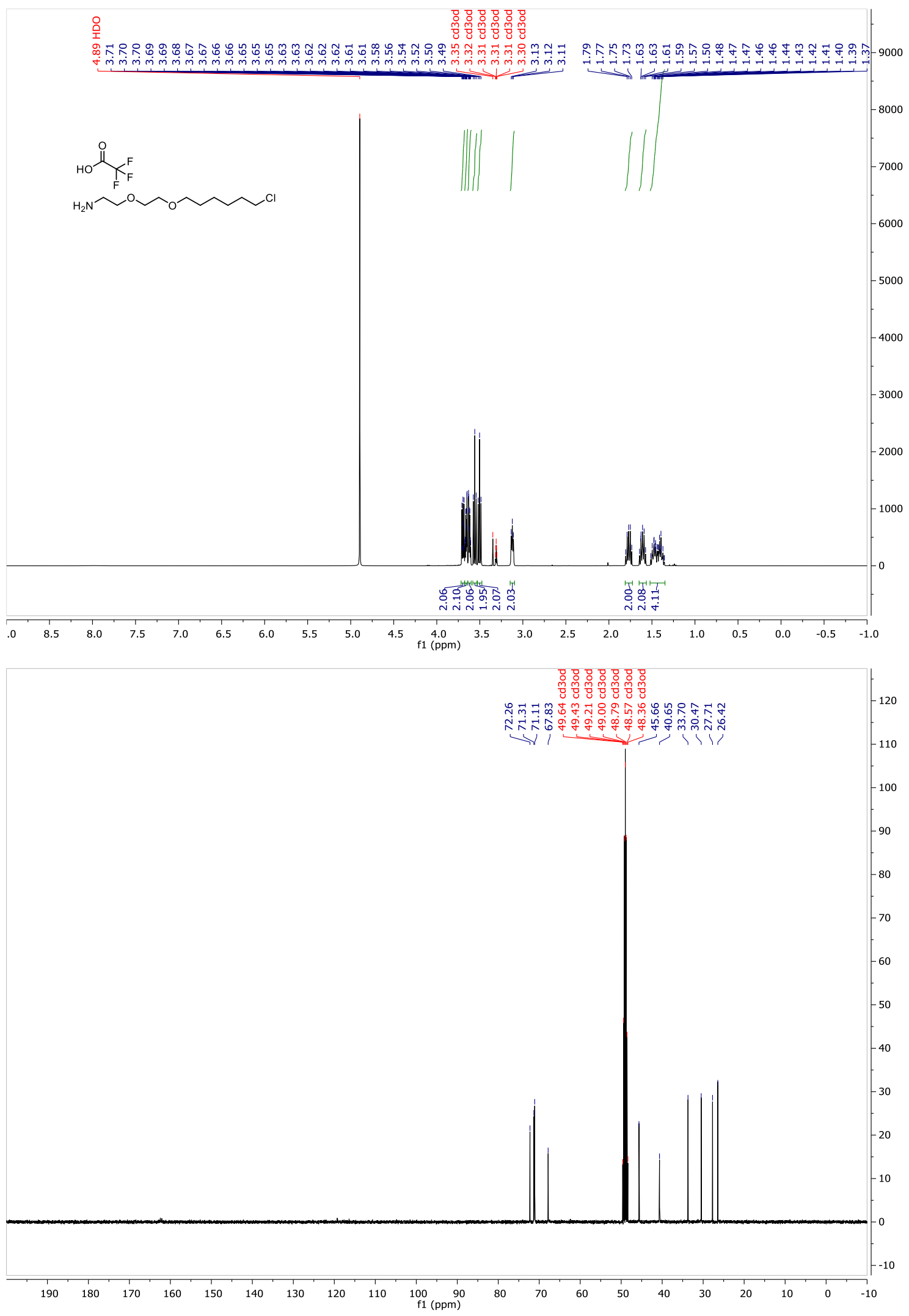


ct-PEG ${ }_{3}-\mathrm{JQ1}(6),{ }^{1} \mathrm{H}-\mathrm{NMR}$ in $\mathrm{CD}_{3} \mathrm{OD}$

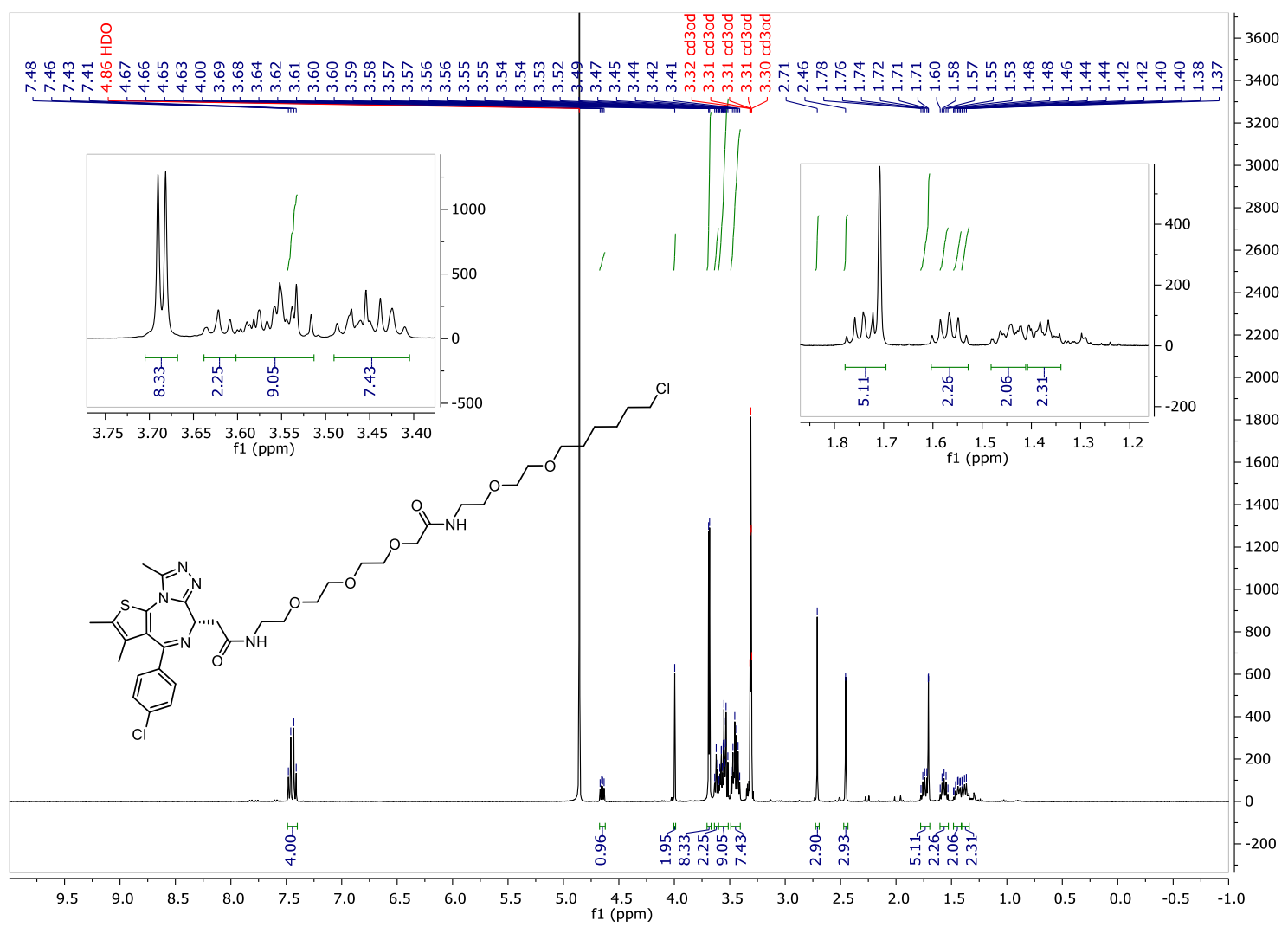


ct-JQ1 (7), ${ }^{1} \mathrm{H}-\mathrm{NMR}$ and ${ }^{13} \mathrm{C}-\mathrm{NMR}$ in $\mathrm{CD}_{3} \mathrm{OD}$

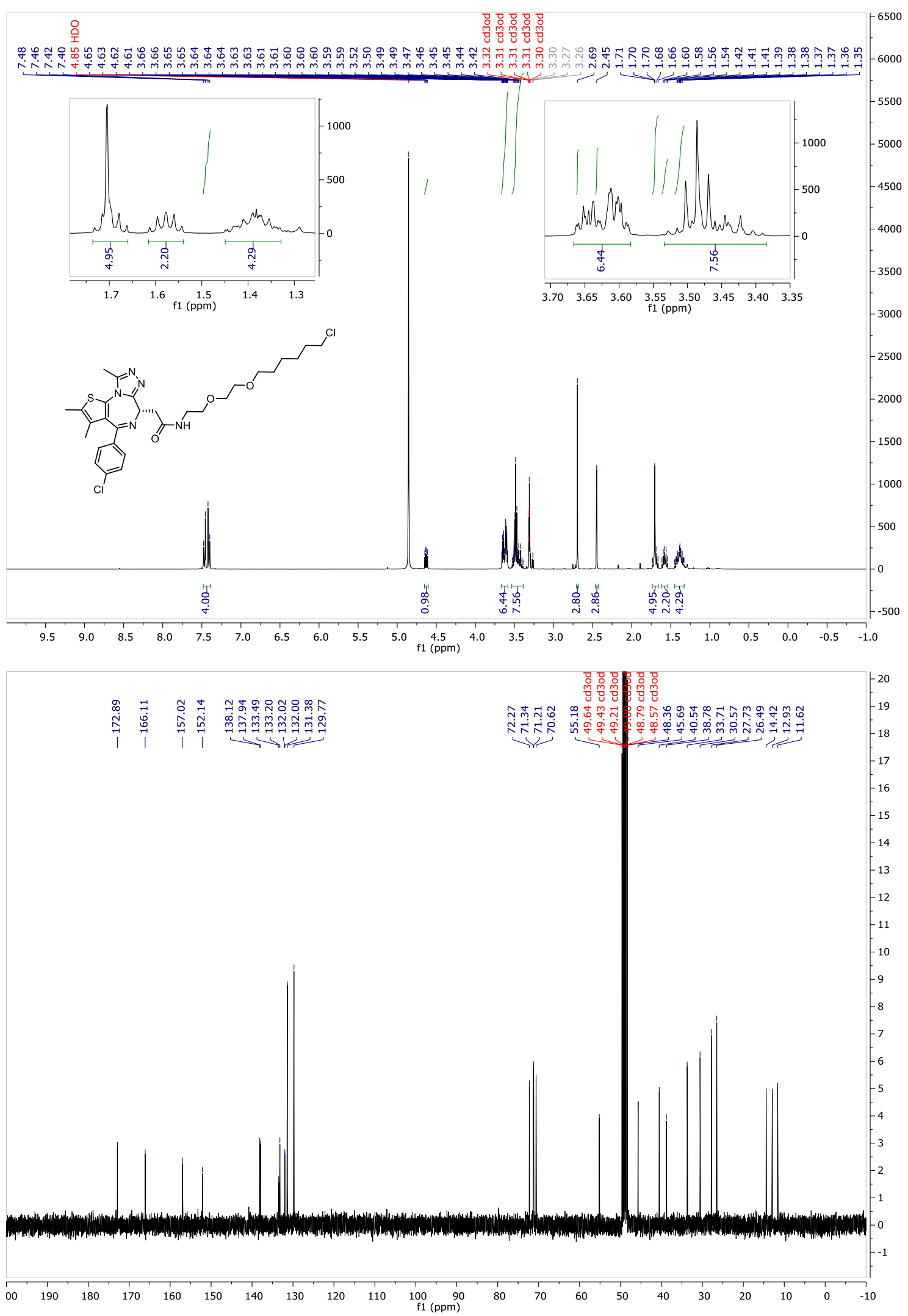


S-VHL (8), ${ }^{1} \mathrm{H}-\mathrm{NMR}$ and ${ }^{13} \mathrm{C}-\mathrm{NMR}$ in $\mathrm{CD}_{3} \mathrm{OD}$

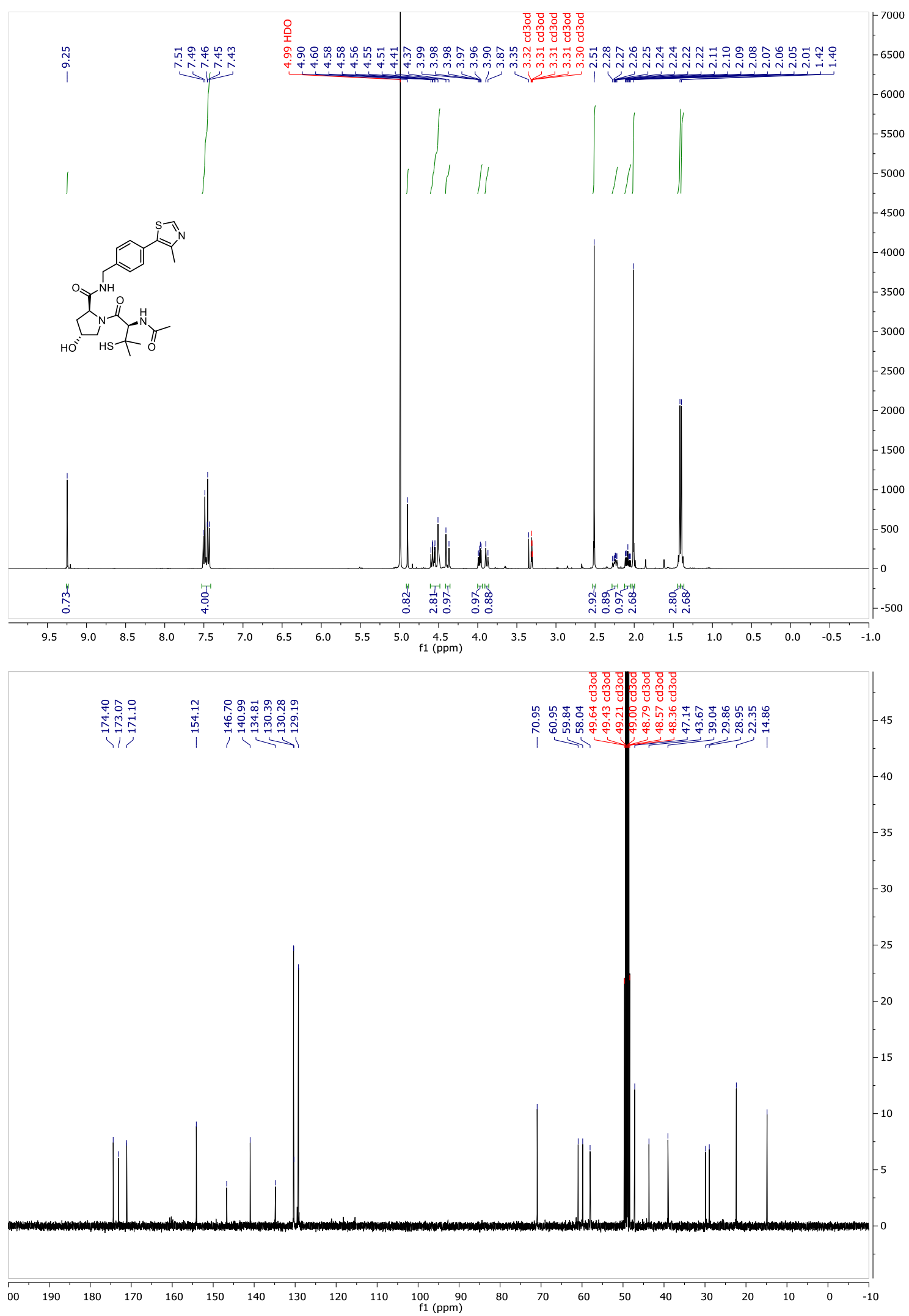


ct-S-VHL (4), ${ }^{1} \mathrm{H}-\mathrm{NMR}$ and ${ }^{13} \mathrm{C}-\mathrm{NMR}$ in $\mathrm{CD}_{3} \mathrm{OD}$

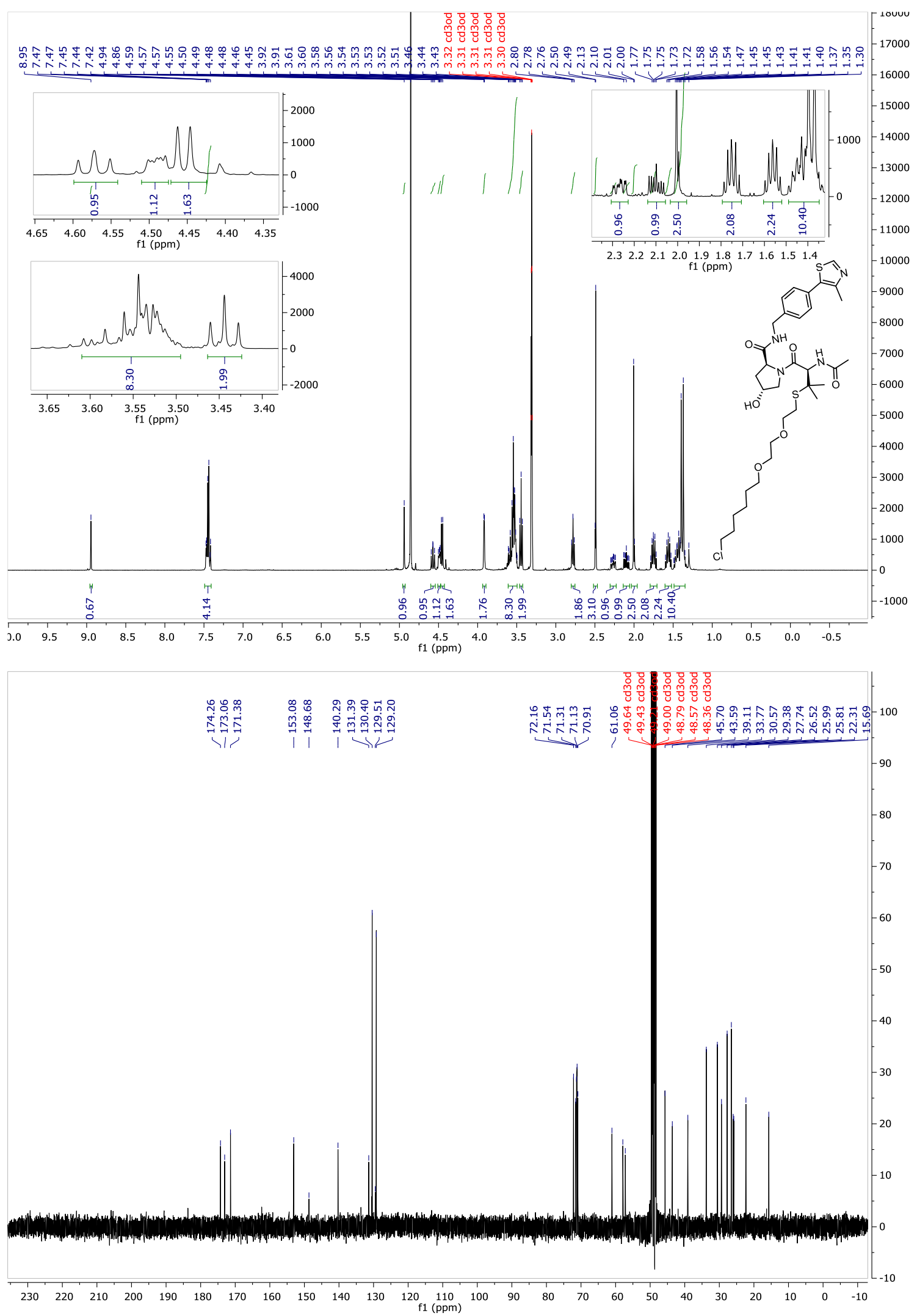




\section{5, ${ }^{1} \mathrm{H}-\mathrm{NMR}$ and ${ }^{13} \mathrm{C}-\mathrm{NMR}$ in $\mathrm{CD}_{3} \mathrm{OD}$}
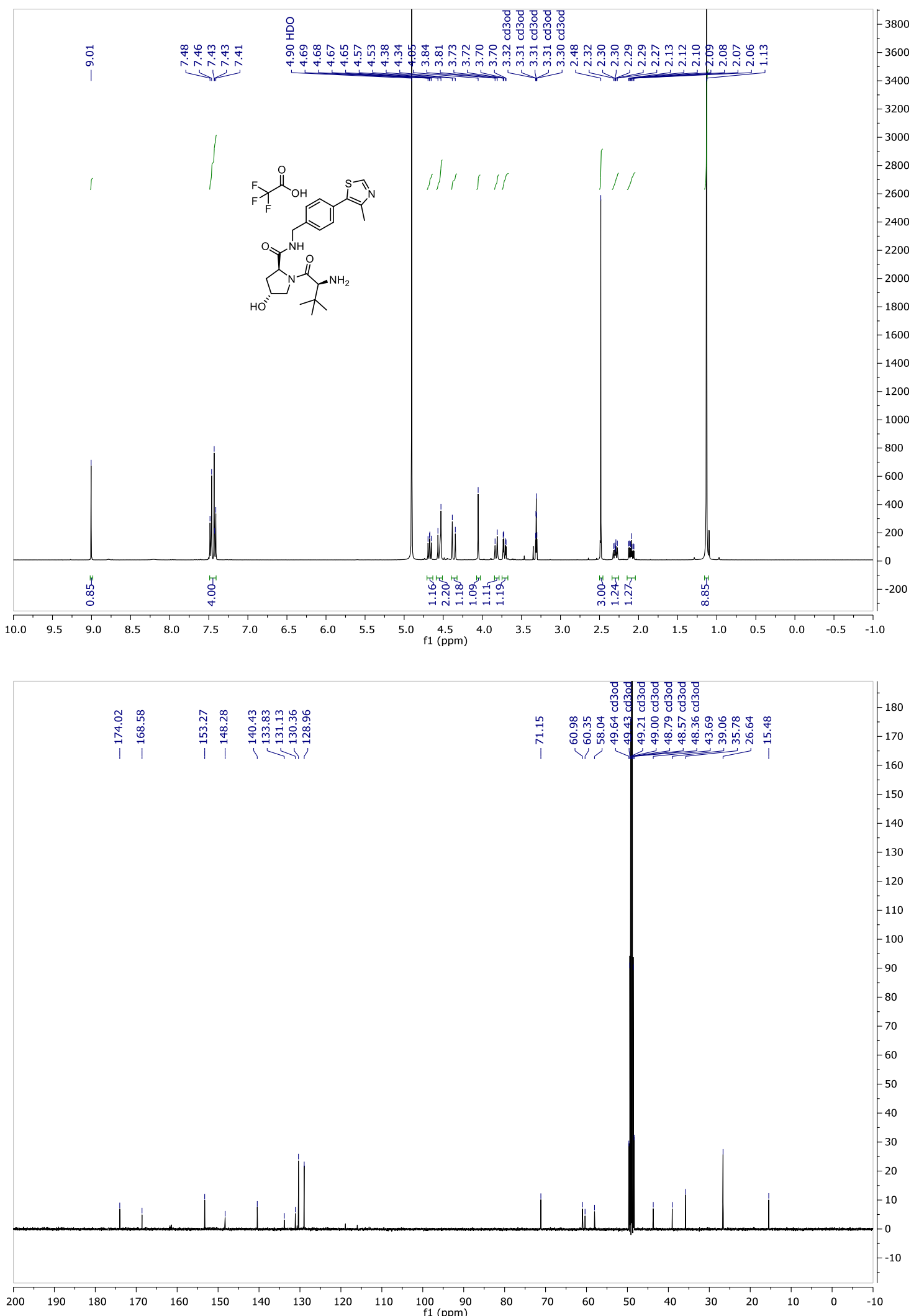


\section{6, ${ }^{1} \mathrm{H}-\mathrm{NMR}$ and ${ }^{13} \mathrm{C}-\mathrm{NMR}$ in $\mathrm{CD}_{3} \mathrm{OD}$}
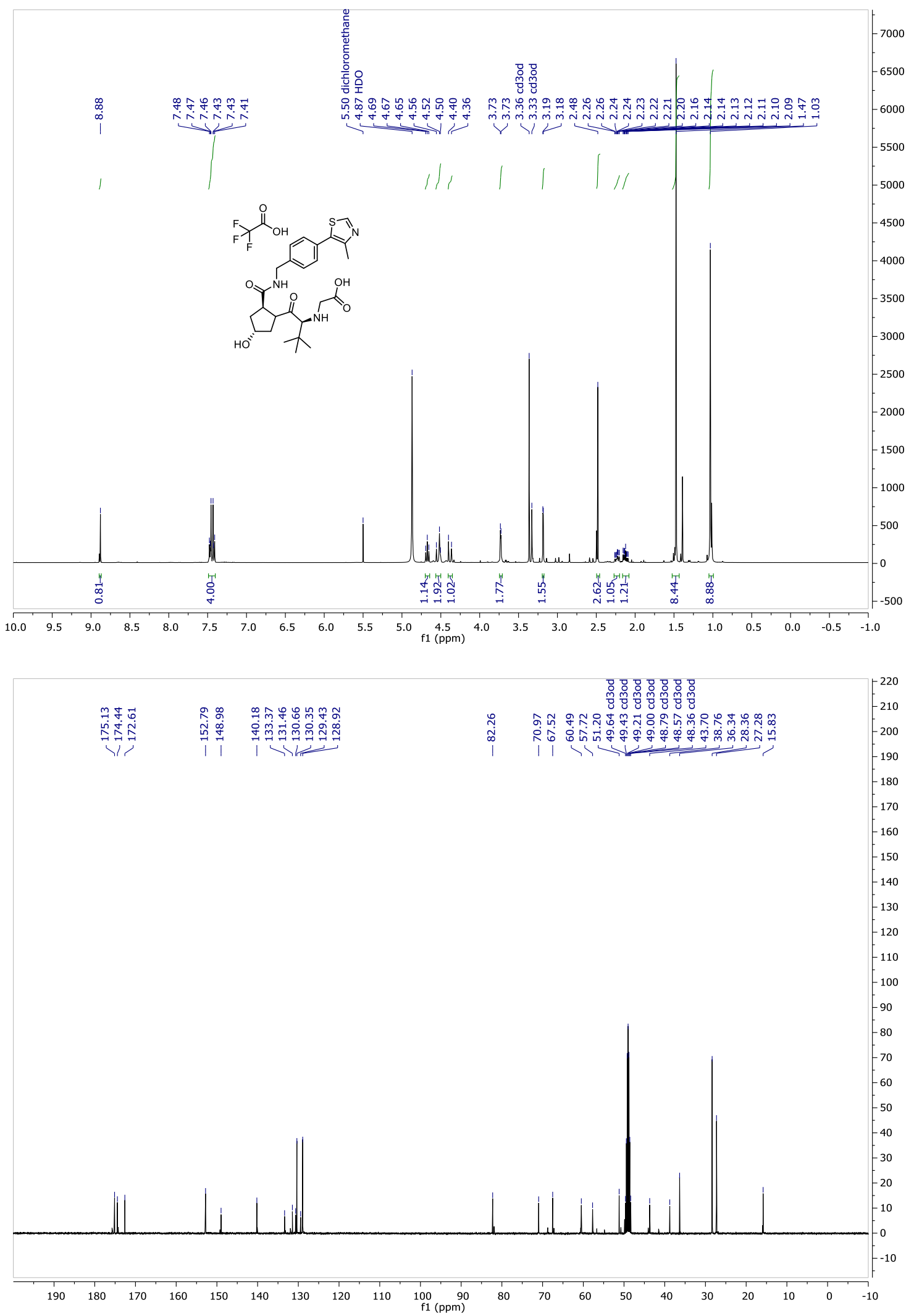
ct-VHL (5), ${ }^{1} \mathrm{H}-\mathrm{NMR}$ and ${ }^{13} \mathrm{C}-\mathrm{NMR}$ in $\mathrm{CD}_{3} \mathrm{OD}$

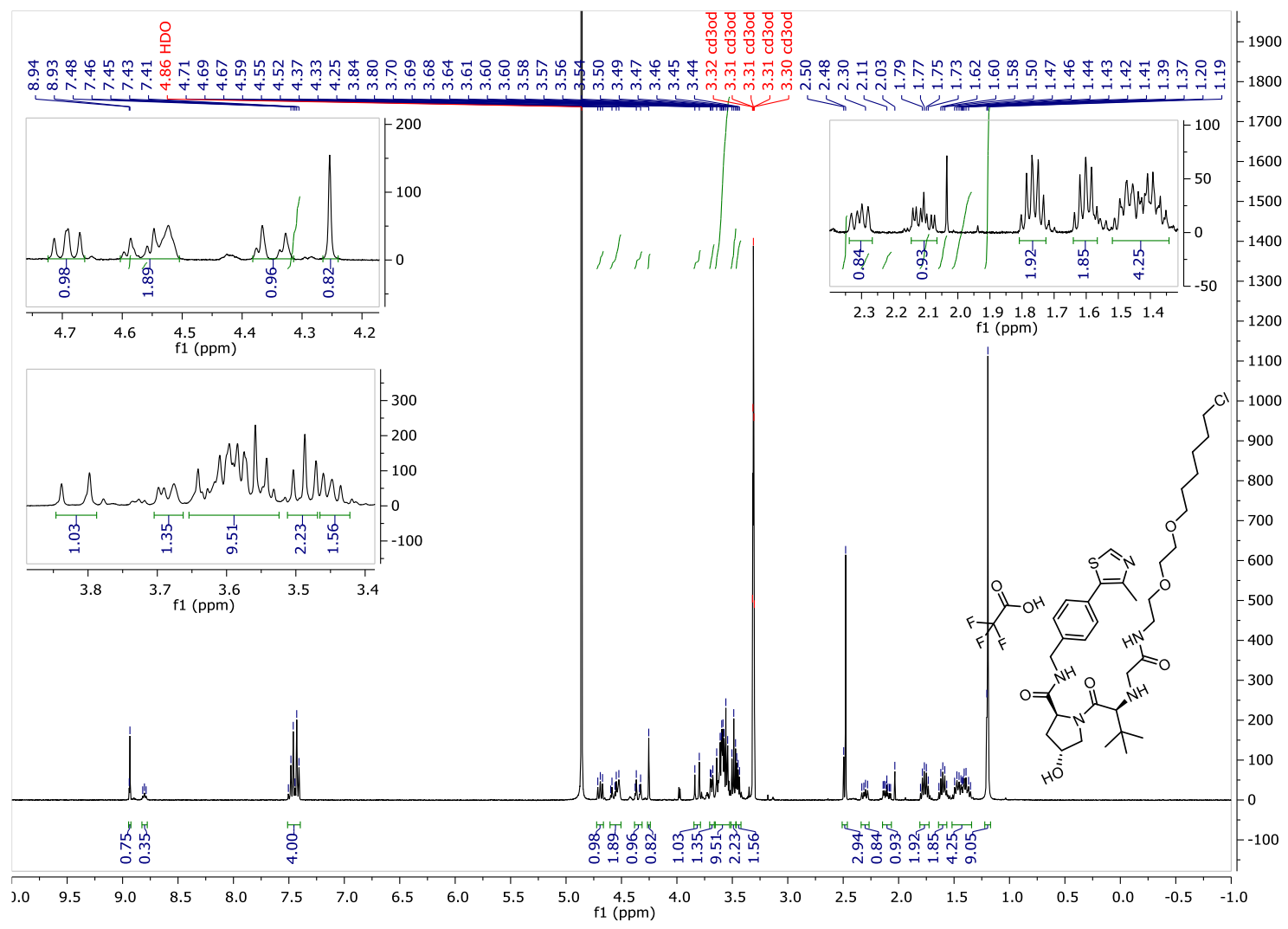

筑 算
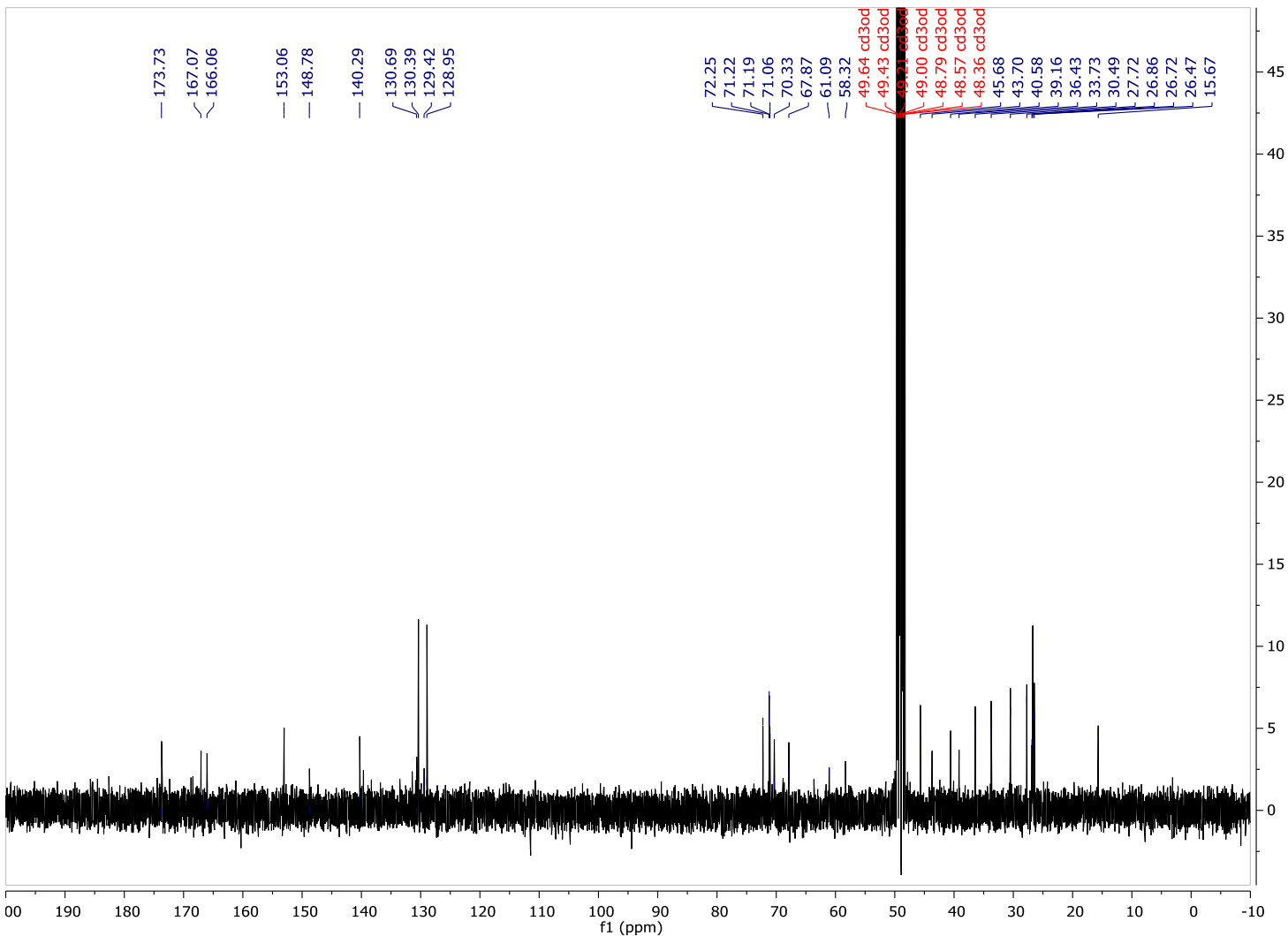


\section{7, ${ }^{1} \mathrm{H}-\mathrm{NMR}$ and ${ }^{13} \mathrm{C}-\mathrm{NMR}$ in $\mathrm{CD}_{3} \mathrm{OD}$}
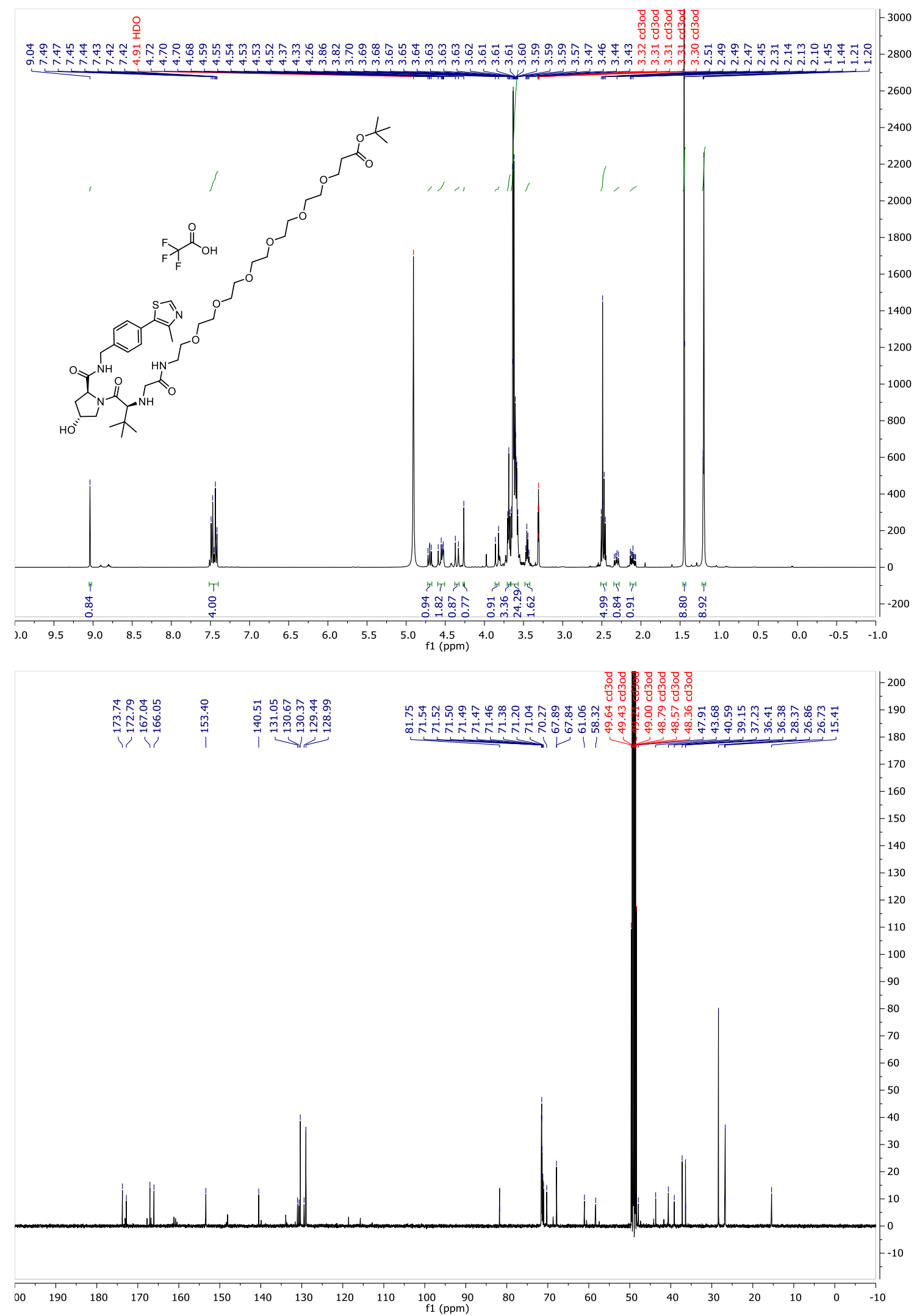
ct-PEG ${ }_{6}-\mathrm{VHL}(\mathbf{1 1}),{ }^{1} \mathrm{H}-\mathrm{NMR}$ and ${ }^{13} \mathrm{C}-\mathrm{NMR}$ in $\mathrm{CD}_{3} \mathrm{OD}$
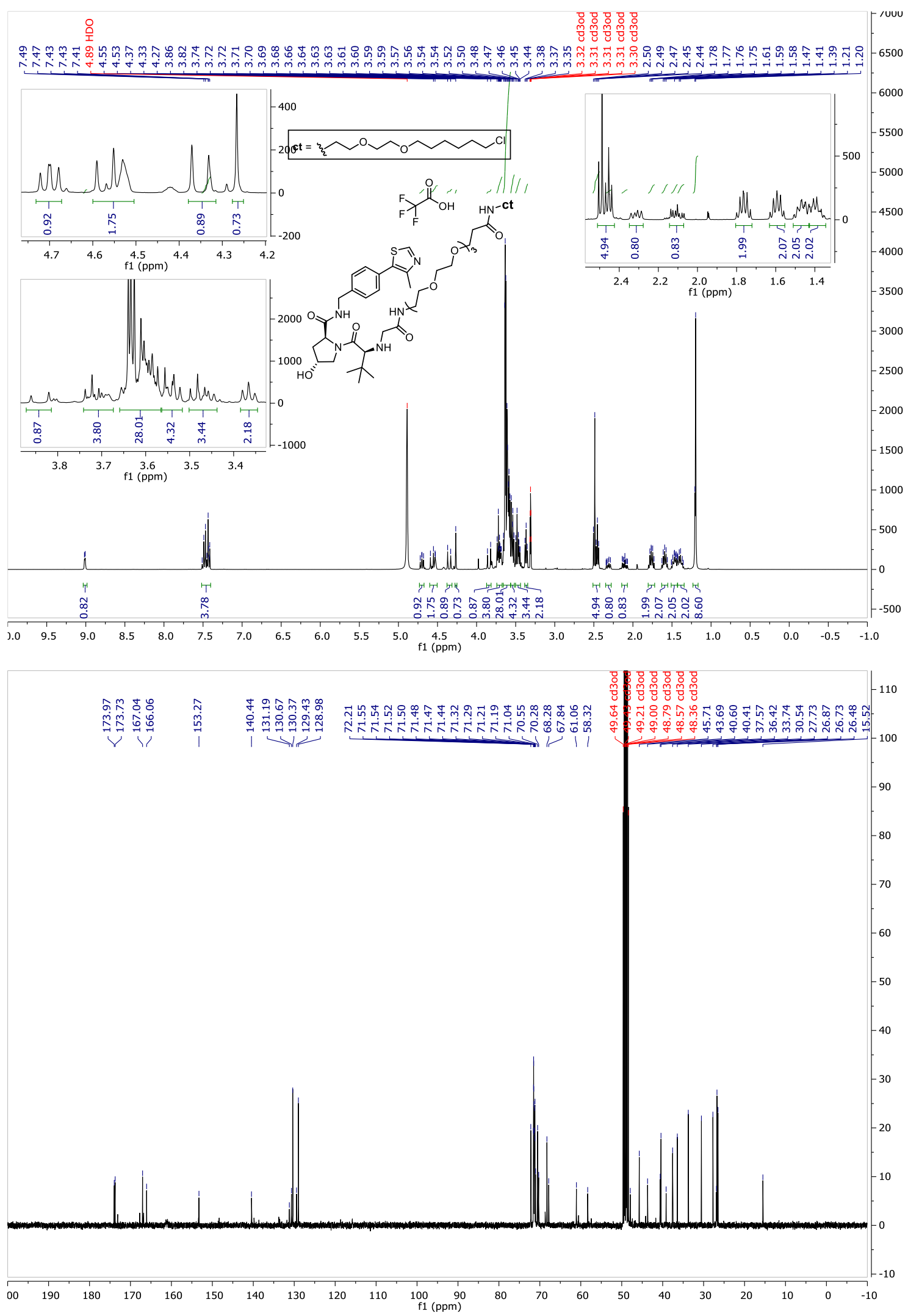
28, ${ }^{1} \mathrm{H}-\mathrm{NMR}$ and ${ }^{13} \mathrm{C}-\mathrm{NMR}$ in $\mathrm{CD}_{3} \mathrm{OD}$

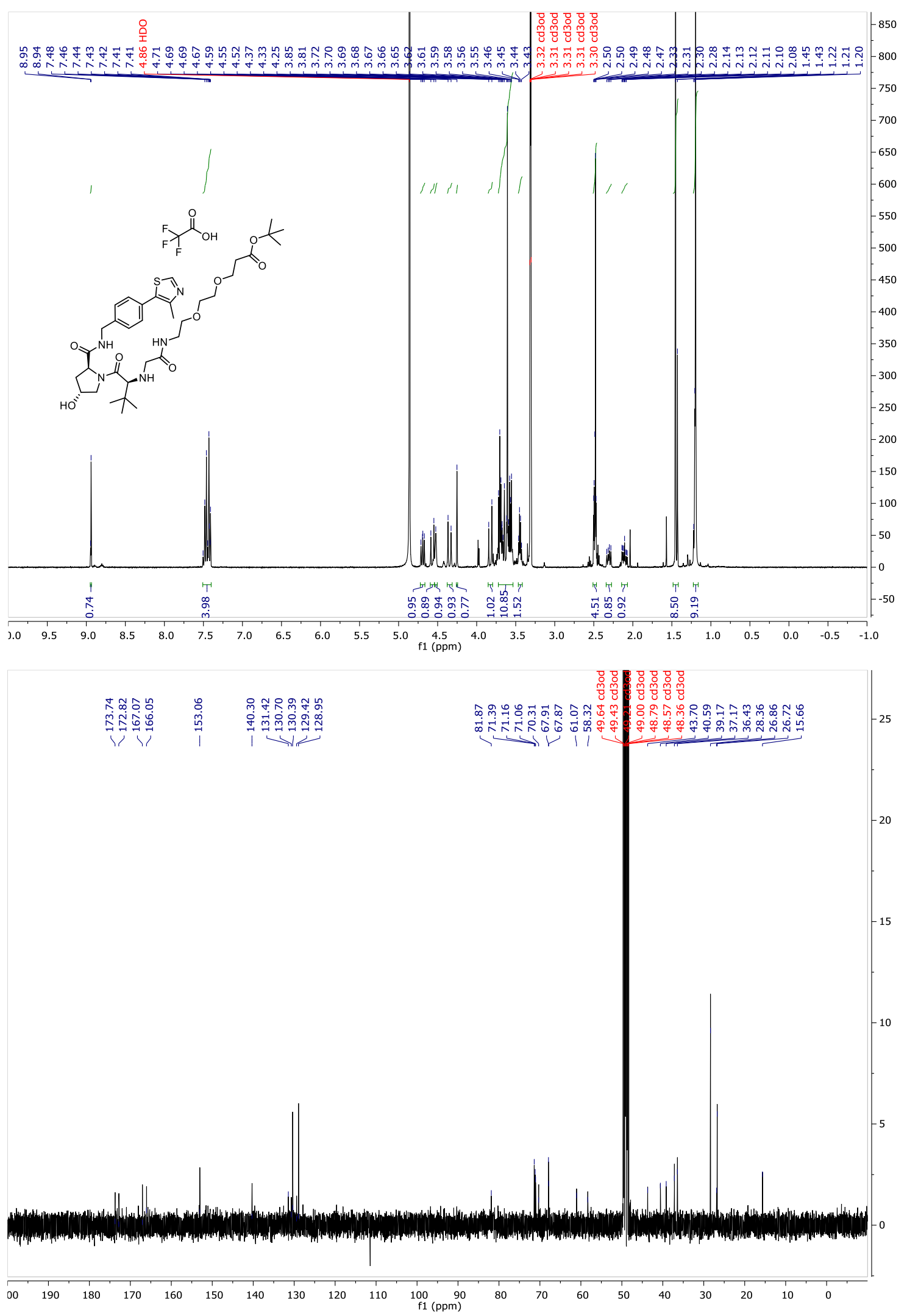


ct-PEG ${ }_{2}$-VHL (12), ${ }^{1} \mathrm{H}-\mathrm{NMR}$ and ${ }^{13} \mathrm{C}-\mathrm{NMR}$ in $\mathrm{CD}_{3} \mathrm{OD}$
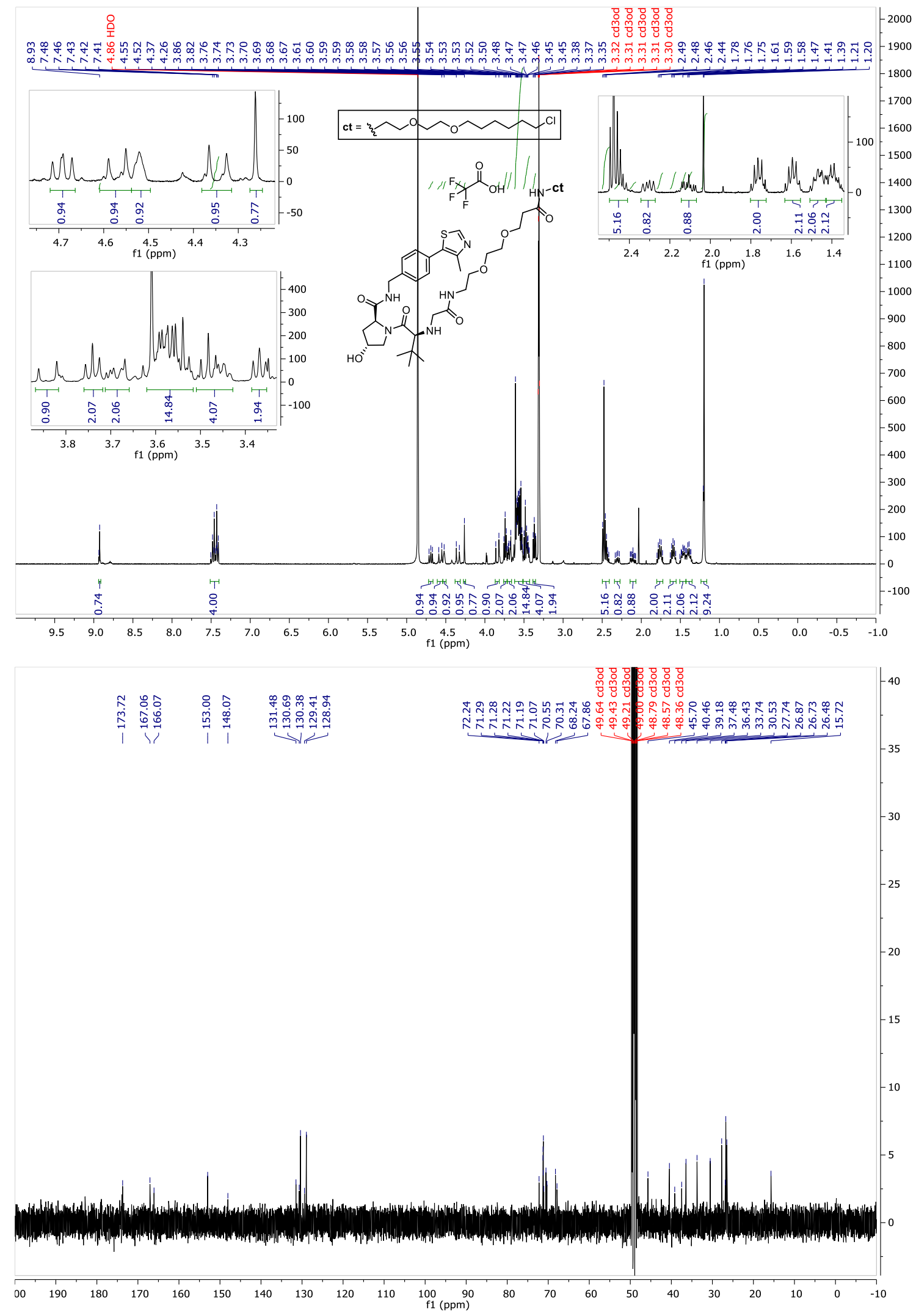
24, ${ }^{1} \mathrm{H}-\mathrm{NMR}$ and ${ }^{13} \mathrm{C}-\mathrm{NMR}$ in $\mathrm{CD}_{3} \mathrm{OD}$

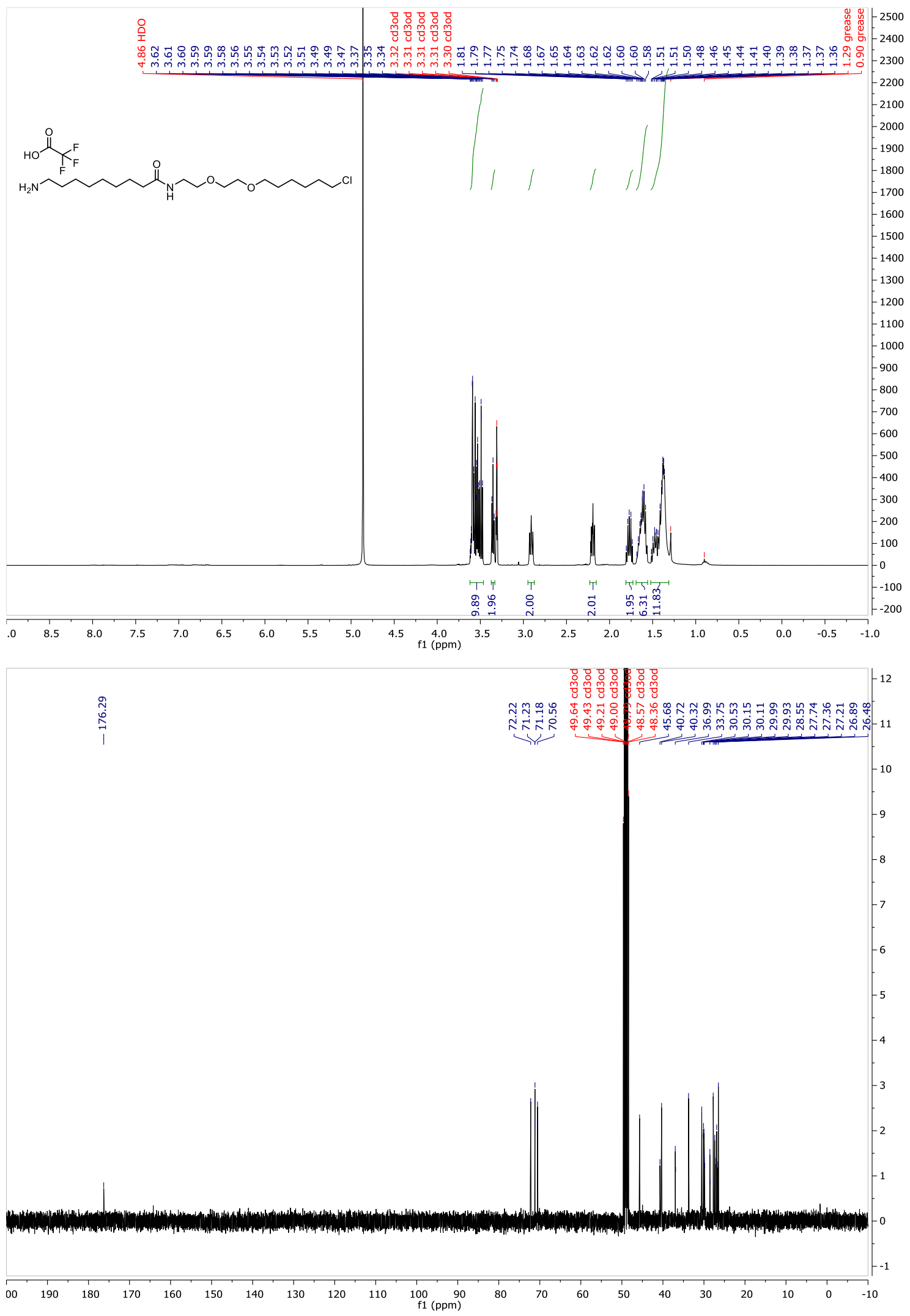


ct-alkyl ${ }_{2}$-VHL (13), ${ }^{1} \mathrm{H}-\mathrm{NMR}$ and ${ }^{13} \mathrm{C}-\mathrm{NMR}$ in $\mathrm{CD}_{3} \mathrm{OD}$
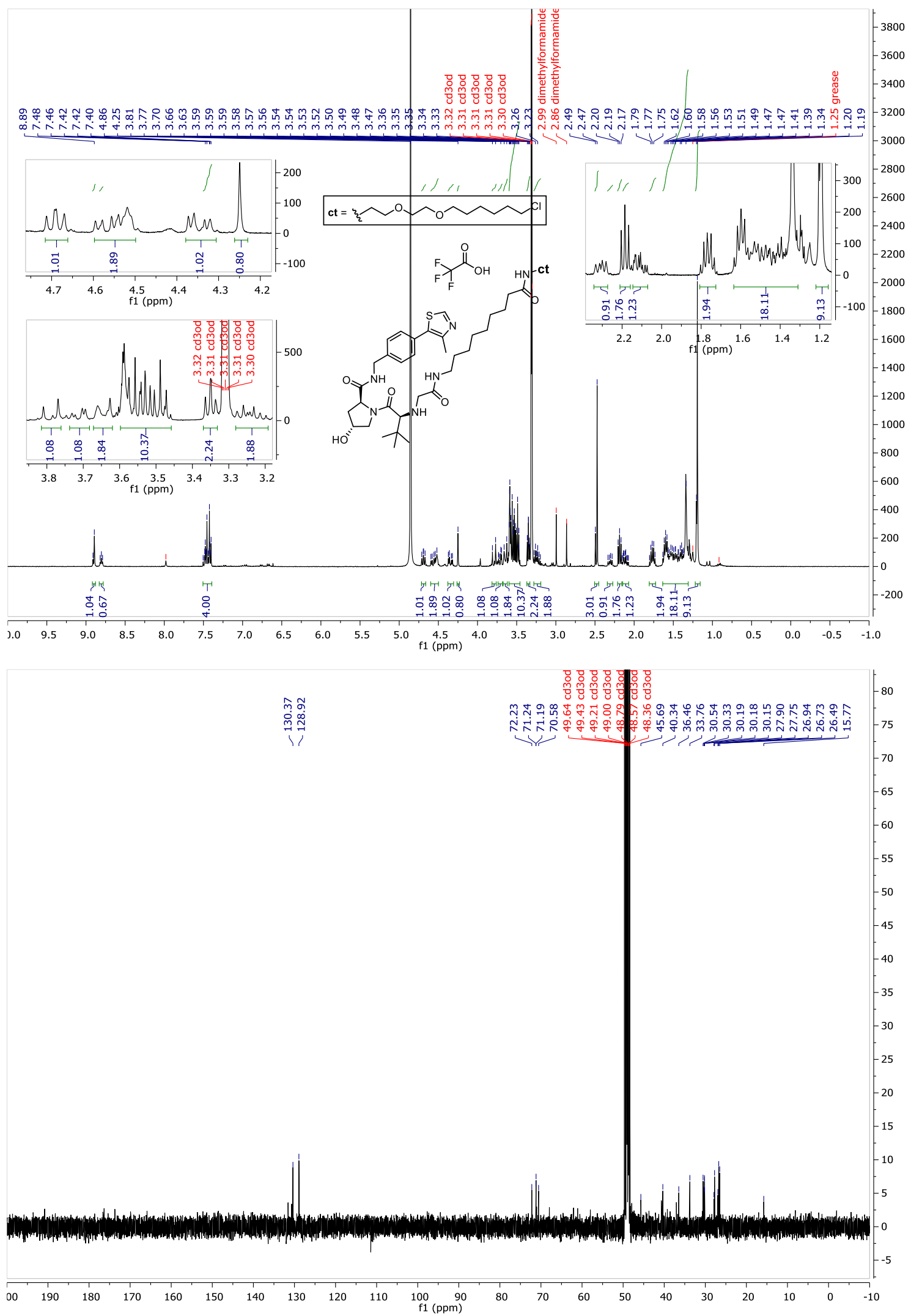
29, ${ }^{1} \mathrm{H}-\mathrm{NMR}$ in $\mathrm{CD}_{3} \mathrm{OD}$

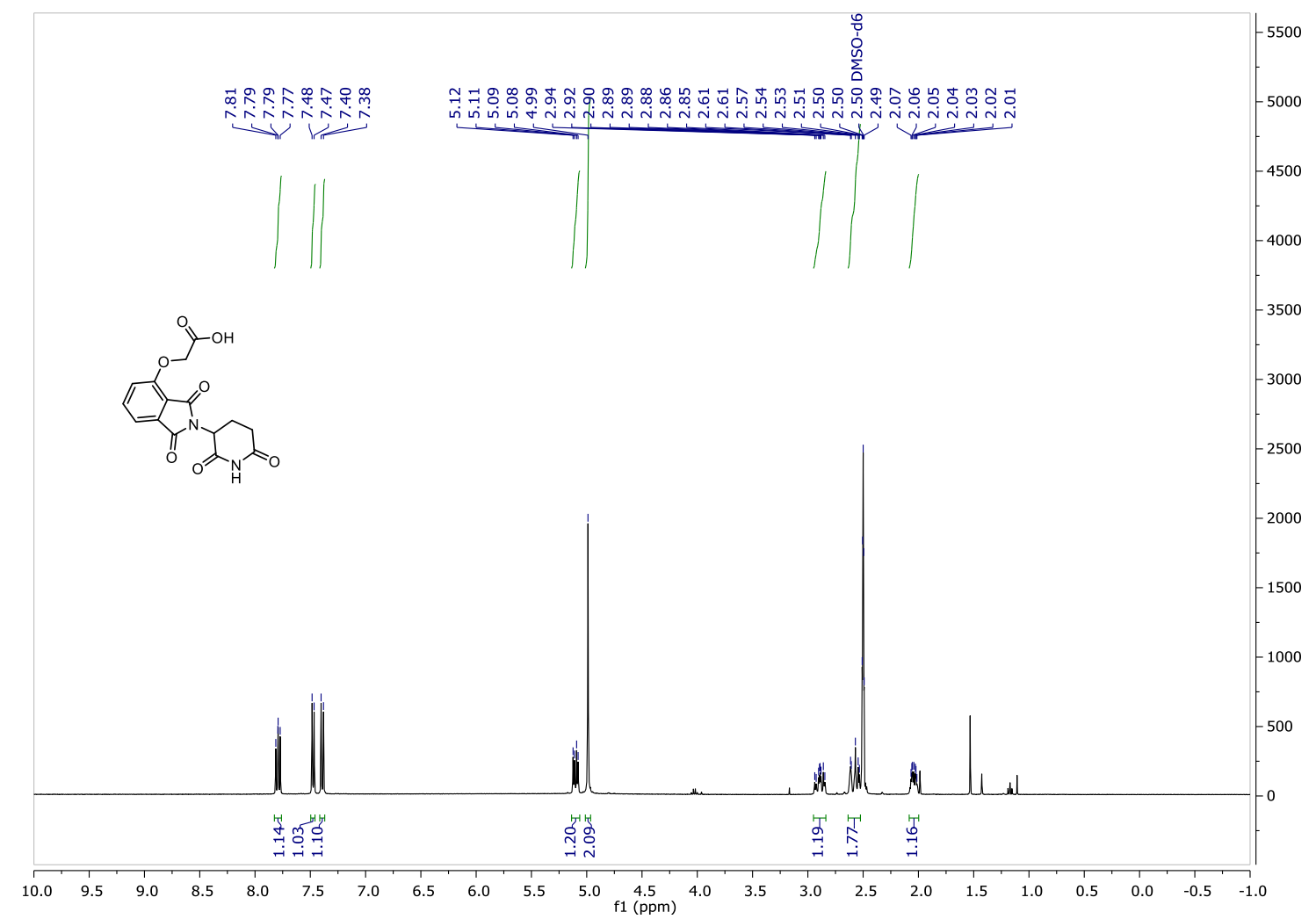


ct-O-Pom, (9), ${ }^{1} \mathrm{H}-\mathrm{NMR}$ and ${ }^{13} \mathrm{C}-\mathrm{NMR}$ in $\mathrm{CD}_{3} \mathrm{OD}$

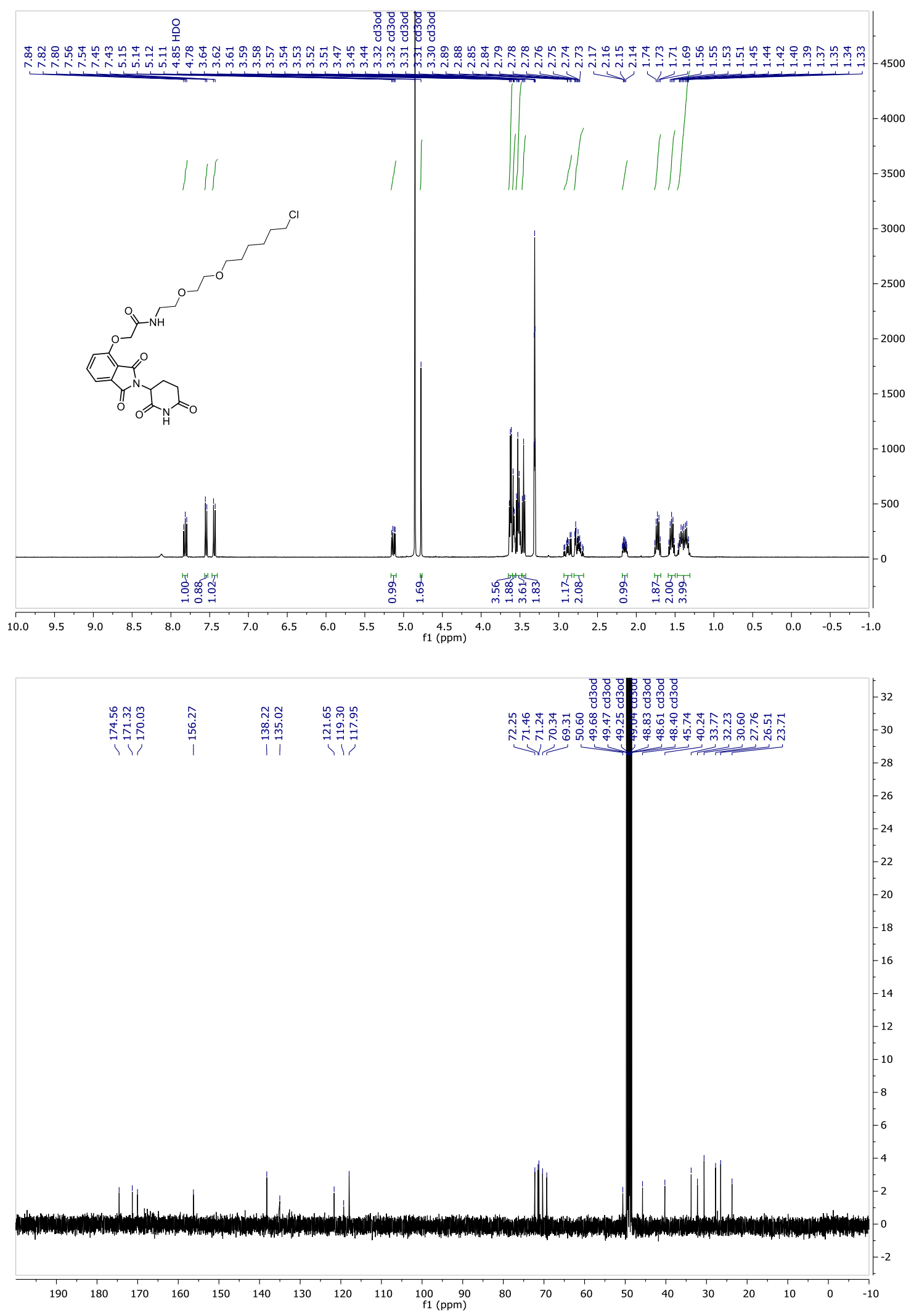


30, ${ }^{1} \mathrm{H}-\mathrm{NMR}$ in $\mathrm{CD}_{3} \mathrm{OD}$

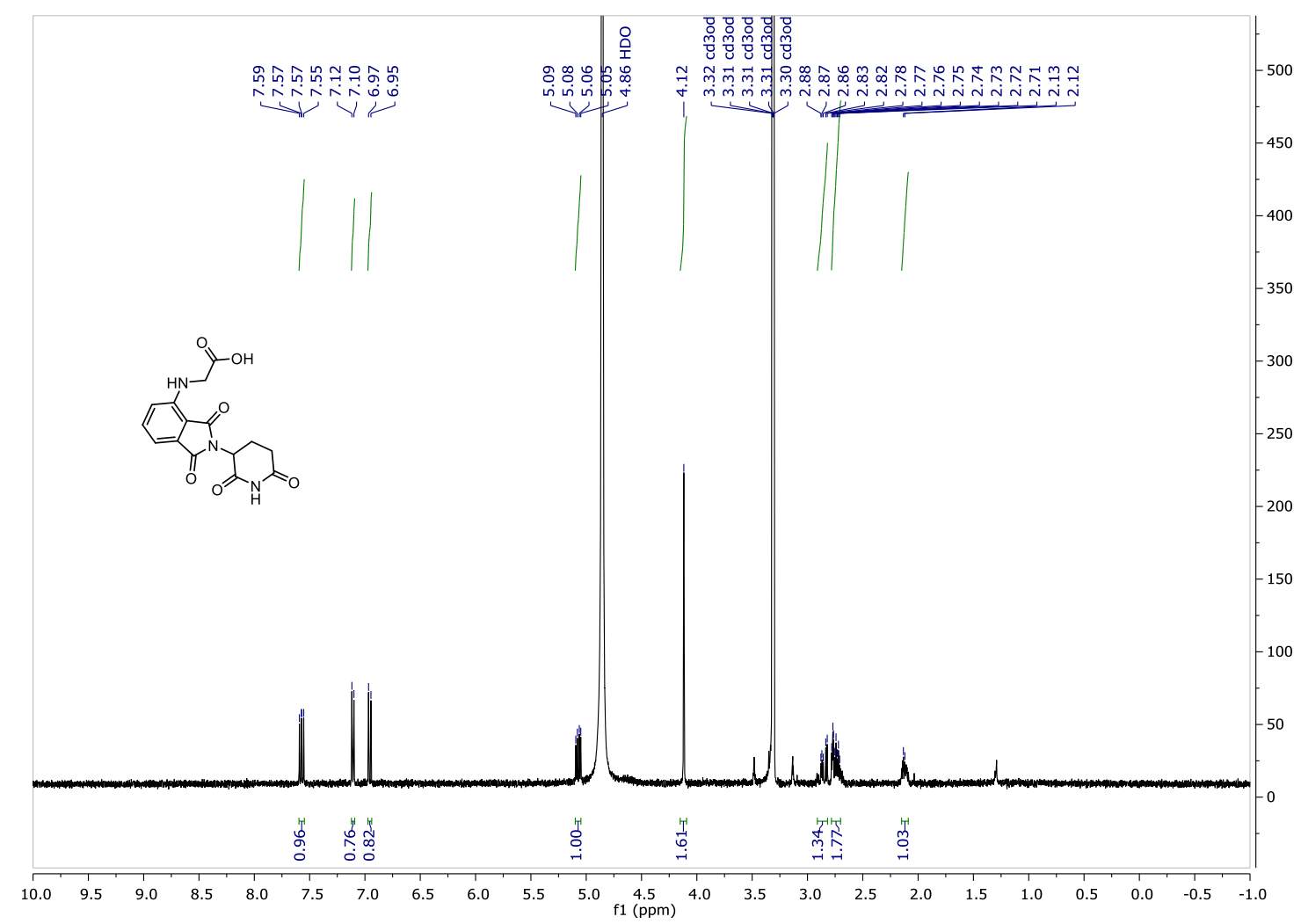


ct-N-Pom (10), ${ }^{1} \mathrm{H}-\mathrm{NMR}$ and ${ }^{13} \mathrm{C}-\mathrm{NMR}$ in $\mathrm{CD}_{3} \mathrm{OD}$
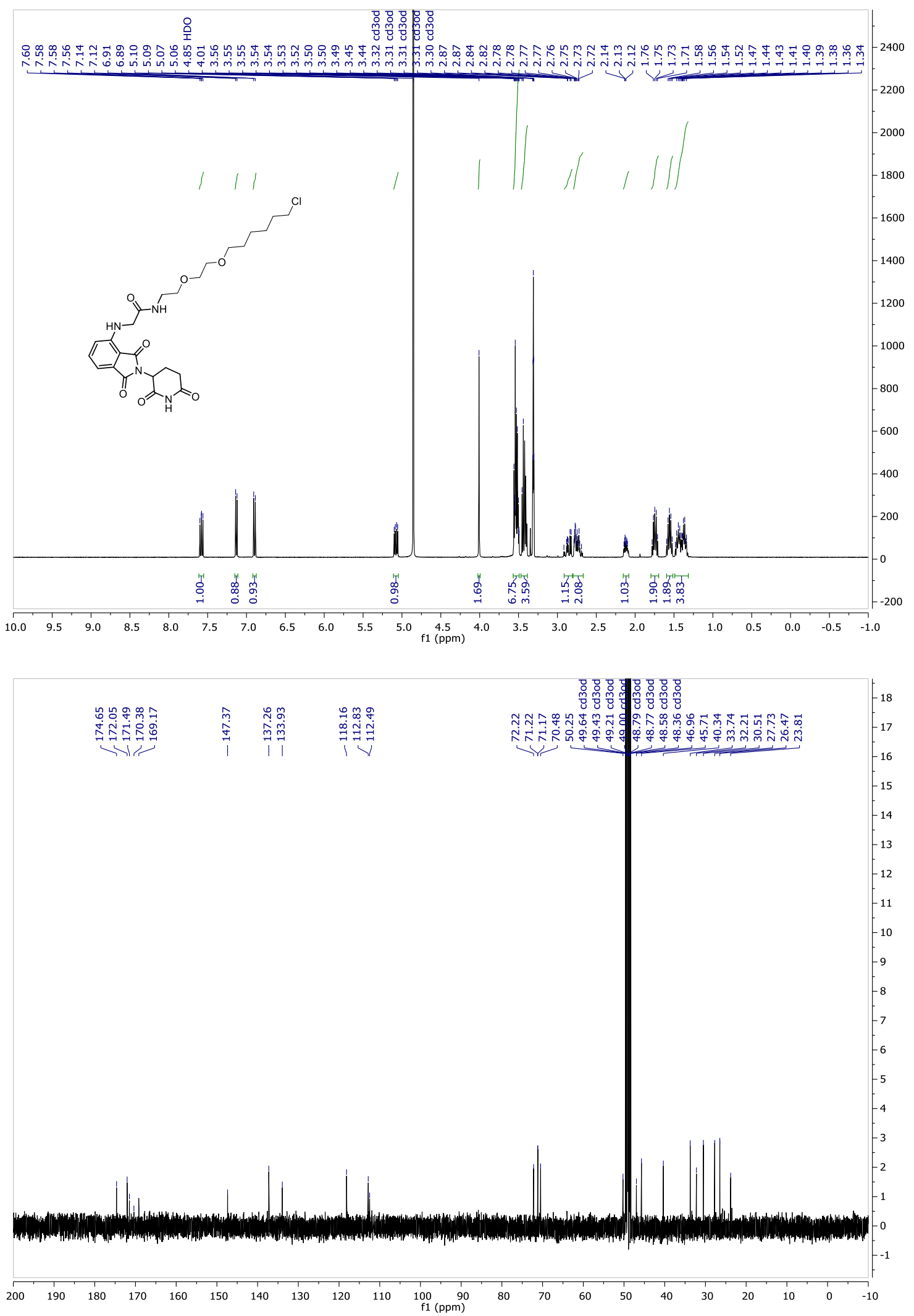


\section{References}

(1) Gadd, M. S., Testa, A., Lucas, X., Chan, K.-H., Chen, W., Lamont, D. J., Zengerle, M., and Ciulli, A. (2017) Structural Basis of PROTAC Cooperative Recognition for Selective Protein Degradation. Nat. Chem. Biol. 13 (5), 514-521.

(2) Peraro, L., Deprey, K. L., Moser, M. K., Zou, Z., Ball, H. L., Levine, B., and Kritzer, J. A. (2018) Cell Penetration Profiling Using the Chloroalkane Penetration Assay. J. Am. Chem. Soc. 140 (36), $11360-11369$.

(3) Galdeano, C., Gadd, M. S., Soares, P., Scaffidi, S., Molle, I. Van, Birced, I., Hewitt, S., Dias, D. M., and Ciulli, A. (2014) Structure-Guided Design and Optimization of Small Molecules Targeting the Protein-Protein Interaction between the von Hippel-Lindau (VHL) E3 Ubiquitin Ligase and the Hypoxia Inducible Factor (HIF) Alpha Subunit with in Vitro Nanomolar Affinities. J. Med. Chem. 57 (20), 8657-8663.

(4) Buckley, D. L., Raina, K., Darricarrere, N., Hines, J., Gustafson, J. L., Smith, I. E., Miah, A. H., Harling, J. D., and Crews, C. M. (2015) HaloPROTACS: Use of Small Molecule PROTACs to Induce Degradation of HaloTag Fusion Proteins. ACS Chem. Biol. 10 (8), 1831-1837.

(5) Zhou, B., Hu, J., Xu, F., Chen, Z., Bai, L., Fernandez-Salas, E., Lin, M., Liu, L., Yang, C.-Y., Zhao, Y., McEachern, D., Przybranowski, S., Wen, B., Sun, D., and Wang, S. (2018) Discovery of a SmallMolecule Degrader of Bromodomain and Extra- Terminal (BET) Proteins with Picomolar Cellular Potencies and Capable of Achieving Tumor Regression. J. Med. Chem. 61 (2), 462-481. 